\title{
GIVING VOICE TO SCHOOL NURSING AS A PRIMARY HEALTH CARE SPECIALTY
}

by

Gillian D. Alcorn

A thesis submitted to the Victoria University of Wellington in partial fulfilment

of the requirements for the degree of

Master of Arts (Applied)

in Nursing

Victoria University of Wellington 


\section{Abstract}

The purpose of this thesis is to give voice to school nursing as a primary health care specialty, and to promote the development of school nursing in New Zealand. School nursing is an invisible practice specialty that is largely funded from within the education sector, to address the health needs of student clients. School nursing is a significant primary health care initiative that can positively influence student health outcomes.

My school nursing practice experience and philosophy is presented prior to reflecting upon the history of school nursing, and the health concerns present within the student population. The work then moves to review and critique school nursing literature from New Zealand, Australia, the United Kingdom, and the United States. This thesis highlights the need for collaborative policy and practice development initiatives including a legislative requirement for school nurses, school nursing competencies and standards, school nurse to student ratios, postgraduate training, professional liaison, practice funding, and research.

A discourse on the reflective topical autobiographical method introduces autobiographical poetry from school nursing practice and reflective inquiry, as the central research endeavour of this thesis. Autobiographical poetry is offered as a window to this specialty practice, and accompanying reflections allow access to a further layer of practice knowledge. Student health needs, the scope of nursing interventions, and the essences of school nursing practice have been distilled from the poetry. Poetic representation and subsequent reflection has facilitated the development of a school nursing framework for use within the New Zealand context, entitled Health Mediation in School Nursing. School nursing is presented throughout this thesis as an important child and adolescent primary health care initiative, which has the potential to reduce health barriers to learning, improve student health outcomes, and build student success in the social, emotional, and educational domains. 


\section{Acknowledgements}

I would like to take this opportunity to thank all those who have contributed to making this writing possible. I am especially thankful to my husband Bruce, and my children Nathaniel, Simeon, Jarryd and Keziah for their love and care. For their support of my study programme over the past five years, and allowing me to spend time on this more recent thesis endeavour. I am conscious of the times that I have excused myself from family activities and commitments, when due dates for assignments and thesis drafts have arrived. The love and friendship that I experience within my family and extended family has given me a strong base from which to undertake school nursing practice, and made it possible to address the challenge of giving voice to school nursing as a primary health care specialty.

I am pleased to acknowledge my teaching colleagues for their personal commitment to students, and their friendship and support as I have undertaken my own study programme. I would especially like to thank past and present members of the Full Service Education team for their professional collaboration, nurture, and friendship. Expressions of appreciation are offered to Ngaire McClutchie and Mark Bradley for your Maori translation assistance and personal encouragement during my research programme. Appreciation is offered to Craig Lauridsen for your graphic design assistance. I would also like to thank teaching staff from within the Graduate School of Nursing and Midwifery at Victoria University that have supported my practice development and academic programme, and encouraged my practice voice. I would like to express my deep gratitude to my supervisor Rose McEldowney, for her friendship, encouragement, and professional academic advice during this thesis programme.

Special thanks are offered to family, friends, and colleagues that have supported my practice development, and my academic endeavour. I offer my thanks to students who have enriched my life, and for whom I work to improve student health. I am pleased to give voice to school nursing as a primary health care specialty, and by so doing, to advance child and adolescent total well-being: hauora in New Zealand. 


\section{Table of Contents}

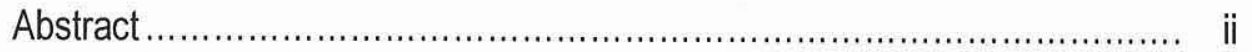

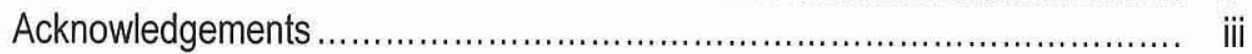

Table of Contents ...................................................................... iv

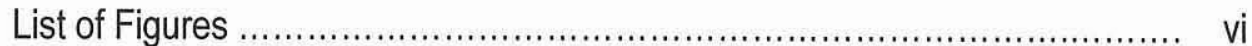

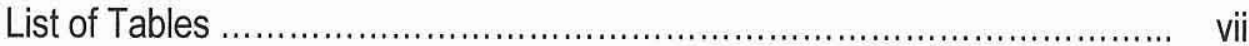

\section{PART ONE}

\section{PERSONAL VOICE: PRACTICE AND PHILOSOPHY}

Introduction to the project ...........................................................

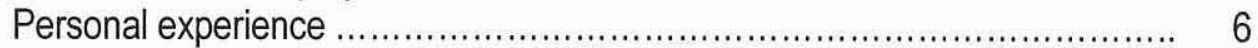

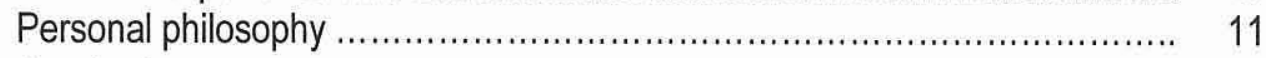

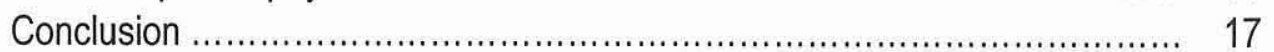

\section{PART TWO}

\section{PRACTICE VOICE: REVIEW AND CRITIQUE OF SCHOOL NURSING LITERATURE}

Introduction

The early years: The development of school nursing as a public health

initiative

Towards a collaborative model of care: School nursing as a specialty practice within the public health nursing domain

Epidemiological trends: Child and adolescent health within the New Zealand context

School nursing as a complementary contribution to child and adolescent total well-being: hauora in New Zealand

The planned future development of school nursing as a primary health care specialty 


\section{PART THREE \\ AUTOBIOGRAPHICAL VOICE: POETRY AND REFLECTIVE INQUIRY AS METHOD}

Introduction …................................................................... 70

Method of data collection and analysis.......................................... 71

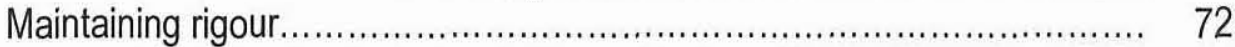

Discussion: Reflective topical autobiographical poetic inquiry ................. $\quad 73$

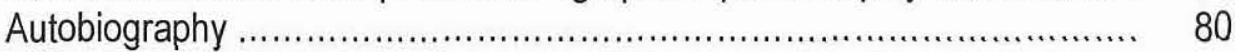

Reflective topical autobiography compared: The relationship between the reflective topical autobiographical method and other research methods ..... 82

Giving Voice ........................................................................... 85

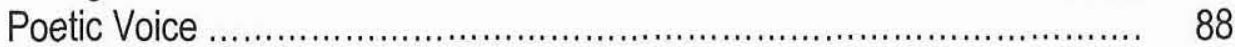

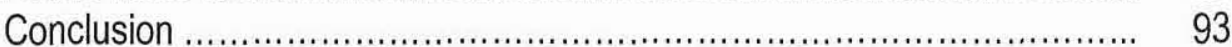

\section{PART FOUR \\ POETIC VOICE: POETRY AND REFLECTIVE INQUIRY}

Introduction

96

Autobiographical poetry from school nursing practice and reflective voice .. 99

The essences of school nursing ..................................................... 129

Resolution ............................................................................. 136

Reflexive poetry as a response to autobiographical voice and as a

resolution

\section{PART FIVE}

CONCEPTUAL VOICE: THE DEVELOPMENT OF A FRAMEWORK FOR SCHOOL NURSING

Introduction

School nursing framework: Health mediation in school nursing

(He pou tarāwaho tiakitanga mō ngā Nēhi Kura: Te Takawaenga Hauora i

roto ingā Kura)

Summation

Glossary of Māori words

Appendices

References 


\section{Figures}

Figure 1. School Health Mediation within the Healthy Schools model, the Health Promoting Schools model, and the Full Service Education model of student care

Figure 2. Mediating Health Care Needs with Individual Students

Figure 3. Mediating Health Care Needs with Family, Caregivers, Whānau

Figure 4. Mediating Health Care Needs within the School Domain

Figure 5. Mediating Health Care needs with Respect to Community Health Services

Figure 6. Mediating Health Curriculum Development, Health Education in the Classroom, Health and Safety Policy Development and Implementation

Figure 7. School Nursing Framework: Health Mediation in School Nursing (He pou tarāwaho tiakitanga mō ngā Nēhi Kura: Te Takawaenga Hauora i roto ingā Kura) 


\section{Tables}

Table 1. Giving voice to school nursing as a primary health care specialty

Table 2. The benefits of developing school nursing as a primary health care specialty in New Zealand schools

Table 3. School nursing as a complementary contribution to child and adolescent total well-being: hauora in New Zealand

Table 4. The planned future development of school nursing as a primary health care specialty

Table 5. School nursing practice framework: Health mediation in school nursing He pou tarāwaho tiakitanga mō ngā Nēhi Kura: Te Takawaenga Hauora i roto i ngā Kura 


\section{PART ONE}

\section{PERSONAL VOICE: PRACTICE AND PHILOSOPHY}

So many of us do not know our own story. A story about who we are, not about what we have done. About what we have faced to build what we have built, what we have drawn upon and risked to do it, what we have felt, thought, feared, and discovered through the events of our lives. The real story that belongs to us alone. 


\section{PERSONAL VOICE: PRACTICE AND PHILOSOPHY}

\section{Introduction to the project}

The purpose of this research project is to give voice to the nature of child and adolescent health care needs, the 'scope' of school nursing interventions, and the 'essences' of school nursing practice in New Zealand. School nursing in New Zealand is an invisible primary health care specialty, which is largely funded from within the education sector. The practice of school nursing seeks to reduce health related barriers to learning, to improve child and adolescent health outcomes, and to promote student success and enrichment in the social, emotional, and educational domains. The urgency to express a voice for school nurses and school nursing is born of my personal practice experience over a nine year period, and a belief that improved child and adolescent health can be advanced by collaborative policy development and practice development initiatives within school nursing.

School nursing practice includes primary health care, health teaching within the classroom, health curriculum development, and health and safety policy development and implementation. It is an under-researched domain of nursing in New Zealand, and as such is little understood and therefore undervalued as a primary health care initiative. School nursing makes possible free, accessible and approachable health care for child and adolescent health care consumers. Improved child and adolescent health outcomes can be achieved by supporting current school-based primary nursing care practice, and implementing collaborative practice development initiatives within New Zealand schools. 
I have presented five PARTS or voices within this thesis document and each part offers a different perspective on this practice domain. A quotation concerning narrative expression, philosophy, and poetry at the beginning of each part sets a subconscious theme within the thesis. Table 1 presented below outlines the five parts within this writing, and summarises the overall direction undertaken.

\section{TABLE 1. Giving voice to school nursing as a primary health care specialty}

\begin{tabular}{|ll|}
\hline PART ONE & Personal Voice: Practice and Philosophy \\
PART TWO & $\begin{array}{l}\text { Practice voice: Review and critique of school } \\
\text { nursing literature }\end{array}$ \\
PART THREE & $\begin{array}{l}\text { Autobiographical voice: Poetry and reflective } \\
\text { inquiry as method }\end{array}$ \\
PART FOUR & $\begin{array}{l}\text { Poetic voice: Autobiographical poetry from } \\
\text { school nursing practice and reflective inquiry }\end{array}$ \\
PART FIVE & $\begin{array}{l}\text { Future voice: the development of a framework } \\
\text { for school nursing }\end{array}$ \\
& \\
\hline
\end{tabular}

The first section of this writing entitled PART ONE: Personal Voice, presents my nursing practice experience, and personal philosophy. Within this section I articulate my personal nursing narrative and my understanding of the school nurse's role within a multi-cultural urban secondary school in New Zealand. I also present my personal nursing philosophy as it underpins my engagement with student clients and sits beneath all my personal, professional and academic activities. Threads from this philosophy are apparent throughout my writing and emerge as essences of practice later in this work. 
PART TWO of this project includes a review and critique of school nursing literature. Within this section entitled Practice Voice, I have analysed New Zealand school nursing literature written by New Zealand school nurses, and New Zealand health and education policy documents that have school nursing and school health embedded in the conversation. I have also examined literature concerning child and adolescent health care needs, and the delivery of primary health care to this client group. I refer to recent New Zealand epidemiological child and adolescent health data, in order to position the school nursing task in the face of such statistical information. School nursing literature from Australia, the United States (US) and the United Kingdom (UK) has been critiqued in order to place this project within an international school nursing context. A major theme that has emerged from the literature is the need for a collaborative model of school nursing development. Proposed future policy development initiatives include; legislation requiring nurses in schools, funding of school nurse positions, training of school nurses and salary and career pathway needs. The proposed future professional practice initiatives explored in this section of writing include; professional liaison, school nursing competencies and standards, postgraduate education, and research.

Writing in PART THREE of this work moves to introduce the major endeavour undertaken within this thesis; Autobiographical Poetry from School Nursing Practice and Reflective Inquiry. Reflective topical autobiographical poetry from school nursing practice is presented as a postmodern, interpretive, qualitative research methodology. I have examined the autobiographical genre, and the relationship between reflective topical autobiography and other research methods in order to position this method within the wider nursing research domain. The emerging research process undertaken within this post-modern method has led me to examine the concept of 'giving voice', and the personal demand recorded throughout history of the poet, to offer social commentary and announce understanding and meaning. In order to maintain academic rigor, a 'discussion' concerning my experience of undertaking school nursing research using the reflective topical autobiographical poetic method has been included. This discussion considers the personal demands of this form of academic inquiry, the subsequent personal rewards, and the benefits of this form of inquiry to the nursing community. 
Poetry that has emerged from my experience in school nursing practice is offered as a 'window' to this specialty practice in PART FOUR of the thesis. Each poem is followed by a reflection, which offers an additional layer of meaning and practice knowledge. I have dwelt with the language that was given and thought deeply about the poetry in order to disclose meaning from within the poems. Poetic writing is viewed as a mechanism for self-disclosure in nursing, which protects the person for whom the nurse cares. Poetic writing enables selfreflection concerning the school nursing domain without individualising caring enactments, or the contexts from which the nursing enactments arise. Reflective topical autobiographical poetic writing concerning school nursing has enabled me to make visible this invisible practice specialty of nursing. Two layers of understanding have been discerned from this reflective form of inquiry. The first dimension exposes the reader to the 'scope' of school nursing interventions, and the complex and concerning health care needs of the student population. The second layer of understanding contained within the poetic text relates to the 'essences' of school nursing practice. These essences are explored in detail as I seek to present my poetry in a way that advances understanding about this nursing specialty.

The Conceptual Voice of school nursing is presented in PART FIVE of this thesis, and includes a school nursing practice framework entitled Health Mediation in School Nursing; Te Takawaenga Hauora i roto i ngā Kura. (A full Glossary of Maori language used within this thesis is included at the end of PART FIVE). This conceptual framework was informed by my school nursing practice experience and the critique of school nursing literature which is included in PART TWO of this thesis. The framework and accompanying commentary emerged out of an essence of practice distilled from my poetry called 'health care mediation'. This framework positions school nursing within the Health Promoting Schools model, the Healthy Schools model, and the Full Service Education model of student care. Four dimensions of health care mediation are included in the proposed school nursing framework; individual student health care mediation, health care mediation with family, caregivers, whānau, health care mediation within the school domain, and health care mediation with respect to community health services. This framework also addresses the school nurse's role in health curriculum development, health teaching, and health and safety policy development and implementation. This conceptual framework of school nursing practice 
articulates the 'scope' of school nursing interventions, and positions school nursing as a primary health care specialty.

A proposed direct benefit of this thesis is to facilitate an academic dialogue concerning school nursing in New Zealand. A further benefit of this work is to advance meaning for other school nurses and professionals working in the child and adolescent health field, and to promote the future development of the school nursing practice specialty in New Zealand.

A significant outcome of this research has been the opportunity for personal reflective thought and the subsequent gaining of personal and practice understanding. Poetic writing has the potential to facilitate a dialogue within nursing and within the public domain, concerning health care provision to the student client group. Writing within this thesis points towards 'best practice' opportunities in school nursing, and interprets school nursing as a primary health care specialty that can positively influence the physical, mental, emotional, social, and educational outcomes of the child and adolescent population in New Zealand.

In the following section I will describe my involvement in school nursing and my understanding of this specialty practice. I have included details of my nursing and teaching experience, and my current practice environment. I believe that school nurses with training in health promotion, health protection and teaching pedagogy are well placed to address the health care needs of the child and adolescent student population in New Zealand.

\section{Personal experience}

Within the context of this research project it is important to describe the nursing practice experience and nursing philosophy that underpin my involvement in school nursing practice. My experience has led me to believe that school nursing involvement makes a difference to the health and well-being of student clients. I have worked in the area of school health for the past nine years, having been involved initially in paediatric nursing, following registration as a comprehensive nurse. I worked as a part-time charge nurse in the care of the elderly prior to 
commencing work in school health nursing, and during my early years as a school health nurse combined both positions.

My Christian faith, and my commitment to offering professional and caring nursing, has sustained my work at both ends of the life continuum. Improved adolescent health outcomes and 'best practice' in school health nursing have been the reason for my undertaking postgraduate study in both nursing and teaching. In 1997 I commenced a Master of Arts (Applied) in Nursing at Victoria University of Wellington and the following year I had the opportunity to undertake the postgraduate Diploma of Teaching (Secondary) at the Wellington College of Education. Teaching staff from the Graduate School of Nursing and Midwifery at Victoria University, and the principal of the school in which I am employed, supported my enrolment in a secondary teacher-training programme. As professional colleagues they recognised the complementary nature of school-based primary health nursing and health teaching, within the secondary school health curriculum.

My motive to study within education was to gain an academic teaching qualification, which would advance the role of school nurses as health educators within the health and physical education curriculum. My academic teaching studies included; teaching pedagogy, teaching strategies, Māori language and culture, information research skills, information technology, professional studies, and the professional curriculum areas of Health and Science. After completing the postgraduate secondary teaching qualification I resumed the Master of Arts (Applied) in Nursing programme. I am conscious of the pedagogical theory that underpins both the education and nursing disciplines, and the importance of nurses becoming familiar with educational theory related to health promotion.

Health teaching and health promotion are integral components of the role of a school nurse (Wainwright, Thomas \& Jones, 2000). Teaching is enacted in both the classroom setting and on a one-to-one basis in the school-based primary health clinic. As a school nurse holding a professional nursing registration, and as a health teacher within the health and physical education curriculum, I am able to mediate between health and education. It is from this position that I reflect on nursing and education practice in this research project, and explore 
the interface between health care delivery in the school setting and the policy direction presented by the Ministry of Health and the Ministry of Education.

My position at the interface between health and education enables reflection about current trends in school nursing in New Zealand and a visioning towards future opportunities for child and adolescent health enrichment. The career pathway that has been established as the result of this dual specialist role is now similar to a school guidance counsellor that has a teaching diploma and a professional guidance counselling qualification. I was initially employed within the school as an ancillary staff member but subsequent to completing the Diploma of Teaching (Secondary) I am now employed under the Post Primary Teachers Association (PPTA) career pathway.

In the early 1980s a school health nurse was employed as part of a Public Health initiative. Over a period of six years the school where I work benefited from having the services of a registered nurse on site in a full-time capacity. The Public Health Service discontinued this primary health care initiative due to the re-contracting of services and the school was without an on-site health nurse for the following three years. In 1992 the Principal in consultation with the Board of Trustees and senior management staff, decided to fund the position of school nurse from their operational grant. I was appointed to the position when it was reestablished. The funding for this position was initially drawn in part from the Equity Fund and subsequently the Targeted Fund for Education which is paid to schools by the Ministry of Education, and which is derived by reference to the socio-economic and ethnic composition of the school. My salary is currently is based on my nursing and teaching qualifications and my professional experience within health and education.

I was initially employed as a school nurse for 15 hours per week, and have for the past six years worked in a full time capacity as a member of the 'Full Service Education' team within the school (Brener, Vernon, Bradley, Santelli, DuShaw, Lewis \& Brainerd, 1999; Dryfoos, 1994). This model includes a guidance counsellor, school support worker, school social worker, mentor co-ordinator, truancy officer, and school health nurse. Students self-refer to the health clinic and referrals are made to the school health clinic from form teachers, the 
dean network and senior staff. Referrals also come from the families, caregivers, whānau of students, and from the local hospital with regard to the follow-up of student clients who have accessed secondary health services.

I currently provide a primary health nursing service to students and staff, and I teach five hours of timetabled health classes each week, as part of the Health and Physical Education curriculum. I also teach Health unit standard's including, 'Provide Resuscitation' and 'Provide Basic First Aid', to senior physical education students and students choosing short courses such as Drivers Education. I work as a part of the guidance/dean structure but I am also regarded as an independent health professional for individual students and staff concerns.

Primary health care delivery within schools ensures that students receive immediate first-aid care in the case of injury. The care of students with physical injuries is a significant component of school nursing care and includes a range from minor physical injury arising from sporting activity and cuts and burns from technology classroom activities, to violent physical assault requiring child protection and police involvement. Prompt first-aid interventions promote healing and reduce the need for students to access secondary health care services.

In my role as a school nurse I care for students with a wide range of health care needs including; intellectual and physical disabilities, and medical conditions such as diabetes, epilepsy, cardiac arrhythmias, immune disorders and cancer. Asthma is a major health concern in New Zealand and as such health care interventions within a school nursing service range from students with mild asthma challenged by athletic sports, to those with acute asthma requiring emergency medical care. Skin infections are student health issues, and cover the continuum from mild infections requiring simple dressings, to untreated wounds and boils requiring antibiotic treatment, and abcesses requiring surgical intervention. I am required to have broad general health knowledge, and specialist knowledge of child and adolescent health concerns, in order to engage in health promotion, health protection and health education opportunities. 
As a school nurse I am able to offer health screening with regard to vision and hearing, and to follow-up self-referrals, and staff and family referrals. I am also able to ensure that students avail themselves of free dental care by arranging appointments, and supporting students to attend and complete their treatment. School-based primary health care engages the student population at the place where they spend a significant part of each day. Free availability, accessibility to the health service, continuity of care, and the ability to self-refer, increases health promotion and health protection opportunities in school-based primary health care services. School nursing practice is difficult to define due to the broad scope of nursing interventions undertaken, and the unpredictable nature of student health referrals. I am also aware that underlying the primary reason for referral or self-referral are additional health issues that require assessment and intervention. I have included a 'Sample Health Clinic Week' (Appendix 1) to describe the scope of school nursing practice. It is not however always possible to discern the time spent with an individual student client from such data. The student presenting with one primary health concern can frequently initiate a discussion about a range of other personal health issues. An additional dimension is that student clients frequently attend a school-based health clinic with a friend or friendship group, thus increasing the opportunity for health information exchange.

I am fortunate to work within a multi-cultural secondary school that has developed a guidance network and currently offers a 'Full Service Education' model of student care. The reason for the development of this model is to reduce the health and social barriers to learning and to promote educational success. Working in a school that offers a 'Full Service Education' model of student care means that I am able to access allied services on behalf of students. I also access additional community health services for students, with students, and on behalf of students and their families. I have become familiar with providing a primary adolescent health care service within a secondary school setting, and teaching within the New Zealand health curriculum. Over the period of nine years my practical and theoretical knowledge concerning student health has increased and my knowledge of students and their families, and community health services, has strengthened my practice. Time spent within the school community has increased the opportunity for the development of trust and 
acceptance, which has lead to referral and self-referral opportunities. Students are known in the wider context of their educational and co-curricular activities and I am able to see them as individuals within the wider family and community context.

Increased health promotion and disease prevention is possible where a school-based child and adolescent primary health care service complements health teaching. In order for students to be ready to learn, physical, emotional and social concerns need to be addressed. My experience has made me mindful of the need to address the total well-being: hauora of student clients. When students bring their immediate health needs for nursing care they present the context of their lives, including family; caregivers, whānau, friendship associations, culture, history, and experience of school.

During my time studying and practising within the domains of nursing and education I have thought deeply about my personal philosophy of care. In the next section I describe my personal nursing philosophy as it underpins all my nursing care and health teaching engagements with student clients. This philosophy described as Total Well-being: Towards Enrichment: Hauora: Whaia Te Ara Tika makes apparent my personal commitment to student well-being and advancing school nursing as a primary health care specialty. I believe that it also has relevance to the wider education and nursing disciplines.

\section{Personal philosophy}

As a registered nurse and postgraduate student within both nursing and education I have reflected upon the nursing philosophies which underpin my practice, and the nursing theorists that have informed my personal philosophy (Benner, 1991; Bowden, 1997; Gadow, 1980; Newman, 1994; Parse, 1992; Rogers, 1970; Watson, 1988,1990). I have developed a philosophy of nursing, which seeks to describe the nurse-client relationship within school nursing, and the wider nursing domain. I have chosen to present this personal nursing philosophy within the context of this project as ideas from this model are woven throughout the thesis. 
My philosophy of nursing and educational practice involves a view of nursing action that commences with engaging with a student client. Subsequent to engaging with the student, the entrusting of need arises (Johns, 1996; Meize-Grochowski, 1980). The student client, in order to receive support with regard to their health need or health concern, offers their 'gift' of need for care (Marck, 1990). The enacting of nursing care is central to the role of school nursing and is where nursing assessment is undertaken, and initiatives towards maintaining physical and emotional integrity are begun. Following from nursing enactment comes the enabling capacity, which is the craft of nursing. Enabling is understood to involve health teaching and support to overcome obstacles to health, or positively address health challenges. Subsequent to enabling is the enriching of both the life of myself as the nurse, and the student client for whom I care. This personal nursing philosophy is demonstrated below.

\section{Total Well-being: Towards Enrichment (Hauora: Whaia Te Ara Tika)}

Engaging

Entrusting

Enacting

Enabling

Enriching 
My philosophy was initially developed in 1997, at the beginning of my postgraduate study programme. While undertaking a paper entitled 'Nursing Knowledge', I was encouraged to articulate a personal philosophy of nursing in the light of historical and contemporary nursing theory. In 1998 I was enrolled in a postgraduate secondary teaching programme, and was exposed to educational theory and practice, which also informed my philosophy. In 1999 following the completion of a Diploma of Teaching (Secondary) I resumed the Master of Arts (Applied) in Nursing programme. I was privileged to participate in a three-day master class taken by Professor Nancy Diekelmann from the School of Nursing, University of Wisconsin Madison, entitled 'Navigating the expanse: Narrative pedagogy and contemporary nursing/ midwifery education' (Diekelmann, 1988; 1990; 1991). As a result of this course I was inspired to return to the study of philosophical writing, and to continue developing my nursing philosophy (Stumph, 1966; Hackforth, 1955). Nursing philosophy is a platform from which practice inquiry can be undertaken. Fry (1992) purports that philosophic inquiry enables clarification concerning the role of nursing in society and the enacting of care.

In the final analysis, perhaps it is not philosophic inquiry that has been neglected in nursing scholarship, but our openness to visualise philosophical inquiry as necessary and fundamentally important with respect to establishing the theoretical foundations of nursing practice and research. It might be appropriate to recognise such inquiry for what it is and to conceptually locate philosophical inquiry within a framework of relevance to the practice of nursing and its role in society.

(Fry, 1994, p.94)

In the following section I have expanded upon my philosophy, giving reference to the theorists and writers that have informed my understanding (Thorne, Canham, Dahinten, Hall, Henderson, \& Kirkham, 1988). I have found that it is relevant to an understanding of my role as a school nurse engaged in primary health care and teaching within the school domain. 


\section{Engaging}

Engaging I believe occurs within the reciprocal nurse-patient relationship where perceived need is established and initiatives towards fulfilling need are begun (Marck, 1990; Morse, 1989; Thorn \& Robinson, 1988). Engaging in the school nurse-student client relationship is where the nurse affords a "healing entrance" into the patient's world (Bowden, 1997, p.118). Within the context of school nursing practice the primary health care nature of individual student care is underpinned by forming an ongoing relationship with a student, and student family, caregiver, whānau, which facilitates engagement and connection (Van Manen, 1990). Benner (1991) discusses the care of an individual as an integral part of a wider family, peer, and friendship association. She describes this association in the area of clinical knowing when she writes "Engaged knowledge of the patient can yield wisdom, and skilful ethical comportment, because knowing a patient typically includes knowing the person embodied and as related to others through everyday concerns and practices" (p.4).

Within the context of this theoretical framework, engagement in the nurse-patient relationship is envisioned as need to care for self, replaced by the need to care for another. Noddings $(1984$, p.140) affirms that in engaged nursing care "there is invariably the displacement of interest" from the nurses reality to the reality of the person in need of care. Engagement is a shared human dialogue, which moves the participants towards entrusting. Nursing involvement and attending engagement brings with it the entrusting mystery, where the nurse becomes a vessel for wise holding, nurture and care.

\section{Entrusting}

Entrusting in the nurse-patient relationship occurs when the 'entrustee' is unable to carry their need, pain or health concern, or chooses to share or gift their need (Morse, 1989). The school nurse is understood by the student to have the insight, knowledge and wisdom to carry and hold the students health concern. Mayeroff $(1971$, p.7) describes caring in words such as 'being with' and 'being for' another, and "being entrusted with care for another". 
Entrusting is central to the art of nursing and is manifest in notions of treasuring, carrying wisely the gift of pain, sorrow, loss, fear, anxiety, joy, wonder, hopes and dreams. Entrusting is where the school nurse recognises his or her practical skill and guards wisely the patients need for autonomy, independence and dignity. The entrusting relationship, which is established between the nurse and the student client, is described by Newman (1990, p.41) as "authentic involvement" and by Parse (1992, p.39) as a "true presence".

Within the context of school nursing I am reminded that the nurse is a vessel or conduit for healing, restoration and acceptance of life challenge. A key question, which lies central to school nursing practice, concerns the ability of the nurse to be a safe space, a "sacred healing vessel" for the student that is referred or self-refers for nursing care (Quin, 1996, p.27). The concept of entrusting holds a central place in all nursing activity. Trust is viewed as a precursor to the "facilitation of empowerment, involvement and knowledge development" (Hagedorn, 1995, p.11). The entrusting moment in school nursing is where a student's personal health concern or need is gifted, 'abandoned' in the moment, hoping for wise counsel, care, nurture and safe holding (Nancy, 1993). Subsequent to the entrusting of health need, is the enacting of nursing care.

\section{Enacting}

Enacting in school nursing is the 'craft' of nursing, where the entrustee is assisted to maintain physical and emotional integrity. The cares encompassed when needs are recognised and mechanisms towards fulfilling need are instituted, constitute enacting in school nursing. Enacting is where the nurse offers 'attention' to the physical, emotional, mental, and spiritual needs of the patient (Thorne \& Robinson, 1988). Thorne and Robinson purport that nursing activity affirms both "the individual's body and the person's meanings" (p.1259).

Excellence in nursing enactment is described by Bowden (1997, p.140) as "personal experiental and responsive caring that are so central to ethical excellence in nursing". Enacting in the nurse-patient relationship is a mutual partnership in which revisiting, 
reordering, and restoring take place. Enacting in the school clinic setting involves being beside students at extremity when self can no longer sustain self. Enactment recognises the sense of 'not-at-homeness: unhemlichkeit' of the student, as the nurse establishes means to restore, assist, and maintain personal integrity, autonomy and dignity (Heidegger, 1962). Enacting in school nursing affirms the need for client confidentiality. The enacting of nursing care honours the young person's journey and respects their personal understanding. Enacting includes physical ministration, sharing of health knowledge, and an attention to the emotional, social, and learning needs of the young person. The desired outcome, of enactment is to enable students to positively manage their personal health needs.

\section{Enabling}

Enabling is viewed within this philosophy as the capacity to overcome obstacles to health or positively address health challenges. Enabling in relation to youth development and decision-making involves "creating conditions in which young people can act on their own behalf and on their own terms" (Ministry of Youth Affairs, 2001a, p.10). King (1994, p.216) affirms the enabling capacity of nursing and suggests that "Nurses will be required to perfect their enabling, empowering, promotive skills". King also emphasises the enabling capacity of nursing in relation to health education. A primary role of the school nurse within the education domain is to facilitate learning about personal health and to enable positive decision making in relation to personal health and well-being.

Bowden (1997, p.117) has described nursing enactment as "the fund of imaginative possibilities through which committed caring practices traverse the gulf between nurse and patient, engaging the personhood of the nurse in the protection and enhancement of the patients own unique personhood". Enabling is central to nursing and can be envisioned as assisting the individual in relation to health need and the school community in relation to health education and health promotion. Enabling within this model of nursing care leads towards personal enrichment. 


\section{Enriching}

Enriching is understood within this philosophy of nursing practice as the possible and welcome consequence of health challenge and need. Enrichment envelops ideas of wholeness, understanding and gaining new insight. The experience of enrichment is described in nursing literature as 'a higher level of consciousness', and 'human becoming' (Newman, 1994; Parse, 1992). Paterson and Zderad (1976) describe this higher level of personal health experience as 'well-being' and 'more-being'. Rogers (1961) equates the experience of enrichment with a notion of 'maximum health potential'. New Zealand health and education sector publications advance the concept of total well-being: hauora, when seeking to describe optimum physical, mental, emotional, social and spiritual well-being (Ministry of Education, 1999; Ministry of Health, 2001b).

Within the reciprocal nurse-patient relationship, Bowden (1997, p.34) speaks of selfenrichment resulting from the caring enactment as "personal growth" where "personal boundaries are challenged by responsibilities to care and nurture - the kind of going out to a person that returns in 'invigorating' self knowledge". Enrichment is an understanding of self in the world, self gifted to other, and self in need of another. This idea finds accord with my personal nursing philosophy, which moves from engaging towards enrichment.

\section{Conclusion}

In order to explain my commitment to practice development with the school nursing specialty I have given voice to my personal narrative and philosophy. The personal philosophy that I have developed is a means for understanding school nursing practice, and also the healthteaching role within a secondary school. I have found that this philosophical framework has assisted my nursing practice, as it is central to all engagements that I have with student clients. I am aware that my motivation to work in this adolescent health care specialty is underpinned by a desire to promote student total well-being: hauora, or enrichment. Students entrust their physical, mental, emotional, social and spiritual health needs for care 
and nurture. They also require nursing interventions that affirm their sense of self, honour their journey, and which respect personal autonomy and choice.

Wisdom in school nursing practice recognises the enabling nature of school-based primary health care delivery. Health care relationships that are established over time promote health teaching opportunities, and facilitate early intervention, with regard to personal health. Ensuring that funding is available for schools to implement school-based nursing services, enables the student population to access free and appropriate health care interventions, as they are required. Students that have their health care needs addressed within the context of a school-based nursing service are enabled to find success in the academic and social domains, and presents students who are towards enrichment in their lives.

In the following section I will review and critique the literature surrounding the school nursing specialty. I have introduced this section with a historical overview of school nursing in New Zealand, and introduced comparative data from the Australia, the United States and the United Kingdom. I have chosen to limit comparative school nursing data to these countries, due to the size and scope of this two-paper research project. It is important to engage with school nursing literature from outside New Zealand in order to position the New Zealand literature. In order to plan for the future development of the school nursing specialty, it is necessary to understand the history of school nursing, the statistical data that surrounds child and adolescent health, and to reflect upon current 'best practice' in this nursing domain. 


\section{PART TWO}

\section{PRACTICE VOICE: A REVIEW AND CRITIQUE OF SCHOOL NURSING LITERATURE}

In composing a poem, one often seems to move directly from ignorance to revelation, instantly from a muddled sense of things to a clear picture, with only the vaguest sense of how it happened. Experience is the ground of this way of knowing. But if visionaries and poets are at the mercy of what they see, they are also called to articulate it. And this requires them to employ another form of knowledge, the linear thought that enables them to communicate their experience to others. 


\section{PRACTICE VOICE: A REVIEW AND CRITIQUE OF SCHOOL NURSING LITERATURE}

\section{Introduction}

The purpose of this review and critique of school nursing literature is to determine current 'best practice' opportunities in school nursing, and to plan for future practice development in New Zealand. School nursing is an under valued and invisible primary health care initiative, which requires re-evaluation, given the current move to develop primary health care services in New Zealand (Ministry of Health, 2001c). School-based nursing services reduce health related barriers to learning, and can positively address child and adolescent health outcomes. School nursing initiatives also support student success and enrichment, in the social, emotional and educational domains. The benefits of school nursing interventions are outlined in Table 2 below.

Table 2. The benefits of developing school nursing as a primary health care specialty in New Zealand schools

1. Reduced health barriers to learning

2. Improved child and adolescent health outcomes

3. Student success and enrichment in the social, emotional, and educational domains 
School nursing publications from the Australia, the United States (US) and the United Kingdom (UK) have been reviewed in order to position this research within a wider nursing context. The Computer Index of Nursing and Allied Health Literature (CINAHL) database, the Cochrane Library, the ProQuest Medical Library, Expanded Academic database and the Health Reference Center database, have been used to access literature pertaining to school nursing. The reference section of articles written by school nurses, have also been a source of research information. Kai Tiaki: Nursing New Zealand has proved to be the main source of New Zealand writing by school nurses. The Journal of School Nursing, the Journal of School Health, the Journal of Advanced Nursing, Nursing Outlook, the Journal of Continuing Education in Nursing, and the Australian Nursing Journal have been the main sources of international writing related to school nursing outside New Zealand.

Publications prepared by the Ministry of Health, the Ministry of Education, the Ministry of Youth Affairs, the Child Health Committee, the Mental Health Commission and the Health and Disabilities Commission have been reviewed, in order to position school nursing in New Zealand within the wider health and education framework. I have found that ministerial, health committee, and health commission publications have school-based health care provision embedded in the conversation, but school nursing is not specifically promoted as a child and adolescent primary health care initiative (Central Health Funding Authority, 1997).

New Zealand newspaper articles, including the New Zealand Herald and The Sunday Star Times have also been sourced to give an additional voice concerning school nursing and student health, as viewed by those from outside nursing. A limited amount of research has been undertaken within the school nursing domain, and few journal articles have been produced to document the nursing interventions enacted within this nursing specialty. School nursing has been identified as a mechanism for child and adolescent health care delivery, by a small group of New Zealand school nursing writers (Cato, 1997; Hamill, 1997; Harper, 1987, 1989; Partington, 1989; Rose, 1997).

Within the New Zealand literature there is a perceived absence of discussion on postgraduate education opportunities for school nurses, and as a consequence research 
opportunities have not been promoted. Practice concerns expressed include; the absence of any legislated requirement for schools to employ school nurses, the impact of geographical isolation on school nursing practice, and the inadequate salary structure and career pathway available to many school nurses. The funding of school nursing positions is also understood as a practice concern. The impact of limited funding has resulted in the downgrading of many school nurse positions to ancillary first-aid positions, and limited the development of school nursing as a practice specialty. School nursing literature in New Zealand documents professional challenges including; the transition from nurse to school nurse, the wide parameters of nursing interventions required within this specialty practice, and the invisibility of school nursing within the wider health sector.

Positive dimensions within the literature speak about the opportunity for school nurses to reduce health-related barriers, and improving child and adolescent health and learning outcomes. The ability of school nurses to undertake early identification and intervention with regard to physical and mental health, and to engage in health protection and health promotion opportunities within the 'Full Service Education' model of health care, are also viewed as positive benefits of school nursing practice (Wold, 1981).

By comparison, a review of school nursing literature from the US and the UK documents a wide range of research and practice development opportunities. School nursing has become established within these countries as a specialty practice, which encompasses primary health care practice and health education delivery (Bradley, 1998; Brindis, Sanghivi, Melinkovich, Kaplan, Ahlstrand \& Phibbs, 1998; Larter, Chernick, Maire \& DuBois, 1999). It has been possible to recognise a similar practice language, and similar practice development issues, when comparing national and international school nursing literature sources. A collaborative model of research, policy development and practice resourcing is a feature of US school nursing literature. The equivalent Ministries of Health and Education, Hospital Boards, University Nursing Departments, and Schools, have undertaken collaborative research and practice development initiatives. 
A critique of New Zealand school nursing literature, and New Zealand health care policy with regard to school health, has enabled similarities with international trends to be recognised. School nursing in New Zealand has developed along a different path than the UK or the US, especially in the area of privatised school-based health care delivery. It is however very apparent that postgraduate education, practice development, and research in the area of school nursing are lacking when compared to international studies. New Zealand is in the unenviable position of having child and adolescent health statistics that compare poorly with our international counterparts (information concerning child and adolescent health and wellbeing in New Zealand will be presented within this section, following an historical overview of school nursing). Literature surrounding school nursing indicates that collaborative policy and practice development and professionally trained school nurses can positively influence child and adolescent health outcomes.

In order to advance understanding about school nursing as a specialty, it is important to consider its historical development in New Zealand. In the next section I will compare and contrast the foundations of school nursing in New Zealand with the US and the UK. I will then highlight the potential for collaboration between school nurses and the Public Health Service. Early school health initiatives were introduced in response to the community health needs of the day. Current child and adolescent health needs vary from those addressed at the beginning of the $20^{\text {th }}$ Century. It is however possible to recognise the need for health promotion and health protection during this time, to advance child and adolescent health.

\section{The Early Years: The Development of School Nursing as a Public Health Initiative}

The history of school nursing in New Zealand is closely connected with the development of the Public Health Service. The Department of Health was established in 1900 with the adoption of the Public Health Act (Gauld, 2001). During this time New Zealand was divided into six health districts, each district being under the jurisdiction of a district health officer. The Chief Health Officer and "principal architect" of early health reform at this time was Dr 
James Mason (Dow, 1995, p.42). In 1901, Nurse Inspectors were appointed within the health districts, which also coincided with the passing of the Nurses Registration Act, 1901. Infectious diseases prominent at this time included; bubonic plague, dysentery, tuberculosis, scarlet fever, small pox, diphtheria, typhoid and influenza.

The occurrence of an outbreak of dysentery in the Wairarapa in 1902 became a catalyst for the development of the native nurses scheme (Deptartment of Health (DoH), 1986). Native health nurses were employed by the Native Affairs Department to work specifically with Māori communities, and in 1912 Miss Amelia Bagley was appointed as the first superintendent of native health nurses. Typhoid was endemic as a result of poor sanitation and inadequate housing. Early health interventions related to quarantine, vaccination, medical examination of passengers, and inspection of factories, hospitals and schools. The 1913 smallpox epidemic, and the 1918 influenza epidemic, were catalysts for preventive medicine opportunities, including sanitary inspection and health education. Nursing initiatives undertaken in the early 20th century were to become a pattern for future nursing activities in New Zealand. Early directions included the "management of nurses by nurses" and the "independence of practice" experienced by early New Zealand nursing superintendents, native nurses, and school nurses (DoH, 1986, p.2).

In 1902, parallel to early New Zealand nursing initiatives, the first school nurse position was established in the United States. Lina Rogers was employed within four New York City public schools to address the high rate of school exclusions due to infectious diseases (Passarelli, 1994). School nursing also developed in the US as an extension of public health initiatives and was in response to the "crowded living conditions, poverty, and high rates of morbidity and mortality, and infectious and communicable diseases" present within communities, as was the experience in New Zealand (p.141). Rogers was a pioneer for school nursing practice in the US and undertook home visits and parent health education alongside student nursing care. She also undertook student health education in relation to nutrition and hygiene, physical development assessment, and dental and hearing screening. This early school nursing practice was a model which "emphasized wellness and prevention" as opposed to inspection for illness and disease (Ross, 1999, p.29). 
In England, school nursing was established with the Education (Administrative Provisions) Act of 1907, which provided for the appointment of medical officers and school nurses. While and Barriball (1993, p.1202) suggest that the establishment of the school health service in the UK was in part due to the high incidence of "poor vision, carious teeth, heart disease and malnutrition" found among potential recruits to the British army. The establishment of school nursing services in the UK and the US was to become a forerunner of developments in New Zealand. School nursing was understood as a vehicle for addressing child health needs, and also for delivering health promotion and health protection to the wider community through student, parental and family education. New Zealand followed the UK example, and in 1912 the first School Medical Inspectors were appointed within the Department of Education. Dr Elizabeth Gunn, speaking of school health in 1914, reported information that was disturbing. She described that out of 61,000 children in her care as a School Medical Inspector, "almost a quarter of those examined suffered from malnutrition, one-third had obstructed breathing, and more than seven out of every ten eight year-old Standard II children had defective teeth" (cited in Dow, 1995, p.79).

Dow (1995, p.79) records the invisible or 'low-status' attributed to those working in the area of school health in the early years, despite the "undoubted abilities of many of its officers". It is evident from more recent school nursing literature that this sense of invisibility and the undervaluing of health care providers within schools are experienced by those currently working in this practice domain (Harper, 1987; Rose, 1997). An interesting parallel can also be observed in that early school health initiatives in New Zealand were under the direction of the Department of Education rather than the Department of Health. A similar pattern is observed today where funding for school nursing initiatives frequently comes from the school's operational grant, which is funded by the Ministry of Education.

In 1917, nurses were appointed to the School Health Service and were responsible for both a rural district and urban schools (Department of Health (DoH), 1986). The School Health Nursing Service was transferred from the Department of Education to the Department of Health in 1921, and from 1921 up until 1930, the Department of Health had both the Native Health Nursing Service and the School Health Nursing Service under its jurisdiction. Miss 
Mary Lambie is recorded as being one of the early school nurses in New Zealand. She worked as a school nurse in the Christchurch District, and was later appointed as the Director of the Division of Nursing within the Department of Health. An article concerning school nursing written in the Kai Tiaki: Journal of the Nurses of New Zealand in 1927 by Mary Lambie, highlights the school nursing interventions undertaken at this time, many of which continue today within school nursing practice.

She (a school nurse) also pays particular attention to and makes record of, all cases of defective hearing, as well as of physical deformities, excessive or unsuitable clothing, malnutrition, skin disease, pediculosis and lack of cleanliness. Regarding the three last mentioned, she takes action by circularising or visiting the mother, without delay. Health habits are discussed with the children, and advice freely given with regard to the care of the teeth and general cleanliness of the body.

Apart from home and school visiting, it is part of the school nurse's duty at a time of epidemic, such as diphtheria etc., to examine the school children's throats and take swabs for laboratory examination; she also takes swabs from diphtheria contacts, who are absent from school

(Lambie, July, 1927, p.116).

By 1930 the School Medical Service was staffed by a director, 12 school medical officers and 31 school nurses. At this time in history, school health was "theoretically a Health Department concern" although given the few numbers employed in the service, health education and health care interventions were enacted in the main by teachers (Dow, 1995, p.111). A similar pattern is evident in New Zealand schools today where student health and well-being is frequently assessed and managed by ancillary staff and teaching personnel. 
In 1930, the School Health Nursing Service and the Native Health Nursing Service were combined to form the District Health Nursing Service. District health nurses were involved in a wide range of community health initiatives including; venereal disease, tuberculosis, child health, health education, immunisation, Māori health, and school health. In 1946 the Industrial Health Nursing Service became another branch of the Division of Nursing within the Department of Health. The roles of district health nurses and industrial health nurses were combined in 1953 and the new nursing service was renamed the Public Health Nursing Service.

The Public Health Service has developed in response to the heath needs of the wider community in New Zealand. Parallel to this development, individual schools have established school-based nursing services to address the health needs of the student population. These schools view school nursing as a means to advance student well-being and to promote student success in the academic domain. School nursing services are able to complement the work of public health nurses by being located on-site, and therefore being directly accessible to the school community. The following section entitled Towards a Collaborative Model of Care, addresses the relationship between the Public Health Nursing Service and school nursing in New Zealand.

\section{Towards a Collaborative Model of Care: School Nursing as a Specialty Practice within the Public Health Nursing Domain}

Since 1953 public health nurses have continued their role at the interface between education and health. Schools in New Zealand continue to have public health nursing support and intervention, and health promotion and health protection opportunities continue to be enacted by public health nurses. They frequently provide a 'bridge' between the school and the family, caregivers, whānau, in relation to the health needs of students (Pybus, 1983). A survey undertaken by members of the Wellington Branch of the New Zealand Nurses Association (NZNA), concerning child health care in forty-five full primary and intermediate schools in the Wellington area, found that, "there was a definite call for the extension of the role of the nursing service in schools" (Peddie, 1982, p.20). All principals and 91\% of 
teaching staff surveyed stated that they valued the public health nurse as a health resource person. Areas of health intervention that were recommended for increased availability of public health nurses include; advice for specific health problems, health teaching, human development and relationship programmes, health programme development, and the physical assessment of children with health needs. Peddie was employed as the supervising public health nurse for the Wellington District Office at the time this article was written. She confirms an understanding that "it is to any community's advantage" that child health promotion and health maintenance is undertaken, in order to "achieve a high standard of healthy children in New Zealand" (1982, p.28).

The Public Health Commission Discussion Document, Healthy Schools: Kura Waiora (1994) re-affirms the importance of school-based nursing initiatives in the maintenance of community health and well-being. This document suggests that, "Schools are uniquely placed 'settings' or locations for improving and protecting public health" (p.2). The 'Healthy Schools' model is based on the Ottawa Charter, which was developed at the First International Conference on Health Promotion held in Canada in 1986 under the mandate of the World Health Organization (WHO). The Healthy Schools model is seen as having two important health components; health promotion and health protection. Within the context of the school these are enacted by developing school health policies, creating healthy school environments, undertaking health education and health promotion activities with students, strengthening community involvement in school initiatives, and developing the individual skills of students to address personal health issues (Public Health Commission, 1994, p.3).

Schools have been encouraged and supported by the Public Health Service to develop health policies that reflect a commitment to the Healthy School's framework. Such policies include, smoke-free environment, mental health, food and nutrition, infectious diseases, antiharassment, sun safety and helmet safety. Health promotion in schools is a significant area that has been purchased through Regional Health Authorities and is now under the direction of District Health Boards. The health reforms implemented within the health sector in the past decade have affected Public Health Service contracts, and in some instances resulted in a reduction of emphasis on personal health care delivery to school students. Individual 
schools have responded to this changing climate in various ways. Some have responded by directing education dollars into improving school-based health care services, while other schools faced with difficult financial choices, have downgraded school nurse positions to first-aid ancillary positions.

The Health Promoting Schools framework is an international initiative supported by the World Health Organization (WHO, 1996) and the Public Health Service in New Zealand. The first Health Promoting Schools Conference was held in 2000. The purpose of this framework is to advance individual student health, family health, and the health of the communities that the school serves (Ministry of Health, 2001b; New South Wales Department of Health \& New South Wales Department of School Education, 1996). Health promotion is advanced through research, policy development and health activities. Public health nursing involvement supports the introduction of school policies which are in line with the Health Promoting Schools concept. These policies are developed to address the need for peer support/mentoring, non violence/anti-bullying/anti-harassment/abuse protection, positive race relations/anti-discrimination, drug and alcohol safety, and mental and emotional wellbeing (Ministry of Health, 2001b, p.20). Public health nurses are available to co-facilitate health education within the classroom when invited to do so by school principals and teaching staff, and facilitate access to health resources including posters, pamphlets, videos, and health education literature.

Individual public health nursing contracts vary widely throughout New Zealand. Some Public Health Services offer student referral services for students and school health policy development support, while other services have devoted individual nurses to primary health care initiatives within schools, and have developed specialist adolescent health nurse positions. Public health nursing services are available to all schools in New Zealand and the links that are maintained between the health and education sector are a vital contribution to child and adolescent health and well-being. Vision and hearing testing, school-age immunisation, and the identification and referral of children requiring additional health care and abuse protection, are some of the protection activities undertaken. 
The re-configuration of public health contracts throughout New Zealand has made many public health nurses less available to offer health protection and primary health care services within schools. This has meant that some schools have chosen to employ nurses in order to meet the health needs of the student population. Marion Partington (1989) a school nurse from Hamilton, describing her understanding of the role of school nursing within the wider public health nursing context says

Traditionally, public health nurses have provided health care in New Zealand schools and I hold these colleagues in highest esteem. However, personnel and resources are sometimes limited so communication is the essence of our relationship and we enjoy a team approach. PHNs (Public health nurses) tend the wider community, while school nurses operate within a more specific part of that environment.

(Partington, 1989, p.28).

A large number of New Zealand schools (especially those within large urban areas) have chosen to fund their own nursing service. An example of this trend, are the sixty-five nurses currently affiliated to the Auckland School Nurses' Group. However, no current data is available as to the geographical distribution of school nurses throughout New Zealand, or the scope of current school nursing practice. Nurses are employed in many private schools, especially those with boarding facilities. Within the state education system in New Zealand, school nurses are primarily found in the major urban areas, including; Auckland, Hamilton, Hastings, Masterton, Lower Hutt, Porirua, Wellington, and Christchurch. Schools that employ a nurse direct money from their operational grant in order to offer a primary health care nursing service to both students and staff. School Principals and Boards of Trustees that support an on-site school nursing service believe that an accessible and free primary health care service has the potential to promote student health and well-being, and to improve the educational outcomes for students. 
The delegates represented at the Public Health Nurses Conference held in Wellington in October 2001, recognised the complementary nature of school nursing and public health nursing practice. In an effort to form a collaborative model of practice, and to advance a collective public voice with regard to child and adolescent health, a remit was passed to include both school nurses and public health nurses under one section of the New Zealand Nurses Organization (NZNO). Delegates also confirmed that school nurses and public health nurses are important partners in providing primary health care services within New Zealand school communities.

Throughout the early development of the Public Health Service in New Zealand, school nursing was seen as a valuable contribution to child, youth, and community health. The infectious epidemics of the early part of the $20^{\text {th }}$ century have been replaced by epidemics of a different nature. The current most prevalent child and youth concerns relate to child abuse, and the corresponding at-risk adolescent behaviour and mental health needs, such as; youth suicide, alcohol and drug misuse, youth violence, bullying, truancy and school failure. The high rate of sexual infections, youth abortions and unplanned teenage pregnancy also feature as significant adolescent health concerns (McNicholas, Bennett, Turley \& Garrett, 2001).

The prevalence of skin infections requiring surgical intervention, meningococcal disease, tuberculosis, asthma, and eating disorders are community health concerns that require planned health interventions. A school community is a representative example of wider society and as such a full continuum of health needs are displayed. Student health needs mirror the community in which the school is placed. Statistics indicate that social and economic determinants directly influence the health needs expressed within a community, and by implication a school community. In the following section I will explore the implications of child and adolescent epidemiological trends, which directly influence the scope of school nursing interventions undertaken within New Zealand schools. 


\section{Epidemiological trends: Child and adolescent health within the New Zealand context}

In order to gain a fuller picture of the context from which school health care delivery in New Zealand arises it is essential that I review the epidemiological data on child and adolescent health. As mentioned on p.31 the scope of school nursing practice reflects the health needs, which are present in the wider community. Current statistical data surrounding child and adolescent health indicates that when compared with international trends, child and adolescent health needs are not well served (Ministry of Health, 1999a).

The financial pressure on many families, due to unemployment, under-employment, and low family income, results in pressure to meet the high costs of housing, food items, and goods and services (Waldegrave, King \& Stuart, 1999). This cycle of poor earning and high living costs, translates to include unmet health needs in the school domain. As outlined on p.9 school-based primary health care allows students to self-refer for care, and consequently reduces the socio-economic barriers to health care access. A full range of health care needs can be addressed within a school-based nursing clinic, and when the need arises, outside health care services can be accessed on behalf of students.

A survey of one hundred and eighty-six students visiting a school nursing service, undertaken by Schneider, Friedman \& Fisher (1995, p.38), found that one-half of students "perceived that stress played a part in their visit" and one-third said they were "extremely or very stressed". They suggest therefore "many visits to school nurses for a somatic complaint may be motivated by underlying psychosocial problems"(p.35). School nurses are well placed to evaluate and enact care with regard to the presenting health concern, and also to determine the relationship between the presenting concern and possible underlying psychosocial problems.

The number of children living in one-parent families has increased over the past ten years. A longitudinal study undertaken in Christchurch, records that by the age of 16 years, $36 \%$ of children have spent time in a one-parent family (Fergusson, 1998, p.58). Research indicates 
that many one-parent families are disadvantaged in respect to income, employment, housing and education, and this disadvantage is translated to include a higher level of health need (Barwick, 1992). New Zealand rates poorly when compared with international studies in the area of child and adolescent health. This is reflected in statistics surrounding youth suicide, teenage pregnancy, youth abortion, sexually transmitted infection, drug and alcohol risk taking, and issues surrounding physical, sexual and emotional abuse (Cheesbrough, Ingham \& Massey, 1999; Coggan, Fanslow \& Norton, 1995; Dickson, Sporle, Rimene, Tahu \& Paul, 2000; Fenwicke \& Purdie, 2000; Howard, 1996; Langley, Nada-Raja \& Aslop, 2000; McNicholas, et al, 1995).

During 1998-1999 the Children, Young Persons and their Families Agency (CYPFA) substantiated that 2,808 children between $0-6$ years, and 3,392 young people aged between 7-16 had received "some form or multiple forms of abuse and neglect" (Ministry of Health, 1999b, p.24). Over recent years there has been a growing concern surrounding the high level of child sexual abuse and physical abuse reported in the media. Statistical information indicates that there has been a significant increase in the reporting of non-accidental injury involving children, which correlates with child sexual and physical abuse (Ministry of Health, 1996; 1997a; 1998a). Underlying these statistics are a further layer of children and young people for whom daily living is punctuated by abuse and neglect that does not appear in statistical records.

Fielden $(2001$, p.26) in writing about the creation of child abuse policies in New Zealand that reflect an ethic of care, contends that "acts of child abuse and the long-term effects of such abuse on survivors are currently viewed in New Zealand as being of major public health concern". The long-term effects of child abuse and family violence are frequently addressed within school-based health services (Ministry of Health, 1998b). These long-term effects include; poor self-esteem, sexual and other risk taking behaviour, violence, truancy, low academic achievement, and an inability to plan or consider future goals. Frequently these behaviours are indicative of student clients for whom the need for trust, nurture and care have been compromised. School nursing care seeks to address student total well-being: hauora, by delivering free and accessible primary health care services, and providing health 
promotion, health education, health counseling, and accessing community health services as required.

The mental health needs of students are regularly assessed within a school-based nursing service, and present in a variety of forms. Mental health concerns can be present in addition to other identified health needs. These can be associated with; family instability and disruption, socio-economic disadvantage, sexual abuse, physical abuse, and other violence. Loss and grief, same-sex attraction, relationship difficulties, drug and alcohol misuse, cultural disassociation, and poor academic success are recorded as significant contributing factors with regard to mental health difficulties (Ministry of Health, 1999b; Ministry of Health, 2001b, p.37). The document Adolescent Health (Department of Health, 1992) contends that "between 10 and $20 \%$ of adolescents require professional mental health care, yet only a small proportion receive it" (p.18). Mental health needs underpin many student self-referrals within school nursing practice, and require assessment and intervention, including the need to refer to secondary mental health services. School-based primary health nursing care can positively address the need for early intervention, with regard to child and youth mental health.

The New Zealand rate of suicide in young males aged 15-24 years is one of the highest among developed countries (Langley et al, 2000). The Strengthening Families document (Ministry of Health, 1999b) records that youth suicide is "an important public health and social issue", and that "sexual abuse in childhood also appears to be a significant risk factor for attempted suicide, along with childhood adversity and social disadvantage" ( $p .34$ ). The National Health Committee (1997, p.5) also reports that "while a sizable proportion of young people may contemplate suicide only about $5 \%$ of young people attempt suicide". The document prepared by the National Health Committee (1997) entitled A guide for schools: The prevention, recognition and management of young people at risk of suicide states that "40-45 young people aged 10-19 will die as a result of suicide each year" and "approximately 600-700 young people aged 10-19 will be admitted to hospital following a suicide attempt each year" (p.5). This document also contends that a larger number will be treated at accident and emergency services of local hospitals and not be admitted. The student 
population of New Zealand schools reflects this statistical information, and school nursing interventions include supporting students with early depressive symptoms and nursing care for students at high risk of self-harm. School nursing involvement on behalf of student clients seeks to offer early intervention with regard to mental health concerns and appropriate liaison and referral as required. The youth suicide rate is an indicator of youth mental health need, and statistical data confirms that improved youth mental health is an important area for health gain in New Zealand (Ministry of Youth Affairs, 2001b).

The results from a research survey undertaken by the University of Auckland concerning youth health, and involving almost 10,000 young people between the ages of 11 and 18 is currently being collated. Information pertaining to 270 young people attending alternative schools in Auckland (who can be considered a high risk group) reveals that "they are three times less likely to make a serious suicide attempt and significantly less likely to drink, take up smoking, or use drugs if they believe an adult at their school cares" (Maling, 2001, p. A5). The mentoring of student clients is a significant area of school nursing practice, undertaken on a daily or weekly basis. At-risk students are supported to manage their emotional, social and academic needs by having access to nursing services.

The Strengthening Families, Report on Cross-sectoral Outcome Measures and Targets (Ministry of Health, 1999b) suggests that drug and alcohol abuse by young people "can have immediate as well as long-term health and social consequences" (p.38). The problems associated with alcohol misuse include; motor vehicle accidents, difficulties in school, unplanned and unprotected sexual activity, violence and criminal offending. Field and Casswell (1999) indicate that $20 \%$ of males aged 15-17 reported consumption of alcohol enough to be drunk at least once a week. Fifteen percent of females in the same age group reported consuming enough alcohol once a week to make them drunk. The effect of high alcohol use by school-aged students is observed in school nursing practice, where unsafe sexual practice results in self-referral for emergency contraceptive assistance and sexual health intervention. The effects of binge drinking and high alcohol intake cause some student clients to access nursing care related to sexual assault, positive decision-making counselling, and wound care following alcohol-related violence. 
A research report entitled Cannabis and Youth (2000) by Regional Public Health; Hutt Valley Health, highlights the extent of cannabis use by young people in the Wairarapa and Kapiti districts. The survey involving 3,988 youth participants found that $12 \%$ of young people described themselves as current users of cannabis, and $18 \%$ of young people that described themselves as Māori were current users of cannabis. This study suggests, "One student in five of any class of 16 year olds could be experiencing the effects of recently taken cannabis. These students are unlikely to be reaching their educational potential" (p.39). The effects of regular marijuana use on young people include; short term memory impairment, slowed reactions and attention difficulties. A longitudinal research project undertaken in Christchurch found that $70 \%$ of young people had used cannabis by the age of 21 years, and "nearly $10 \%$ of the cohort showed clear symptoms of cannabis dependence by the age of 21 years" (Ferguson and Harwood, 2000, p.156). Cannabis-related concerns are evident amongst the school student population, and present as students with ongoing attendance problems and learning difficulties. School-based nursing services offer a positive way to address drug and alcohol education and also a vehicle for assessment, individual counseling, and liaison with specialist drug and alcohol services.

Fertility rates for 15-19 year old women in New Zealand are the second highest of all OECD countries. In 1998, there were 1,245 live births for women under 18 years of age, which indicates a rate of 9.5 per 1000 females aged between 13-17 years (Statistics New Zealand, 2000). In 1998, the fertility rate for Māori females aged between 13-17 years, was 26.2 per 1000 births. The abortion rate in 1998, for females aged less than 18 years was 1,232; this represents an abortion rate of 9.4 per 1000 females aged 13-17 (Abortion Supervisory Committee, 1997). A study undertaken by Fenwicke \& Purdie (2000, p.460) of 654 forth form students from the Bay of Pleanty, involving a self administered anonymous questionnaire, found that $39.4 \%$ had experienced sexual intercourse, and of those who were sexually active, $30.2 \%$ reported their first sexual intercourse at age 12 or younger. This study also found that $74.9 \%$ of fourth form Māori students were sexually active. These research findings indicate the high need for appropriate and timely sexuality education, access to contraceptive information and provision, and sexual health interventions. 
Sexual health and reproductive health is a significant area of health education and health protection undertaken within the school nursing domain. Student clients are able to self-refer for health education exchange including; menstrual cycle education, self-care, decisionmaking counselling, and safe sexual practice education. School nursing care has a primary function in providing contraceptive education and sexual health education, and in providing support for students to access sexual health services, family planning and medical care as they are required. The annual salary of a school nurse can be easily recovered by preventing unplanned teenage pregnancies, the subsequent discontinuation of education, and the need for government financial assistance for teenage parents. School nurses working in New Zealand schools can positively influence youth sexual and reproductive health.

Recent statistical information records significant child and adolescent health concerns. School-based nursing services are an important means of delivering free and accessible health care to the student client group, and thereby improving child and adolescent health outcomes. In the following section I will present a critique of school nursing literature that identifies the complementary contribution to child and adolescent well-being: hauora offered by developing school nursing services in New Zealand. I will then discuss a range of policy development initiatives and practice development initiatives that have the potential to advance the future development of school nursing in New Zealand.

\section{School nursing as a complementary contribution to child and adolescent wellbeing: hauora in New Zealand}

School nurses are described as 'boundary dwellers' because their practice includes health care provision and education delivery (Igoe, 1990). Hacker and Wessel (1998, p.410) also express a belief that school nursing "bridges the gap between health and education" but also contend that there is a negative effect of this boundary position. The risk, which they express, is that school nursing is "somewhat peripheral to both domains and ultimately lacks 
solid support from either" (p.410). Funding for school nurse positions is an area which highlights this paradox in that health initiatives within schools are frequently financed by education dollars.

The link between health and education provided by school nurses has allowed some writers to describe school nurses as being 'expert' in both health and education (Larter et al, 1999). Larter et al $(1999$, p.21) suggest that, "the school nurse is perceived by school personnel as the expert who can combine knowledge of health care and education to develop a program that best fits the needs of the child and school personnel". Paladino (2000, p.30) asserts a belief that the school nurse is able to "translate health issues into language that educators can understand". She describes this position of health care mediation as "brokering health care" for students, family, caregivers, whānau and teaching staff (p. 30).

There is an understanding within school nursing literature of the significant role which school nurses play in the addressing the total well-being of students and the positive impact of such initiatives on the educational outcomes of students. Paladino $(2000$, p.6) contends that, "Certified School Nurses are truly partners in education and do indeed support student success". School nurses are actively involved in primary health care, student health education, early identification and intervention, and health promotion within the 'Full Service Education' model of student care.

Four broad themes can be determined from the literature, which promote school nursing as a means to provide a complementary contribution to child and adolescent total well-being: hauora in New Zealand. These themes are outlined in Table 3., on p.39, and will be discussed in the following section, giving reference to the literature within this specialty. The first theme to be discussed is School nursing as a community based primary health care initiative. 
Table 3. School nursing as a complementary contribution to child and adolescent total well-being: hauora in New Zealand

1. School nursing as a community based primary health care initiative

2. School nursing involvement in health education within the New Zealand health curriculum

3. Early identification and intervention with respect to the physical and mental health needs of students

4. School-based nursing services within the 'Full Service Education' model of student care

\section{School Nursing as a community based primary health care initiative}

The table above introduces school nursing as a community based primary health care initiative. New Zealand literature concerning school nursing from the late 1980s highlights the concern expressed by school nurses that all secondary schools should have schoolbased nursing services focused primarily on student health care. 
There has been a developing understanding within school nursing literature in New Zealand that school nursing is a primary health care initiative. Harper $(1989, \mathrm{p} .18)$ describes school nurses as being "uniquely placed to provide cost-effective primary health care". Almost ten years later Rose (1997, p.7) writing on the same topic records the, "huge potential" offered by school nurses to address adolescent health needs. She considers that school nursing offers "a unique opportunity to provide cost-effective, primary health care to a needy consumer group - adolescents" (p.7).

Almost one decade ago the Department of Health $(1992$, p.11) gave voice to an understanding that health care services for young people "should be affordable, accessible, and available to all young people, when required". Pat Lynch, the president of the New Zealand School Principals Association in 1993, was interviewed following a visit to the United States concerning his experience of school-based nursing initiatives, and the implication for New Zealand schools. During an interview with the New Zealand Herald he stated that school-based services were a "powerful model" and that having health services based in schools "made all the difference" (Carroll, 1993, p.3). He also reminded his readers that if New Zealanders wanted to address serious issues such as adolescent suicide, we would need to consider school-based health services as a means to address the problem. He stated that school-based services are an ideal vehicle for delivery of health care to the adolescent population, and "not only were they improving the health and mental attitude of students from schools in deprived areas, they were also proving to be the basis of higher academic achievement". Lynch also expressed the opinion in this article that "Adolescent health is not being adequately catered for. We need to look at having a trained nurse and health support services, for all secondary schools" (p.3).

The publication Healthy Schools: Kura Waiora (1994, p.2) produced the following year by the Public Health Commission, recognises that schools are a 'unique' vehicle for addressing adolescent health needs. Within this document it is stated that, "schools are uniquely placed as 'settings' or locations for improving and protecting public health". The Ministry of Health document Effective Services for Young People: Te Toiora O Tōku Whanaketanga (1995) 
published in the same year includes a discussion concerning adolescent health in New Zealand. The document reflects on the high incidence of suicide, mental health problems, sexual health and contraceptive needs, high abortion rate, youth violence, sexual abuse and drug and alcohol problems among young people in New Zealand. This publication also alerts the reader to the important place school nurses can play in health promotion and disease prevention, and contends that "School-based centres can also provide health promotion and disease prevention to a degree not possible in off-site settings" (Ministry of Health, 1995, p23). In the concluding pages, this document details the importance of accessibility as a feature of school-based services. The benefit of developing school-based health services is described by saying, "School-based primary health centres are organized around young people. This helps to reduce the need for young people to access off-site services, which are often scattered and uncoordinated" (p.23). This document also discusses school-based services in the United States and suggests "School-based centres provide young people with better access to health care, a wider range of services, and greater in-depth attention for psycho-social needs" (p.23).

School-based nursing services offer students continuity in primary health care, as an important relationship is established between the student and the school health nurse which may be over a five-year period. The Ministry of Health publication the Primary Health Care Strategy (2001c, p.7) describes the perceived value of continuity in primary heath care where people, or in this case student clients, "have a usual source of care, and can use that source for advice and help over time". This document also subscribes to the importance of "bringing health care as close as possible to where people live and work", or in this instance study and socialise (p.29).

Clendon and White (2001, p.171), following a community needs analysis to determine "the feasibility of establishing a nurse practitioner-led, family focused, primary health care clinic within a primary school environment" in Central Auckland, found that such a service was feasible and a positive new direction for nursing. This study also found that the desirable school-based primary health care service would include, "health information, health education, health counselling and health services, and case co-ordination"(p.177). Clendon 
and White contend that the nurse practioner employed to deliver this type of school-based nursing service would need "preparation to an advanced level of practice" (p.171). Child and youth health outcomes have the potential to be improved by basing primary health care services within schools and appropriately training school nurses to work within this specialty domain of nursing.

Over the past fifteen years a range of ministerial and health sector publications have included discussions concerning school-based health services. A literature review of publications from the Ministry of Education and the Ministry of Health has found that schoolbased services are described as a mechanism for the delivery of primary health care to the child and adolescent population in New Zealand. It is important that policy direction and funding initiatives reflect a commitment to developing school nursing services in New Zealand. The next section addresses the contribution that school nurses can make towards health teaching in primary health care practice, and health education within the New Zealand health curriculum.

\section{School nursing involvement in health education within the New Zealand health curriculum}

Harper (1989) in writing about the role of the school nurse within the education sector records a commitment to health education and student wellness. Rose (1997) reflecting on the school nurse's role in health education alerts the reader to the potential for school nurses to engage in health curriculum development and the delivery of health teaching. The Central Regional Health Authority document Young and Healthy: Whiti Te Ra (1995, p.31) advances the opinion that "it would be best to strengthen the provision of health screening, health promotion and health education services through schools". The discussion engendered by New Zealand school nurses over the past decade points to a significant role in health education within the health clinic environment and in the classroom setting.

The New Zealand health and physical education curriculum has been developed in consultation with leading teachers and health educators in the field of health education, 
physical education and home economics. The new health curriculum document was made mandatory from the beginning of 2001 and has been developed around three key concepts. These concepts include; total well-being: hauora, health promotion, and a socio-ecologic perspective. Total well-being within the context of the New Zealand Health and Physical Education Curriculum is viewed as having four dimensions which influence and support the other; taha tinana - physical well-being, taha whānau - social well-being, taha hinengaro mental and emotional well-being, and taha wairua - spiritual well-being (Ministry of Education, 1999, p.31). The concept of health promotion as a central element to improving total well-being is advanced by the Public Health Service's commitment to the 'Health Promoting Schools' framework (Ministry of Health, 2001b).

Health education in schools has been recognised as an essential component of health promotion within the community (Charleston \& Denman, 1997; King, 1994; St. Leger \& Nutbeam, 2000). School nurses that hold postgraduate qualifications in teaching are in a key position to deliver health education within the classroom, in conjunction with primary health care provision within schools. The American National Association of School Nurses publication School Nursing Practice: Roles and Standards (Proctor, Lordi \& Zaiger, 1993) has a standard that relates to improved student, family, and community wellness, through the delivery of appropriately designed health education programmes. Bradley (1997, p.6) highlights the importance of school nurses providing classroom health teaching based on "sound learning theory". School nurses are understood to provide individual health education, which is described as 'client teaching' and 'health counseling', or 'anticipatory guidance' with respect to "health education in advance of clients participating in risk behavior" (p.6). This literature describes school nurses as 'consultants' and 'resource persons' with regard to classroom health education delivery and health curriculum development unless they have received formal health teaching certification as Certified Health Education Specialists. Bradley comments that there is a requirement in some states in the US for school nurses to hold 'teaching credentials' in order to be employed as school nurses. 
Bradley (1997, p.4) in her discussion of school nurse education says that, "In some states credentialing as a school nurse requires a fifth year of college-level work that may or may not include health education, pedagogy and teaching strategies". The Department of Education Reform Act 1993, in Massachusetts, legislated that school systems must employ certified school nurses to school nurse positions. The National Board for Certification of School Nurses and the American Nurses' Association undertake testing and certification of school nurses, and the National Commission for Health Education Credentialing, Inc., undertakes the testing and certification of health educators within the United States (Bradley, 1997). Bradley in writing about school nursing in the US indicates that some school nurses have health teaching qualifications including; college units in health education, curriculum development, teaching strategies, and hold a national certificate as Certified Health Education Specialists.

Nurses are well equipped to provide a 'bridge' between health and education, and grounding in teaching pedagogy is of strong benefit to nurses working in school nursing. Whitmarsh (1997, p.40) contends that the development of "teaching skills within the school nurse profession" needs to be addressed as part of school nursing training. It is now possible for nurses to be employed as primary health care providers and health teachers, following teacher registration. Such training allows a career pathway for school nurses within the education sector, and also enables nurses to hold positions of responsibility in Health.

Currently many schools in New Zealand are reviewing the delivery of the Health Education curriculum or developing new health education programmes, and schools will require trained health educators to enable the delivery of this curriculum area. There are some schools currently teaching to the new curriculum, while other schools have teachers untrained in health education delivering this curriculum due to gaps in their timetable. School nurses are well placed to teach health in the primary and secondary school setting. School nurses as trained health education specialists, are able to undertake health curriculum development and heath education within the classroom. School nursing involvement in Health teaching has the potential to promote healthy decision-making and to improve student health and well-being. 
In the next section of writing, early identification and intervention with regard to the physical and mental health needs of students is advanced as a complementary contribution to child and adolescent total well-being: hauora in New Zealand.

\section{Early identification and intervention with respect to the physical and mental health needs of students}

Within school nursing literature the reduction of health barriers to educational achievement is a re-occurring theme. Patricia Cato (1997, p.14), writing from the New Zealand context considers that "the service provided by school nurses is a powerful and cost-effective way to improve the health of young people". The Ministry of Education (1999) publication Health and Physical Education in the New Zealand Curriculum suggests "in order to foster academic achievement and provide students with equal education opportunities, schools need to address the broad health issues that affect students' learning" (p.5). Throughout this document schools are interpreted as being in a primary position to undertake early identification and intervention with respect to a range of health needs.

Literature surrounding mental health services for young people promotes a belief that early intervention is the key to positive outcomes for young people. The publication Mental Health Services for Young People (Ministry of Health, 1997b) reminds readers "if early identification and intervention occur before the onset of more serious disorders then the prognosis is better and long term disability and dependence on the State is minimised" (p.6). Trained school nurses are in an important position to enact early identification and intervention for students across a range of mental health needs. It is recognised by the Ministry of Health, that $20 \%$ of the child and adolescent population has mild and moderate mental health problems, this represents 6 young people in a class of 30 students, or 200 young people in a school of 1000 students (p.6).

School nurses in partnership with teaching staff, are able to form positive and caring relationships with student clients that support at-risk students to better cope with personal challenges (Mailing, 2001). Resnick (2000) confirms the importance of student's having 
connection to significant adults within school organisations, and deems these to be protective factors against a range of at-risk behaviours. Positive mental health is viewed within the Health and Physical Education in the New Zealand Curriculum (1999, p.36) as a "prerequisite if students are to reach their highest academic, physical, and social potential". School students are assisted to find success in the educational and social domains when physical and mental health concerns are recognised, students at risk are identified, and early and appropriate interventions are enacted (Dychkowski, 1998; Jennings, Pearson \& Harris, 2000).

The Primary Health Care Strategy (Ministry of Health, 2001c, p.15) recognises that, "primary health care is the first level of contact with the health system". This document also proposes "it is often at this level that an individual's need for other services is identified"(p.15). Schoolbased health services are a first point of contact for student clients. The school nurse's role includes; assessment, intervention, referral, liaison and advocacy for students and family, caregivers, whānau in relation to health needs or health concerns. The school nurse in this instance, works on behalf of the student or student family, caregiver, whānau as a health care mediator. Health care mediation is an 'essence' of school nursing practice that will be explored later in this research within the context of reflexive poetic analysis, and as a proposed school nursing framework.

Cotton, Brazier, Hall, Lindsay, Marsh, Polnay and Williams (2000, p.1089) in undertaking a quantitative economic analysis and qualitative descriptive study related to the costs and potential benefits of school nursing within four school nursing districts in England, report that young people value "a sympathetic health care system that offers them expert advice, understanding and confidentiality". School nursing can be viewed as a means to enable student self-referral and referral, a means to implement early identification and intervention with regard to physical, emotional and mental health, and a vehicle to ensure that a full range of additional health services are engaged as required. School nursing services that are appropriately funded, and supported within the 'Full Service Education' model of student care can advance a complementary contribution to child and adolescent health. 


\section{School-based nursing services within the 'Full Service Education' model of student care}

School nursing literature from the US describes the development of school-based nursing centres since 1987, and the proliferation of such centres to service the primary health care needs of school students (Kisker \& Brown, 1996). School-based centres usually operate in parallel to school nursing services and are staffed by nurse practitioners and general practitioners. Some centres have developed to include social workers, guidance personnel and mental health staff. Community health centres, medical practices and hospitals, usually operate school-based centers while school nurses are employed by individual schools or clusters of schools (Hacker \& Wessel, 1998; Verhey \& Ferretti, 1996). A study undertaken in the US by Crosby and St. Lawrence $(2000, p .22)$ found that students generally trusted school-based services and regarded them as "convenient and helpful". They contend that "SBSs (School-based Services) that include reproductive health services have the potential to serve large numbers of US adolescents, thus reducing national rates of adolescent STD and unintended pregnancy'" (p.22).

School nurses have traditionally worked as independent and specialised professionals, and the development of school-based health centres has required a collaborative model of student care. School nurses in the US have been called upon to work in partnership with school-based centers to improve student health and educational outcomes (Passarelli, 1994). Papa, Rector and Stone (1998, p.415) suggest, "There is a developing consensus that the interests of the education system and the health and social services system must be joined to meet the needs of today's children and youth". The school is an environment where young people spend a significant part of the week. Therefore concentrating primary health care services in this venue ensures accessibility and continuity of nursing care.

School nursing literature from New Zealand speaks about the relationship between the school nurse and the wider school community. Harper (1989) describes this involvement as being part of the 'pastoral team', including guidance counsellors, teachers, deans and senior management. The 'pastoral care model' has been expanded in some schools in New 
Zealand to include a 'Full Service Education' model of student care (Dryfoos, 1994). Full Service Education complements the traditional guidance and dean structure within schools and includes such school-based services as a school nurse, guidance counselor social worker, truancy officer, mentor co-ordinator, and community liaison personnel. The recently established positions of resource teacher of learning and behaviour (RTLB) have assisted school personnel to develop individualised educational programmes for students referred due to learning and behaviour difficulties. RTLB interventions on behalf of student clients are understood as offering a complementary contribution to the Full Service Education model of student care. The Full Service Education model of student care can also include part-time access to a doctor, physiotherapist, and drug and alcohol counsellor. The reason some schools have moved towards this model of student care is to enable better access to health care, to promote student well-being, and to reduce barriers to learning.

\section{Summary}

A review of school nursing literature has found that the benefits of developing school nursing include; reducing health barriers to student learning, improving child and adolescent health outcomes, and building student success and enrichment in the social, emotional, and educational domains. School nursing literature illuminates the complementary contribution to student health, made by school nursing involvement in primary health care delivery and health education within schools. Early identification and intervention with regard to physical and mental health needs are also established as primary functions of school nursing practice. School nursing services supported within the 'Full Service Education' model of student care have the potential to improve child and adolescent health outcomes in New Zealand. In the following section I will present an outline of school nursing policy initiatives and practice development initiatives that can facilitate the future development of school nursing practice in New Zealand. 


\section{The planned future development of school nursing as a primary health care specialty}

In order to progress school nursing practice in New Zealand, it is important to evaluate the literature that pertains to school nursing policy development initiatives and practice development initiatives. The future development of school nursing as a primary health care and health education initiative is dependent upon a clear understanding of practice deficits, and 'best practice' goals (Boykin \& Schoenhofer, 1993; Felton \& Keil, 1998). Recognition has been made in school nursing literature that in order to advance child and adolescent health and educational outcomes, collaborative models of research, policy planning and practice development are required.

A qualitative, descriptive study involving ten school nurses from a large metropolitan school district in Alaska, was undertaken by Felton and Keil (1998, p.5), to elicit the "perceptions and visions" of their practice. The five themes that emerged from this research were, preparation for practice, essences of school nursing practice, scope of practice perceptions, powerlessness, and future outlook. The essences of school nursing practice illuminated by this inquiry were found to be caring, independence, isolation, flexibility, collaboration, and satisfaction (p.7). This research project was valuable, in that it allowed school nurses from the US to 'voice' their practice specialty, and to offer insight concerning their future practice development needs. International school nursing literature can inform future practice development in New Zealand. However it is important to establish a research agenda within school nursing in New Zealand. This thesis has been an opportunity to 'give voice' to the 'scope' and 'essence' of school nursing practice, and to address the policy and practice development needs particular to the New Zealand context.

The relationship between health and education is an area that needs to be explored when addressing the future development of school nursing. The Central Regional Health Authority document Young and Healthy: Whiti Te Ra $(1995$, p.15) discusses health care provision for the adolescent population and contends that, "Developing a close relationship between the health and education sectors is critical to the success of these services for young people". 
The goal of Government departments forming collaborative relationships that benefit young people is expressed in the document Supporting the Positive Development of Young People in New Zealand (Ministry of Youth Affairs, 2001a). This document states that Government agencies need to be "influenced less by organisational boundaries and definitions and more by understanding and acting on the best interests of young people" (p.15). Positive youth development requires "training health professionals in relating to and working with the diversity of young people" and "an inter-departmental approach to effectively addressing the needs of young people" (Ministry of Youth Affairs, 2002, p.34). This knowing can be translated into the school domain where health and education sector personnel need to creatively work towards developing school-based nursing services that can benefit student consumers. The health needs and educational needs of school students are "inextricably intertwined", as such "efforts to improve school performance without addressing health are as ill-conceived as focusing on improving health while ignoring education" (Papa et al, 1998, p.415).

Within the US, partnerships for teaching in the area of school nursing have been developed between University Schools of Nursing, Health Boards, Hospitals, Children's Hospitals and Public Schools. Inter-sector collaboration between health, education and welfare has made possible postgraduate school nursing education initiatives (Hacker \& Wessel, 1998; Larter et al, 1999). Some school-based nursing centres have adopted collaborative management structures that work to address quality management opportunities, such as the quality of patient care, and ongoing practice and service improvements (Verhey \& Ferretti, 1996). It is important that collaborative relationships are established to support school nursing in New Zealand. Collaborative opportunities are possible between school nurses and public health nurse, schools and District Health Boards, Colleges of Education and Graduate schools of Nursing and Midwifery, and the Ministry of Health and the Ministry of Education. Collaborative school nursing opportunities are possible in the areas of policy initiatives, funding, postgraduate education, practice development and research. Table 4 on p.51 outlines the collaborative policy development initiatives, and the professional practice development initiatives that are required to support the planned future development of school nursing as a primary health care specialty. 


\section{Table 4. The planned future development of school nursing as a primary health care specialty}

\begin{tabular}{|c|c|c|}
\hline $\begin{array}{l}\text { Collaborative } \\
\text { policy } \\
\text { development } \\
\text { initiatives }\end{array}$ & 4. & $\begin{array}{l}\text { Legislation for registered school nurses in schools } \\
\text { Funding of school nurse positions } \\
\text { Postgraduate training of school nurses } \\
\text { School nursing salary and career pathway }\end{array}$ \\
\hline $\begin{array}{l}\text { Professional } \\
\text { practice } \\
\text { development } \\
\text { initiatives }\end{array}$ & 1. & $\begin{array}{l}\text { New Zealand National Association of School Nurses } \\
\text { Standards of school nursing practice } \\
\text { Professional school nursing competencies } \\
\text { Postgraduate education in child and adolescent health and } \\
\text { Health teaching } \\
\text { Identification of school nursing interventions } \\
\text { School nursing research }\end{array}$ \\
\hline
\end{tabular}

In the following section I will introduce proposed future collaborative policy development initiatives that are needed to support the development of school nursing in New Zealand. School nursing literature has been examined to determine current practice trends, and to guide proposed future practice development initiatives. The first practice development initiative to be explored is legislation for registered school nurses in schools. 


\section{Legislation for registered school nurses in schools}

The need for registered school nurses in schools was articulated by Harper $(1987$, p.18) on behalf of the Auckland School Nurses' Group, where she describes an aim of the group is "to see a professional nursing position established in all secondary schools, free from the constraint of ancillary staffing conditions". She also records that "the nurse should be present for the full school day and must have access to in-service education" (p.18).

Ann Harper (1987) an Auckland school nurse contends that there is no mandatory requirement for schools to employ registered nurses to school nurse positions. This situation has not changed in the intervening years. She also voiced her concern that "Under present Education Department policy there is no mandatory requirement for secondary schools to employ a nurse. Despite the fact that many schools have rolls of over 1000 pupils, the decision to employ a nurse is left entirely to the individual school". Under the Education Act 1989, School Principals are required to ensure the health and safety of students and staff. Schools are required to ensure staff members are trained in first-aid in order to meet the requirements of the Department of Labour, Health and Safety in Employment Act, 1992. In addition, some school principals have chosen to employ school nurses to meet the health and safety needs of students. There is no requirement under the Health and Safety in Employment Act, 1992, for schools to employ nurses to address health and safety issues as the legislation relates to employees within an organisation. Students are deemed to be products within the education industry and as such do not require a specific nurse to student ratio as in some states in the United States (Bradley, 1997).

School nursing publications from the US document research concerning the desirable ratios of school nurses to student clients. The US National Association of School nurses records that a ratio of one nurse to 750 students is a desirable school nursing practice ratio. A practice ratio of one nurse to 225 students is suggested for mainstreamed students with special needs, and one nurse to 125 for severely disabled students (Bradley, 1997, p.4). It is noted by Proctor et al $(1993$, p.144) that legislation has been enacted in 16 states which requires, "school health services be provided by a registered professional nurse and two 
states have mandated a specific student-to-nurse ratio". Continuing education is a requirement in several states, and some require certification in school nursing, and continuing education as a condition of employment (Blaber et al, 1997). Brenner et al (1999, p.57), writing from the US context purport that "more than half of the states require schools to offer school health nursing services, and most offer certification for school nurses".

The New Zealand Nurses Organization (NZNO) has passed policy remits concerning school nursing which articulate a belief that "the provision of nursing services within schools should be provided by Registered nurses" (NZNO Policy, 1995, p.S1). Due to financial constraint, and the need for school principals and Boards of Trustees to work within a limited operational grant to achieve their primary educational brief, some schools have down graded school nurse positions to first-aid ancillary positions. Government legislation needs to be enacted that requires school Boards of Trustees to employ registered nurses within schools, and to determine a safe student to school nurse ratio. Future directions also need to address the funding of school nursing positions.

\section{Funding of school nurse positions}

School nursing in New Zealand is largely an invisible primary health care initiative, currently unsupported by the Ministry of Health, and the District Health Board process. Government agencies need to ensure that appropriate funding is directed into schools, to make possible quality school-based nursing initiatives. Despite the rhetoric espoused by New Zealand ministerial and health sector publications, little financial support has been given to improve school-based nursing services, and to facilitate postgraduate training opportunities for school nurses.

The operational grant provided to schools by the Ministry of Education, is the mechanism by which schools fund all school initiatives. Schools in New Zealand are able to direct financial resources into school based health services, but all decisions rest with the school Principal and the Board of Trustees, as to the level of health care they provide. School communities contain a large range of learning environments that have the potential to cause injury, as in 
other occupational settings. Industrial facilities with a similar number of personnel as school facilities, require occupational health nurses to be employed. Patricia Cato (1997, p.14) highlights the broad range of facilities found within a school community that have the potential to give rise to accidental injury.

Schools contain not only classrooms, laboratories, kitchens, workshops, sewing rooms and swimming pools, all of which are high risk areas. In any commercial organisation this size, occupational health nurses would be required by law.

(Cato, 1997, p.14)

The Ministry of Health (2001c, p.27) reports that the "Government is committed to funding additional health promotion, disease prevention, and community development services in primary health care". School-based nursing services are an important mechanism for the delivery of primary health care to the child and adolescent population and as such are in need of appropriate and expedient funding. These services require funding at a national level, to ensure that schools are not required to use their operational grant to implement child and adolescent health care provision.

Collaborative discussions between the Ministry of Youth Affairs, the Ministry of Health, the Ministry of Education, and representatives from the Public Health Nurses and School Nurses Section of the NZNO, and the Auckland School Nurses Group are required, in order to develop a strategic plan with respect to school nursing in New Zealand. Proposed negotiations need to address; legislative requirements for registered school nursing provision in New Zealand schools, funding of school nursing services, salary and career pathway needs, and government funded postgraduate training opportunities. School nursing positions need to be funded at a level that recognises professional qualifications and experience, addresses school nursing practice costs, and which allows them to attend regional study days, national conferences, and postgraduate training courses. 


\section{Postgraduate training of school nurses}

The Postgraduate Certificate in Child and Family Nursing offered by selected New Zealand universities and polytechnics currently receives funding from the Clinical Training Agency (CTA). This course is a possible vehicle for developing a school health nursing specialty course. Option papers in school nursing, child and adolescent health nursing, and a thesis component, could allow postgraduate nursing students that have undertaken the Certificate in Child and Family Nursing course, to further their academic studies by completing a Master of Child and Family Nursing/School Nursing/Adolescent Nursing (Applied). The opportunity to gain such qualifications would allow New Zealand school nurses to align themselves more fully with their international counterparts, who have completed master's coursework in public health nursing with an adolescent health/school health focus, and doctoral level qualifications. School nurses with practice and academic training in school health would be well placed to engage in international dialogue concerning child and family health, adolescent health, and school health.

The Ministry of Education supports a model for the training of guidance counsellors in New Zealand schools that involves the funding of training and paid professional release for course related educational commitments. Similarly, the training for Resource Teachers of Behaviour and Learning (RTLB) from the year 2000 has included postgraduate study towards a fourpaper certificate, which can be incorporated in a master's level programme. The Ministry of Education sponsors RTLB training, and teacher relief time is funded in order that staff can undertake professional course requirements and meet study commitments. A similar model for training school nurses to achieve postgraduate qualifications in school nursing needs to be urgently explored. Professional education opportunities for RTLB and guidance personnel are models that could also be adapted for school nursing education. A collaborative model of school nurse training supported by the Ministry of Health and the Ministry of Education is desirable in order to improve student health outcomes. The following section address the need to establish an appropriate school nursing salary structure, which reflects professional expertise and responsibility, and which forms the basis of a career pathway within this specialty practice. 


\section{School nursing salary and career pathway}

The salary paid to school nurses has been an area of concern. Many school nurses employed for their nursing expertise have found that their professional qualifications have been under valued within education. School nursing literature in New Zealand highlights the professional concern, that school nurses employed in ancillary positions during part of the school day are expected to assume a professional nursing role when medical incidents or physical injury arise. Many school nurses have historically been paid less than the new graduate salary within the hospital sector. This trend has minimised professional qualifications, practice knowledge and experience. The negative result of an underpaid work force has been a high turnover of school nurse positions and the consequent erosion of the body of knowledge, which pertains to 'best practice' in school nursing. Ann Harper (1987) reminds readers about the range of nursing interventions undertaken within schools, and the large number of students and staff, for whom the school nurse is responsible. She also advocates a salary structure for school nurses that recognises the independent nature of school nursing practice, and "the responsibility inherent in a sole charge position which provides health care for a large number of people" (p.18).

School nursing literature from the Australian context confirms the need for a salary structure that reflects professional and independent nursing practice. Eileen Collard, a school nurse from the Northern Territories of Australia details negotiations that took place to set an award for school nurses in 1994. The Industrial Relations Commission was approached on behalf of Collard, the Northern Territories of Australia Nurses Foundation, and the Education Department. Resulting investigations "set the school registered nurses award at the level of charge nurse in a community health centre" (Collard, 1994). It is important that similar negotiations are undertaken in New Zealand between the NZNO, the Ministry of Health and the Ministry of Education, in order to determine a professional salary for registered nurses in schools.

The professional career pathway open to school nurses in the US includes the teaching career pathway or "teacher tenure track", and continuing education including the achievement of college credits improves the salary of such school nurses (Blaber, 1997, 
p.263). The opportunity for school nurses to undertake postgraduate teaching training and to accept health teaching positions within schools, presents a future career pathway for school nurses in New Zealand.

\section{Summary}

The future development of school nursing as a practice specialty requires the development of national policy initiatives. These policy initiatives need to include; legislation for registered school nurses in schools, funding of school nurse positions, government funded training of school nurses, and a school nursing salary and career pathway that recognises experience and qualifications in health and education. Planned future policy development initiatives in school nursing need to affirm the complementary contribution to student well-being provided by having nurses engaged in primary health care delivery in schools, and health education within the classroom setting.

The future advancement of school nursing in New Zealand requires the development of a planned approach to school nursing policy development. It also requires attention to professional practice development initiatives. The first proposed practice development initiative to be discussed is the formation of a New Zealand National Association of School Nurses.

\section{New Zealand National Association of School Nurses}

The Auckland School Nurses Group was established in 1985, as a sub-group of the Community Health Special Interest Section of the then New Zealand Nurses Association (NZNA). The purpose of this group was to facilitate communication between school nurses, given the geographical isolation experienced by some in their practice, and to advance collective goals including; professional recognition, salary structure improvements, educational opportunities, and practice development (Harper, 1987). Geographical isolation is a professional concern within school nursing as educational opportunities, knowledge sharing, and practice development possibilities are diminished by such professional isolation 
(Passarelli, 1994). School nursing services are undertaken throughout New Zealand, although this specialty practice is largely represented in Auckland. The Auckland School Nurses Group represents approximately 65 school nurses, and provides professional liaison and learning opportunities. School nurses in other parts of New Zealand are more isolated in their practice, and future policy development needs to include a New Zealand National Association of School Nurses.

There are approximately 30,000 school nurses practising in the US, and the US National Association of School Nurses has a membership, which exceeds 10,000 school nurses. This professional nursing group advances policy, education, and practice development opportunities (Bradley, 1998, p.54).

The inclusion of school nursing and public health nursing within one special interest section of NZNO at the Public Health Nurse's Conference in November 2001 is a positive move towards national collaboration with regard to child and adolescent health in New Zealand. A National Association of School Nurses is also required in New Zealand, as in other countries, to facilitate liaison and collaboration both nationally and internationally with regard to school nursing practice. A professional association for school nursing would address the practice concern of geographical isolation, and would also ensure that professional school nursing competencies and standards of school nursing practice were developed.

\section{Standards of school nursing practice}

Standards of Professional School Nursing Practice (Proctor et al, 1993) have been developed by the US National Association of School Nurses and include, clinical knowledge, problem-solving, client interventions and communication skills. These professional standards also include; school health programme development, liaison with family, caregivers and the community, research, and professional development. McDonald, Langford and Boldero (1997, p.264) suggest that school nursing as a specialty practice needs to focus on two areas, "the provision of training and development leading to new career opportunities, and a workable method of quality assurance". 
As previously mentioned there are no legislated requirements that New Zealand schools to appoint registered nurses to school nurse positions. There is also no requirement that school nurses complete postgraduate qualifications in the area of school health, child and adolescent health, or health teaching. School nurses are involved in health teaching with student clients and are also involved in classroom teaching. School nurses are well positioned to deliver the health education curriculum in New Zealand schools if appropriately trained. There is a need to explore the professional school nursing competencies and postgraduate qualifications required by those working in the area of school health education and school-based primary health care delivery.

\section{Professional school nursing competencies}

Professional school nursing competencies and the relationship to undergraduate nursing education and postgraduate training opportunities is an area that has been explored in school nursing publications. Proctor (1998) maintains that four areas of formal study are essential for those undertaking school nursing practice. These include; knowledge of legal and educational issues as they relate to special education students, classroom health teaching, and individual and family health promotion. They also include physical assessment including; neuromaturation, hearing and vision, and knowledge of the educational system. Poster and Marcontel (1999, p.34) continue the theme of professional competence and practice standards when they write, "How will school nurses attain, maintain, and advance their professional competence in an evolving school nursing and school health environment". The Southern Regional Educational Board responsible for overseeing nursing education in 17 member states in the US, have prepared curriculum guidelines concerning competencies required by school nurses at the undergraduate level. University nursing departments and school of nursing faculty have been supported to "identify competencies needed by school nurses" and encouraged to "prepare graduates to work effectively in school systems" (p.38).

It is important that school nursing in New Zealand as a specialty practice develops professional competencies, and that these competencies are addressed within undergraduate nursing education programmes. In order to equip future school nurses for 
their role in child and adolescent primary health care delivery and health teaching, professional competencies need to be established and postgraduate education opportunities need to be supported.

\section{Postgraduate education in child and adolescent health and health teaching}

In 1992, the Department of Health (1992) recognised that New Zealand was behind its international colleagues with respect to adolescent health as a specialty domain. It was written that, "training in adolescent health care for adolescent health care providers working, or intending to work, with young people is considered to be an essential element for developing a quality adolescent health care service" (p.13). It is important that this knowing is translated into the area of school nursing provision within New Zealand schools. The need to ensure professional liaison and continuing education opportunities is highlighted by those working in this practice specialty (Blaber et al, 1997). Some New Zealand school nurses have described the need for school nurse preparation and education. Ann Rose (1997, p.7) while working as a school nurse in Wellington advised readers that she did not "see school nursing as a job for a new graduate as experience and good assessment skills are essential". Marion Partington (1989, p.20) a school nurse from Hamilton writes that the "huge professional transition" to school nursing is a significant task, and it was one that she was not prepared for. Postgraduate school nurse education is a mechanism to ensure that those entering school nursing have the prerequisite skills and knowledge to work in this specialty domain.

McClure (1995, p.29-30) writing from within the American school nursing context proposes that, "The future development of a school nursing specialty needs to be in the hands of welleducated and confident school nurses, and underpinned by a body of practice-based school nursing knowledge". A planned education programme for school nurses currently working in the area of school nursing and for those intending to work in the area that is nationally recognised, would advance knowledge relating to child and adolescent health and improve the health outcomes for this client group. 
The Primary Health Care Strategy (2001c) continues a discussion recorded in earlier Ministry of Health documents about the need for nurses to receive specialist training in order to provide quality primary health care. This document expresses the opinion that "Primary health care nursing will be crucial to the implementation of the Strategy, and will therefore be best addressed at the national level" (Ministry of Health, 2001c, p.23). School nurses currently undertake an ad hoc professional development, which is dependent on school support, release time, and personal interest. School nurses practising in the Auckland area are more easily able to access short courses and study days offered by the Centre for Adolescent Health, and the Auckland School Nurses Group offers three study days each year as a means of professional liaison and professional development. School nurses working outside the Auckland area are able to attend courses offered by the College of Education in their local area, or individual study days offered by the Public Health Service. It is however important that a national programme be developed to meet the postgraduate needs of school nurses in New Zealand.

School nursing literature from the US, the UK, and Australia recognises the importance of school nurses being supported by their schools to undertake professional development and professional liaison opportunities both locally and nationally. Blaber et al (1997, p.267) suggest that, "Because many schools nurses work in isolation, their professional development is strengthened when continuing education opportunities include group involvement and networking". Within some states in the US continuing education is required to maintain certification as a school nurse (Borgatti, 1999).

Charleston and Denman (1997) conducted twenty semi-structured interviews, from a random sample of school nurses in the Nottingham health district in the UK. One-third of school nurses interviewed found the school nurse training programme to be "too medically oriented" and "too short to be of benefit" (p.303). The school nurses in this study did however indicate that courses on health teaching and teaching strategies had been of great benefit. A research project undertaken by Whitmarsh (1997) about the confidence of school nurses to provide sexual health education in the classroom found that there was a link between the possession of higher qualifications and teaching confidence. Whitmarsh records in her 
conclusion that "statutory school nurse training" including a "teaching skills component" has the potential to equip school nurses for their role as health educators (p.40).

School nursing literature from the US supports and promotes advanced training opportunities for school nurses. In a random study undertaken on behalf of the US National Association of School Nurses in 1993, it was found that out of the 2,069 school nurses surveyed, 510 held a master's level qualification. A total of 1,963 had additional preparation in addition to licensure as registered nurses (Bradley, 1997, p.4). Literature from the US, documents an understanding that postgraduate qualifications are becoming a requirement to undertake nursing within this specialty domain. Passarelli $(1994$, p.145) offers the opinion that "As school nursing continues to evolve as a specialty practice, master's level preparation will be increasingly needed". Specialist postgraduate school nursing programmes have been developed which recognise the wide range of nursing interventions undertaken within this nursing specialty and the "nature and complexity of student health problems" presented by the student population (p.142).

School nursing in the US has developed to include the positions of School Nurse Practitioners. This training has been implemented as an extension of the Paediatric Nurse Practitioner Programme (Brindis et al, 1998; Papa et al, 1998). School nurse practitioners have been employed in the US as a "response to the growing need to provide direct primary health care to the school-age population" (Ross, 1999, p.28). Ross examines the role of clinical nurse specialist's in school health and articulates the professional role of "clinician, educator, consultant, researcher, and leader/manager" with regard to individual student health, and community health (p.28). The need to equip school nurses for their role as child and adolescent primary health providers is articulated by Brindis et al (1998, p.179); "school nurses occupy a strategic position and can potentially contribute to child and adolescent health in a comprehensive, cost effective manner".

In the UK there have been calls to have school nurse training made mandatory (McClure, 1995). A range of training is offered including diploma level courses and a B.A. (Hons) degree in community health studies specialising in school nursing (McClure, 1995). The 
outcome of planned initiatives to advance continuing education and professional supervision opportunities for school nurses in the US and the UK has meant school nurses are better equipped to implement health promotion and health protection. It is important that the Ministry of Health, the Ministry of Education, the Clinical Training Agency, University and Polytechnic Nursing Schools and Colleges of Education form a collaborative relationship to support and develop postgraduate school nurse training in New Zealand. Postgraduate education in the area of school nursing needs to be addressed, in order to improve the health, social and educational outcomes for students in New Zealand schools. Postgraduate education supports research endeavour, and serves to identify the nursing interventions undertaken within this specialty practice.

\section{Identification of school nursing interventions}

The document Adolescent Health (Department of Health, 1992) records that the health care needs of adolescents differ significantly from adult or child consumers. This document states that, "the adolescent requires health care settings that recognise their specific developmental needs" (p.11). The school nurse is in a position in a secondary school to enable assessment and intervention across a range of health care needs.

There is an absence of quantitative research data in New Zealand that determines the range of nursing interventions performed within the school context, and from which a planned approach towards school-based primary health care delivery can be implemented and evaluated. Nursing articles pertaining to school nursing describe to the wide range of nursing interventions enacted within the school context. Patricia Cato (1997, p.15) contends, "Health problems affecting adolescence are many. They can include diabetes, arthritis, mononucleosis, renal failure, attention deficit disorder, leukeamia, Hepatitis $B$, cerebral damage, growth hormone deficiency, heart valve and rhythm abnormalities, depression, anorexia, bulimia, epilepsy, and physical and mental abuse". Ann Harper (1989, p.17) a school nurse in an urban secondary school in Auckland with about 1200 students, extends the list of daily school nursing activities to include; health curriculum planning, classroom health education, first-aid certificate teaching, parental/caregiver consultation, liaison with 
community agencies, liaison with the "guidance counselor, deans, form teachers and senior administration". She suggests that "a typical day would include one teaching period and seeing between 25-30 pupils at the health centre' (p.17).

Research has been undertaken in the US to determine the frequency of nursing care interventions enacted by school nurses. Paladino $(2000$, p.3) articulates the broad spectrum of health interventions undertaken by school nurses within this specialty practice,

The Certified School Nurse must have state of the art assessment skills, critical thinking and decision making skills and be knowledgeable and skilled in the nursing areas of emergency care, chronic illness management, complex medical conditions, epidemiology, prevention, safety, teaching, screening, documentation, counseling, health promotion, crisis management, communicating, care management, policy development, social work, budget and fiscal issues, program development, grant writing, employee health, community health, legal issues, politics, advocacy, care plan development, pharmacology and computer documentation.

Paladino $(2000$, p.3)

Research surveys have been useful in determining school nurse case management, patterns of practice delivery and a language common to this area of practice (Bednarz, 1991). The adoption of a standardised language is recognised as having positive outcomes including; promoting professional dialogue, providing a language for school nursing education, and a means for the analysis of nursing interventions enacted within this specialty (Cavendish, Lunney, Kraynyak \& Richardson, 1999; Dennehy \& Poulton, 1999; Redes \& Lunney, 1997). Cavendish et al (1999) also report that the implementation of computer-based patient record keeping within school nursing practices facilitates comprehensive documentation, and makes practice statistics available for research. It is important that school nursing interventions are made visible to the health and education sectors to facilitate collaborative 
policy development and practice development. School nursing research is a practice development initiative that needs to be supported in order to advance this specialty.

\section{School nursing research}

School-based nursing research has the potential to promote 'best practice' opportunities for school nurses in New Zealand. Little research has been undertaken within the New Zealand school nursing context. A survey was undertaken by the Auckland School Nurses Group fourteen years ago that involved 50 participating schools. The questions asked included; the type of health services provided, whether a nurse was employed, the full nature of duties performed including nursing and non-nursing duties, the budget provided, the range of equipment used, and the average number of students seen per day (Harper, 1987). Initial survey data found that a wide continuum of nursing practice was being undertaken in schools, from basic first-aid services from ancillary clerical staff to registered nursing practice in "a well equipped health center" (Harper, 1987, p.17). The survey also showed that many school nurses were required to undertake clerical duties, teacher aid work, and receptionist activities, alongside nursing interventions.

In comparison to research undertaken in the US, limited research data is available in New Zealand concerning the current geographical distribution of school nurses, and the nursing care enacted in schools. Literature concerning school nursing from the US records that money is being directed into research from the education sector and the health sector. School nursing research has been undertaken to advance school nursing practice, to determine the effectiveness of interventions, and to improve the quality of services (Brener et al, 1999; Dennehy, 2000; Price, Telljohann \& King, 1999). Research has also assisted school nurses describe the cost-benefit ratio of the service and to determine the scope of practice within the wider health care delivery system (Bradley, 1998; Cotton et al, 2000). School nursing within the US has developed to include approximately 30,000 practising school nurses, 10,000 of whom are members of the National Association of School Nurses (Bradley, 1998). This population base of school nurses has enabled professional development and research opportunities in school nursing. 
Funding for school nursing research in the US has come from the National Association of School Nurses, the education sector, the health sector, and community hospitals. A research project entitled Redesigning of a School Health Workforce for a New Health Care Environment: Training School Nurses as Nurse Practitioners was undertaken by the University of Colorado School of Nursing, Denver Health and Hospitals, the Denver Children's Hospital, and Denver Public Schools (Brindis et al, 1998). A further example of collaborative research is a US Department of Education funded project, assessing alternative methods of delivering school nurse education. The project was undertaken by the Education Development Center Inc. and the National Association of School Nurses (Blaber et al, 1997).

School nursing services in New Zealand are very fragmented, and liaison and research opportunities have not been supported. School nurses are largely isolated in their practice, challenged by low levels of funding and the demands of offering quality primary health care in an unsupported health care environment. This pattern of isolation and the absence of postgraduate school nursing training opportunities have resulted in the absence of a research agenda for school nursing. It is important that a base line of research data is obtained concerning geographical distribution, level of qualifications, scope of practice, school nursing interventions, health education commitments, and practice development needs. This data is an important resource if well-informed policy decisions are to be made concerning the future development of school nursing as a primary health care and health promotion initiative in New Zealand.

\section{Conclusion}

A review and critique of school nursing literature has been presented in order to determine 'best practice' models in school nursing, and to advance future policy and practice development initiatives within New Zealand. School nurses who undertake primary health care within the school setting, and also deliver health education as part of the Health and Physical Education Curriculum, are in a position to promote student total well-being: hauora. 
School nursing has been presented as a means to reduce health barriers to learning, and to improve child and adolescent health outcomes. The future development of school nursing as a practice specialty, requires the development of national policy initiatives (Ministry of Health, 2000a; 2000b; 2001c). A planned approach to school nursing policy development in New Zealand includes; enacting legislation which requires a safe student to school nurse ratio. Collaboration between the Ministry of Health and the Ministry of Education is desirable in order to address the future funding of school nursing positions. The negotiated salary rate for school nurses needs to reflect the professional qualification and experience, and a career pathway within this specialty practice. Policy initiatives with respect to funding need to also address school health clinic practice costs, postgraduate training needs, and opportunities for professional liaison.

The development of professional school nursing competencies and school nursing care standards are an essential part of future practice development. School nursing care standards need to be developed as part of a national consultation in a forum such as a New Zealand National Association of School Nurses. Postgraduate education for school nurses is a practice development issue that requires collaborative action. Future initiatives in the area of postgraduate education for school nurses need to include a child and adolescent primary health care focus, and also a health education component. School nurses that receive professional training as health teachers within the Health and Physical Education Curriculum, and who undertake primary health care initiatives within schools, can advance health promotion to the student population.

The development of 'best practice' for school nursing in New Zealand includes school nurses sharing a common language to describe their practice. A common language enables comparison between school health services and allows funding providers to readily recognise the health care interventions enacted by school nurses. School nursing literature documents the development of a specialty practice that includes; school-based health services, school nurse practitioners, and clinical nurse specialists of school nursing. It is important that school nursing be understood within the new health care environment as a community based child and adolescent primary health care initiative. 
Research concerning school nursing practice is a future practice development opportunity. School nurses that undertake postgraduate education in school nursing will become active participants in creating new research and knowledge for this emerging nursing specialty. School nursing research advances future practice development and ensures that 'best practice' initiatives are examined and implemented. School nursing in New Zealand is a significant child and adolescent health care initiative that requires intensive policy and practice development. School nurses that are highly trained in primary health care delivery and health education pedagogy can improve the health outcomes of student clients. Students who have their health needs addressed and receive health promoting interventions can be enabled to find success and enrichment in the social, emotional and educational domains.

In the following section I move this research concerning school nursing practice from the domain of published literature and analysis to the world of poetic representation. I will explore reflective topical autobiography as a means to give voice to the school nursing practice specialty. I will detail this research method, and give an account of my decision to include autobiographical poetry within this work. The writing in the following section includes a discussion concerning the use of this method, the relationship between reflective topical autobiography and other research methods, the concept of giving voice, and the announcing of poetic voice. 


\section{PART THREE}

\section{AUTOBIOGRAPHICAL VOICE: POETRY AND REFLECTIVE INQUIRY AS METHOD}

The lightness of the poet is made of this passivity, responsive to the inspiration and the fragrance of the Muse's garden. It is from these risks or these indulgences in these "gardens or valleys" that they must find the honey which they furnish to us. They do not make the honey, they retrieve it, and poetic spontaneity does not consist in fabricating or in creating (for it would be necessarily techn_, but "in furnishing us" with what they gather. It is a gift - and it is a gift which is given by the Muses. 


\section{AUTOBIOGRAPHICAL VOICE: POETRY AND REFLECTIVE INQUIRY AS METHOD}

\section{Introduction}

In PART ONE and TWO of this thesis I have given voice to personal experience and philosophy, and reflected upon school nursing literature, in order to determine future practice development opportunities for school nursing in New Zealand. PART THREE of this writing introduces the reflective topical autobiographical research method that is to be used as the central endeavour within this thesis. Reflective topical autobiography is placed within the postmodern, qualitative, interpretive research paradigm, and is a means to give voice to practice knowledge within the nursing domain (Johnstone, 1999; Watson, 1995). Reflective topical autobiographical poetry from school nursing practice and reflective inquiry is presented in PART FOUR as the chosen process to gain access to personal school nursing practice experience and understanding.

The raw data for this research are the poems that have been given pertaining to school nursing. My interest in philosophy, naturalistic inquiry, reflexive enquiry, and personal narrative has supported my choice to include autobiographical poetry within this thesis (Diekelmann, 1991; Lincoln \& Guba, 1991; Nehls, 1995). I am aware of the personal risk and challenge associated with presenting nursing research in the form of poetic vignettes.

In this part of my writing I have included the method of data collection and analysis, and the concept of academic rigor in relation to this research project. I then offer a discussion about my experience of the research process using reflective autobiographical poetry as a qualitative and interpretive method of inquiry. The use of 'autobiography', and 'the relationship between reflective topical autobiography and other qualitative research methods' is examined in detail. In the final part of this section I discuss the concept of 'giving voice', 
and the purpose of 'poetic voice' in the wider context of interpersonal relationships and literature. The discussions presented in this part of my thesis form a foundation for the use of reflective topical autobiographical poetry and reflection, as a means of giving voice to school nursing practice. Poetic writing is viewed as a process for self-disclosure in nursing, which protects the person for whom the nurse cares. The use of poetic writing in nursing identifies the health care needs of the client group and the 'scope' of nursing interventions, while keeping individual clients safe and free from harm. Poetic representation of practice enactments is presented as an ethical means to undertake practice inquiry.

As stated in PART TWO, school nursing in New Zealand is an under-researched and an invisible health care specialty. Giving voice to school nursing is an academic and aesthetic task. My commitment is to advance child and adolescent total well-being: hauora. I wish to illuminate the practice of school nursing as I consider it is timely to position school nursing as a significant child and adolescent primary health care initiative. In the following section I have summarised the method of data collection to be used.

\section{Method of data collection and analysis}

Reflective topical autobiography is placed within the postmodern/postpositive paradigms and as such has connection with the naturalist form of inquiry. These research paradigms recognise the qualitative and subjective dimension of inquiry and reporting. They affirm the necessity of the researcher to be open to new understanding, and what emerges. In the section entitled 'Discussion', I have recorded the process of engaging in reflective topical autobiographical inquiry concerning the primary health care specialty of school nursing.

The raw data for this project is reflective topical autobiographical poetry from school nursing practice. Poetic writing was collected in a notebook and then transferred to computer disc. The reflective notes written during the process of this research and poetic drafts have also been regarded as data. 
At the beginning of this research I was unable to determine the length of time required to write the poetry from practice and when the analysis would commence. The writing of reflective autobiographical poetry about school nursing practice occurred between March 2001 - June 2001. The poetry was then set-aside for two months to incubate and to enable distance to be established between the writing of the poetry and the reflective analysis and interpretation. In-depth thought and introspection were required in order to distil qualities and meanings from the poetry. It was examined to illuminate the health needs of student clients and to unfold the 'scope' of school nursing interventions presented. The poetry was also examined to distil the 'essences' of nursing practice. Reflective topical autobiographical poetry from school nursing practice, and reflective commentary will be presented in PART FOUR of this research project. The following section reflects upon the academic rigour that has been a part of this method of inquiry.

\section{Maintaining rigour}

Autobiographical research contains by its nature, subjective meaning and risk. There is risk associated with entrusting one's story into the care of another, as it is a risk to care in nursing. Reflective inquiry demands gifting of the self-lived-enactment narrative, which in turn assumes the potential for rejection and vulnerability (Cash, Brooker, Penney, Reinbold. \& Strangio, 1997). To be honest with one's self in searching self for meaning of livedenactment, contributes to acceptance of narrative expression as valid and trustworthy.

The key features of academic rigour within this interpretive and qualitative writing are credibility, fittingness, and auditability. Trustworthiness and confirmability are found where these features are in accord. In reflective topical autobiography as in other qualitative research methods, credibility is found where the narrative discourse and subsequent illumination finds resonance and 'similarity' with the lived-enactment or 'lived experience' and meanings of others (Roberts and Taylor, 1998).

Fittingness is described as when the research context, question or theme finds congruity when viewed from "contexts outside the study setting" and where the research has "meaning 
and relevance" to the situation of others (Roberts and Taylor, 1998, p.174). Reflective topical autobiography is deemed trustworthy where there is auditability (Lincoln \& Guba, 1991). Auditability is understood to occur when the research process is made visible to the reader. The autobiographical writer states that it is he or she who has lived the enactment and that it is their privilege to disclose meaning from lived-enactment. 'Narrative truth' or 'narrative fidelity' is understood in reflective topical autobiography to mean that the narrative or autobiographical work is "lifelike, intelligible and plausible" (Sandelowski, 1991, p.164).

Trustworthiness in reflective topical autobiography is found where credibility, fittingness and auditability combine to demonstrate confirmability. A narrative autobiography of self-livedenactment, which resonates with others, is a demonstration of trustworthiness. Research which moves the participants towards enrichment, is also deemed to assess the trustworthiness of reflective topical autobiography as a method of academic inquiry. Reflective topical autobiographical poetry as a method of nursing research, has the potential to advance understanding concerning the school nursing specialty, promote the development of school nursing in New Zealand, and to enrich the wider nursing domain.

In the following section I have included a discussion about the process of reflective topical autobiographical poetic inquiry. I have articulated the self-enactment of the research process undertaken within this project, in order to disclose the emerging research design and to confirm academic rigour.

\section{Discussion: Reflective Topical Autobiographical Poetic Inquiry}

I commenced the writing of autobiographical poetry relating to school nursing practice five years ago when I began postgraduate nursing study. Poetry emerged as a means to engage in reflective practice inquiry. My interest in philosophy, heuristic research, and narrative inquiry were a catalyst for exploring poetry as a means of illuminating practice knowledge and understanding. This method of research has close links with the naturalist paradigm which commences with a focus or purpose, but which is open to unfolding (Lincoln \& Guba, 
1991). The naturalistic method of inquiry affirms the research being undertaken in its natural setting, the close relationship between the researcher and the researched, the importance of intuitive knowledge, and the acceptance of multiple realities.

In 2000, I was enrolled in a research paper which required participants to investigate a range of research methodologies and methods. As a result of the course I became interested in reflective topical autobiography as a means to examine nursing practice. At the beginning of 2001, I made a decision to undertake reflective topical autobiographical research within the context of a wider project to advance understanding about school nursing practice. I experimented with journal writing and narrative expression, and found that autobiographical poetic vignettes emerged from practice. These poetic vignettes established in written form, are self-lived enactments from school nursing practice.

I set time aside to write poetry from practice, and I also spent time engaged in selfintrospection and contemplation. Often the poetry emerged late in the evening at the end of my working day when family commitments had been completed. Lines of poetry appeared when I gave myself the time and space to reflect and think. I wrote by hand in a book dedicated to this poetic endeavour, and as lines and verses emerged, I re-read the poetry and played with rhythm and metre, with the sound and the form. Words were given, lines were given, verses were given, and poems were given. On occasions, lines were incomplete and words to advance meaning remained out of reach. I needed to wait, and listen. I became familiar with exploring a language to describe school nursing interventions, and the context from which school nursing care arises. A full picture of past nursing enactments was available for recall, and nursing enactments were collected in my mind according to time, context and concern. Individual nursing enactments merged to present poetic vignettes of youth health challenge and need.

The description of interpersonal human experience within the school nursing context has required active engagement in the world of personal meanings and understandings. Themes have emerged within my poetry as I have had the opportunity to dwell on 'lived experience' or lived-enactments from within my school nursing practice (Van Manen, 1990). Memories 
from nine years of school nursing practice emerged and lines of poetry were given to express my practice. I was conscious that my writing evoked troubling pictures of student client grief, health challenge and need. I was aware that some of the poetic stories would speak clearly to those in school nursing practice, but I was equally aware that they might cause discomfort to the reader unfamiliar with this practice domain.

I was initially concerned that the difficult and troubling end of the school nursing continuum had surfaced in the poetry, and wondered why the joys and privilege of practice did not arise within the poems. To see such stories written in text was to be unable to escape from the reality of child and adolescent abuse, neglect, pain and grief. I was very mindful of the broad scope of school nursing practice undertaken on a daily basis that did not emerge as poetry Student self-referrals and referrals, including minor injuries, accidents, viral infections, skin irritations and abdominal discomfort. Numerous memories of health discussions and examples of health exchange that feature as an important practice dimension. The significant relationships that developed over time, the family connections that had been established, the increasing maturity and independence observed in students over time. The trust and friendship that developed over five years of health interventions, and health teaching opportunities that afforded connection, involvement and care. It was not until later in the process of research, that I was able to recognise the poetic task of social commentator, moral advocate, and agent for expressing social conscience. Over time I had an increasing awareness of the poet's role in protesting injustice and advancing idealism and hope (Thompson, 1978). It was then that I understood why the less concerning was absent and that the profound emerged.

Many of the poems in their creation almost left me bereft of words to describe this practice. I was acutely aware that being 'entrusted to care for another at extremity' is a privilege in school nursing, and the essence of 'wise holding' was profoundly moving as it emerged (This essence of practice will be examined further in PART FOUR). I found that although I could clearly discern individual nursing interventions, the poetry that surfaced maintained confidentiality. The poetic images were removed from the individual, set in time and place, but represented many individuals that had come for care. Reflective poetry from my school 
nursing practice places 'private' lived-enactment's within the 'public' domain, and as such makes them available as a form of knowledge sharing and development in nursing (Bowden, 1997). I found that the adolescent health care interventions explored in this poetry called me to question the socio-political nature of child and adolescent health care delivery in New Zealand, and the relationship between cultural heritage and health determinants.

I often re-read the poems and when I was content with the form of a poem, I transferred it from the handcrafted form to computer text. To read the poems in computer text on clean paper seemed to remove the words further from my own hand, and allowed me to view the poems afresh. Most of the poems included in this project were written between March 2001 - June 2001, and were then set-aside for two months. This was a deliberate decision, which allowed me time to remove myself from the emotional dimension of the writing process. This was not a decision I could have made prior to commencing this form of research. It was determined by how the process felt. This aspect of the project was subsequently understood as the 'unfolding' of an 'emergent design' (Lincoln \& Guba, 1991). I became so close to the poems and narrative they represented that I needed to create a space to hold these stories. I needed time to gather myself for the second time of reflection. Over the next two months I concentrated on other parts of this project including; my personal practice narrative, my personal philosophy and a review and critique of school nursing literature.

I returned to read and re-read the poetry in August and recognised the importance of having established a time-space between poetic writing and the interpretation of narrative content. As the autobiographer I have had the ultimate facility to re-flect, re-visit, and re-constitute meaning from self-lived enactment. Mayerhoff and Metzger (1980) in their writing about autobiographical endeavour, propose that reflection upon 'multiple images' allows the writer to distil the essence of knowing. This project has required two episodes of intensive reflective inquiry. The first occurred during the writing of poetry, and the second occurred when the poetry was re-examined for content and essence of care.

It is my experience that over time I have come to understand the 'essence' and meaning of the school nursing enactments I have described. By the means of reflective topical 
autobiography I have been able to 'illuminate' topical life events by 'immersion' and 'contemplation' (Moustakas, 1990). I have found that deep introspection and time for the poetry to 'settle a while' has made available self-illumination, and has opened new 'horizons of insight' concerning the research topic (Johnstone, 1999). The privilege of having students entrust their health need has been recognised, and individual 'essences' of school nursing practice have been distilled. I found that poetic reflection gave rise to two distinct elements of expression. The first element is the continuum of adolescent health need, and the 'scope' of school nursing interventions undertaken within school nursing. The second element to be discerned from the poetry is what I describe as 'essences' of school nursing practice. I had now perceived the positive dimension of care woven within the poetry. Beyond the need was hidden the caring act. The craft of nursing within this specialty domain was distilled. I recognised entrusting, gift giving of health need, providing a safe space, wise holding, building success and health care mediation as essences of school nursing enactment. I have given full expression to the reflective autobiographical poetry, the 'scope' of school nursing practice and child and adolescent health care need, and the 'essences' of school nursing practice in PART FOUR of this project.

My decision to choose the reflective topical autobiographical poetic form of inquiry in nursing is to offer a new means of practice understanding. I am deeply conscious that to choose a new method of research necessitates attention to academic rigour, and a clear explanation of the decisions made during this project. As I reflected upon the poetry I became mindful of my need to understand further the concept of 'giving voice', in the context of advancing nursing knowledge, and in the wider context of poetic and literary expression. I spent some time exploring the literature surrounding the idea of 'giving voice', and I have included an overview of this concept within this method section. I have also felt the need to explore further my knowledge with regard to poetic representation. Poetry as a research method has been utilised within the discipline if sociology, but this research method is largely unfamiliar within the nursing domain.

The sociologist writer Richardson (1992) describes the breaking of qualitative and sociological research norms when she constructed a sociological interview as a poem. She 
describes the ability of poetic narrative to "convey meanings" and to announce "multiple" openings to understanding (p.126). The conscious re-reading of poetry allows the reader to access a deeper level of understanding. Richardson contends that poetic research has the potential to alter an individual's perception and to facilitate public understanding, which in turn has the potential to provide "policy makers with a different slant" on the material presented (p.134).

The use of poetry in nursing research breaks nursing research norms and opens "windows on lived experience" (Richardson, 1992, p.136). Ellis and Bochner (1992) contend that subjective writing such as poetry can challenge the emotions, evoke self-identification and remind the reader of similar situations or conditions. They also propose that subjective writing has the potential to move the reader to "redefine a personal problem or public issue" (p.11). As a result of this research it is proposed that the reader may come to redefine the nature of school nursing practice and the nursing needs of the adolescent population.

Throughout the research process I have found the rewards of being open to poetic entrance, and through reflective inquiry I understand more clearly how I and other school nurses make a difference to the lives of students for whom we care. As I have spent time re-reading the poems, I have come to understand the moral imperative to speak out and address the needs represented in the poetry. I have found that the poems and my reflections have impinged upon my work and family time and consumed my solitude. I continue to be open to exploring school nursing by other means, and consider this method of research to be an opening for further research opportunities. Poetic vignettes from school nursing practice have the potential to inform, to challenge, and to change how school nursing is understood.

In many ways poetic writing has proved to be a healing journey as stories were brought forward from the past-as-undisclosed to past-as-disclosed. I was conscious that within the stories, healing, restoration, nurturing, sustaining, caring, and wise holding were revealed. The craft of nursing was displayed in extremity as students entrusted their pain, loss and grief into my care. I recognised that many students bring or gift small health concerns as a 'test of care' prior to opening themselves to the vulnerability of entrusting the profound. The 
privilege of 'being there' in the moment, 'being chosen' as the one to care, was and is a remarkable place to be.

I have spent some time reading poetic critique and analysis, in an effort to understand more clearly the urgency to announce meaning, and the intellectual and moral imperative which is frequently experienced by the poet. I do not assume to present a full literary exposition concerning the poetic craft and method, but within the scope of this project I have sought to be accountable for entering this literary domain. I include a brief exposition concerning poetic writing and poetic intent. As this research progressed, and in order to position the understanding that emerged I found it important to undertake further reading in the area of postmodern, postpositive and naturalist inquiry (Lincoln \& Guba, 1991; Lyotard, 1992; Norris, 1993). I have established the philosophical connection between autobiography, reflective topical autobiography, narrative inquiry, heuristic research, hermeneutic endeavour, phenomenology, and naturalistic inquiry.

As a means of resolution and conclusion I again felt the need to attend to the internal demand to write poetry. It was as if the need to reflect on school nursing practice by means of autobiographical poetry had been completed. I was free to express different thoughts and understanding. I needed to integrate the research process and reflect on the method, and to connect my nursing practice and my personal philosophy. The poetry concerning student health need was placed to one side, and the new poetry that emerged contained a language representing thought, poetic announcement, the human condition, hope, and justice.

Being open to a postmodern research method has involved being open to a different means to undertake the research process. I was able to move from troubling poetic images and reflections on child and adolescent health need and conclude in a place where my Christian faith, ministry, philosophy, purpose, personal meaning and understanding co-exist. I have included this final set of poetry in the belief that it may offer the reader the same sense of completion, and to make visible my academic journey with regard to this project. 
The following section of writing attends to the purpose and activity of autobiography, the relationship between reflective topical autobiography and other methods of inquiry, and the concepts of 'giving voice' and 'poetic voice'. This writing also intends to set the scene for introducing my poetry and reflective discourse in PART FOUR of this project.

\section{Autobiography}

Autobiographical writing places the writer at the centre of the discourse. Historical context, cultural realities, and political voice are layered upon personal experience. Relationships, places, values, and motivation are examined in order for the individual to draw meaning from memory. The subjective reality of autobiographical discourse is given voice by the narrative expression of memory or "narrative arrangements of reality" (Elbaz, 1987, p.1). Memory is shielded by self, choosing to remember self, but is also open to insightful understanding of self opening to self.

In autobiographical writing the author chooses, or refrains from choosing, experiences that will explain self in relation to self-lived-enactment. Denzin (1989, p.78) describes autobiographical narrative as "the words we speak and attach to ourselves". Memories of time and space are remembered due to the impact of the experience or the "emotional intensity" of the event (Conway, 1990, p.104). Conway offers the opinion that autobiographical memories are indelible recollections, recorded by the self due to the power of the lived-enactment and as such they are, "detailed, highly available for recall and comparatively resistant to forgetting" (p.104). They are significant because the meaning that attends them draws them from lived-enactment-as-undisclosed to lived-enactment-asdisclosed.

Autobiographical interpretation of self is understood as self-entrusting to self-disclosure. Gooch (1996, p.139) describes this self-disclosure or self-revelation as "a coming to see". The reflective enactment, which enables individuals to touch their souls and fashion personal meaning, is a hermeneutic sojourn (Draucker, 1999; Gadamer, 1976). Jones (1997, p.457) purports that "autobiographical telling cannot but unfold within the hermeneutical situation of 
the person". The term 'hermeneutic' is taken from Greek thought, where Hermes was understood to be the son of Zeus, and a messenger of the gods. Hermeneutic research has at its core the bringing of meaning, interpretation, disclosure or announcement (Heidegger, 1962; Van der Zalm \& Bergum, 2000). Hermeneutics as a research position is the discovery or revelation of the message or participation in the disclosure of layered meaning, a sojourn or opening to knowing and understanding (Nancy, 1990). Nancy (1993, p.108) describes the reflective hermeneutic process as "thought [abandoning] itself to its own opening".

Within the context of this research it is important to recognise the difference between reflective inquiry and reflexive inquiry (Jones, 1997). Reflective activity is understood to involve meditation and thought, while reflexive inquiry implies a person or "agent's action upon himself' (Fowler \& Fowler, 1969, p. 691). The type of research which seeks to mediate self-awareness and active self-change. Autobiographical memory and subsequent writing and recording are an articulation of 'reflexive positioning', where "persons position themselves privately in internal discourse" (Tan and Moghaddam, 1995, p.387). Reflexive positioning is the mechanism by which the self positions self in relation to "unfolding personal stories" (p.387). Reflective topical autobiography is "located in the hermeneutic circle of reinterpretation" as meaning, purpose and future direction are explored (Sandelowski, 1991, p.165).

Ellis and Bochner (1992, p.95) contend narrative writing "constitutes an active and reflexive form of inquiry" as shared understanding is experienced by autobiographer and the reader. Personal understanding is captured by a memory, and is mirrored and reflected by self to shed light and meaning to lived-enactment. The writer of autobiography enacts a gifting of self, entrusting the opening of stories to self and others. As nurses we are constantly engaged in the formation of stories. Stories we hide, stories we share with nurses' alone, stories of pain, risk, loss and grief, stories of unimaginable privilege and joy.

Personal narrative writing is currently becoming more accepted and valued as a "[source] of knowledge", a "healing power" and an "emancipatory" force (Sandelowski, 1991, p.161). Story telling requires an attitude of honouring memory and valuing that which has been 
before. This honouring and valuing sits well within nursing, as nurses seek to honour and value wisely that which is offered in the nursing enactment. Remen (1997, p.XXV) describes story telling as "the way the wisdom gets passed along". By story telling and the articulation of attached meaning, humanity exchanges memory, for memory and meaning. Reflective topical autobiography deems the autobiographical narrator to be central to the memory uncovered and narrative to be disclosed. Reflective topical autobiography also has close connection to other forms of inquiry. The relationship between reflective topical autobiography and other research methods will be explored in the next section of writing.

\section{Reflective topical autobiography compared: The relationship between the reflective topical autobiographical method and other research methods}

Reflective Topical Autobiography as a research method is "located within the postpositivist interpretive research paradigm" (Johnstone, 1999, p.24). A link between postpositive and postmodern research applications can also be made (Lincoln \& Guba, 1991; Lyotard, 1992). Lyotard (1992) suggests that the postmodern artist or writer steps beyond pre-established guidelines and schemes and resolves to implement a new means to share knowledge and understanding. When considering the postmodern method "the artist and writer therefore

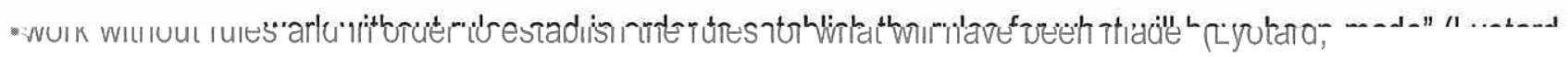
1992, p.15).

Naturalistic inquiry shares similar features with reflective topical autobiography. These similar features include the postpositive paradigm which both inhabit; the inseparability of the researcher and the researched, the absence of prior theorising, the researched being undertaken in its natural setting, the legitimization of intuitive knowledge, and the recognition of multiple realities (Lincoln \& Guba, 1991). As such naturalistic inquiry is a postpositive research method in which the researcher and researched are "inseparable" and influence one another (p.37). Within the naturalist paradigm it is acceptable for the research design to emerge or flow, and for theory to emerge from the inquiry. Lincoln and Guba confirm that "data analysis is open-ended and inductive for the naturalist" and that it is "likely to be qualitative in nature" (p.224). This form of inquiry seeks to inform by describing an individual 
case, and does not presume to make generalisations. The context of the research is fully explored and the naturalist researcher undertakes the inquiry, and where necessary obtains assistance from a research assistant. Intuitive knowing is accepted within this research paradigm and inductive data analysis is accepted as a means to express the "multiple realities that are likely to be encountered" ( $p .41)$. Research questions that are addressed by the naturalist form of inquiry, engage the researcher in intuitive data gathering and interpretation.

The use of the reflective topical autobiographical research method affirms the notion that individuals find meaning by interpreting and making sense of that which is around them. Finding purpose, meaning and knowing is bound by the context of the lived experience or lived-enactment (Denzin, 1978,1992). Research based on lived-enactment allows nurses to honour this kind of knowing, and to examine nursing practice in the light of 'intuitive and situated knowledge' (Fitzgerald, 1995, p.3). This method of research honours the need for 'tandem knowing'. Tandem knowing proposes that objectivity and subjectivity are reflections of one another, and that understanding and knowing are achieved by seeking to view both presentations. Baum (1995) suggests that we cannot 'know' anything objectively, the implication being that, scientific and postmodern applications both affirm individuals in their quest for understanding.

The activity of reflective practice engagement in nursing has a close relationship to the study of phenomenology (Roche, 1973). Phenomenology recognises that "the people who live the experience daily are in the best position to speak of it, to inform others of what the experience is like" (Van Manen, 1990, p.235). The reflective method described, relies on the individual autobiographer to illuminate their lived-enactment in order to achieve personal insight and enrichment, and collective enrichment.

Heuristic research has its beginning in the Greek word 'heuriskein' to discover or to find and has a close link to reflexive enquiry and reflective topical autobiography. This form of inquiry demands an ability to focus in depth on an experience or phenomena in order to distil qualities and meanings from lived-enactment. Research participants using the heuristic 
research method, are required to inquire within, and to disclose meaning from an 'epiphany'. An epiphany is described as an event which confounds, confuses or arouses an individual to the extent that it leaves them floundering or "without an interpretive framework to make sense of their experience" (Denzin, cited by Ellis and Bochner, 1992, p.80). Heuristic inquiry demands facility with 'self-enquiry', 'intuition' and 'indwelling' (Moustakas, 1990).

Reflective topical autobiography is an under-utilised method of research in nursing. I have included a discussion concerning autobiography and the relationship between the reflective autobiographical method and other research methods in order to position my use of autobiographical poetry from school nursing practice and reflective inquiry to announce the practice specialty of school nursing. The writing of autobiographical narrative by means of poetry enables the holding and 'gifting' of practice stories, and the entrusting of story telling to another (Sandelowski, 1991). We share stories to educate, to align ourselves with others and to establish links with self-lived enactment. We tell stories to bring forward from the distance the known in order to understand and control the unknown. We tell stories to humour, to frighten, to enlighten, to encourage and to inspire. Story telling and narrative expression is at the essence of sharing past lived-enactment. Ornish in the preface to the book Kitchen Table Wisdom by Naomi Remen (1997) reminds the reader that the purpose of story telling is to facilitate self-knowing and collective knowing, and to build relationships. Ornish suggests that, "in the telling of stories we also learn what makes us similar, what connects us all, what helps us transcend the isolation that separates us from each other and from ourselves" (p.XV).

The use of autobiographical poetry from nursing practice is a form of narrative expression, where "the development of a narrative from a story brings new conceptual depth to the nurse's understanding of the experience" (Aranda \& Street, 2001, p795). Denzin (1978, p.221) suggests that autobiographical reflection is "an excision from the life of the subject and as such it invites comparison with other kinds of lives". By the use of autobiographical poetry from practice and reflective inquiry, I have been able to access personal practice knowledge and understanding, to offer connection with other school nurses, and to give voice to the specialty practice of school nursing in New Zealand. 


\section{Giving Voice}

My decision to give voice to school nursing as a primary health care specialty has led me to investigate the concept of 'giving voice'. Giving voice is a phrase which is used when not enough has been said or a new understanding is to be shared. The invisibility and silence of school nursing in New Zealand, is in part due to the absence of a collective practice voice to describe this specialty. This section of writing examines the concept of 'giving voice' and establishes the reason why I have chosen to make visible the nature, 'scope' and 'essences' of school nursing practice.

Central to the concept of 'giving voice' is the word hermenia (from hermeneutic), in which is contained the bringing of meaning, disclosure or announcement (Nancy, 1993). The purpose of this research project is the quest for understanding of the school nursing specialty, which might enlighten and enrich the nursing domain which pertains to child and adolescent health. Li Biondo-Wood and Haber (1994, p.274) suggest that "voicing narratives" is of benefit to the nursing discipline. Johnstone (1999, p.25) contends that by presenting an account of lived experience a person "advances shareable understanding of common human experiences".

The human voice is in the musical sense an instrument with the ability to frame the sounds of words and invest them with tones (Scholes, 1970). The singer when singing has to bear in mind the tune and the poem, so that both are in balance. When speaking we choose the tone, the volume, and words sufficient to convey meaning. We also make decisions concerning timing, the context and the audience. Our decision to voice beliefs, knowing or need, or to refrain from voicing is based on experience, opportunity, confidence and trust.

By giving voice we make connections with creation or the creator. We speak in silence, in our heart, in our prayers, and we rehearse the words we might announce in public. We speak informally to friends and family, and formally to those we do not know. We speak automatically without censure and we speak deliberately with thought and conviction. Emotions are clearly displayed when we give voice. We are known by our voice, and we make known by our voice. 
Voicing ideas, beliefs, understanding, and concerns, can enable individuals to understand themselves more fully, and enable individuals to be understood by others. Voices can add to what is already spoken, and they can address the silence. Giving voice has the potential to build relationships, to harm relationships, to result in acclamation or derision, to engender confidence and personal growth, or to cause embarrassment and shame. To voice beliefs and knowing accepts vulnerability and rejection, and hopes for acceptance and welcome.

Giving voice can occur in the auditory world but equally can occur in the poetic world of language. Written expression can be familiar or formal, personal or academic, accessible or inaccessible, subjective or objective, qualitative or quantitative. This activity of 'voicing' assumes a decision to place an idea outside oneself. To challenge, to advise, to illuminate, to affirm, to suggest, to compliment, to request, to humour, to share, to entrust. Voicing opinions, values, beliefs, knowledge, and understanding is a mechanism to enable sharing, and connection. It also allows the producer of the voice a sense of agency and the means to affect change.

The giving of voice presumes that something necessitates announcing. Giving presumes a capacity to offer. Voicing presumes a listener or reader, although at times voices remain unheard. Voice is recognised as a sharing construct, fixed in time, context and culture. Voicing considers gender, socio-political position, age and experience. As individuals we choose the voices we share and are selective of a language of announcement. We speak differently according to the purposes of our speaking.

Freidrich (1998) suggests that, as individuals we are familiar with selecting the voices we need to present ourselves, and that we do so involuntarily. He describes these voices alternatively as "variegated voices", "plural voices"' and a "multiplicity of voices" (pp.103104). Freidrich contends that we 'tread aesthetically' between language as our purposes change.

Knowing how to tread aesthetically between language that bespeaks the scientist's need for precision and consistency, 
and the complementary claims of elegance, forcefulness, fluency, literacy and a more nuance-bound meaningfulness.

(Freidrich, 1998, p.108)

Clandinin and Connelly (1998, p. 172) describe the task of the researcher as seeking to articulate their "own voice in the midst of an inquiry designed to capture the participants' experience and represent their voices". They describe this independent interpretive activity as, "the development of voice out of silence" (p.172). They assert that revealing one's voice is recognition that one has something valid to say. Clandinin and Connelly contend that in breaking the silence researchers choose to emphasise some data, and withhold consciously or subconsciously the voicing of other data.

King (1995) describes the relationship between her 'academic voice' and her 'body voice'. She explores the pressure she experiences as a nurse academic to make her academic voice conform to the dominant research voice. Alternatively she describes her 'body voice', as her experience of life including her physical reality, and her emotional and intuitive worlds. King (1995) affirms her body knowing, including her experience of life as a woman, wife, mother, and practitioner of nursing. The tension between these voices, gives way to the articulation of an 'embodied voice'. Her embodied voice integrates her experience as a woman, nurse, and teacher, and validates her knowing bodily, practically, experientially and academically (p.227). She explores the need for nurses to address embodied knowing, and to 'legitimize' the non-academic voice. She believes that, "the challenge for the nursing academe is to find a way to embody all our knowing, to give it value and develop a new academic model" (p.233). By the unconventional use of poetic language, King voices alternatively her academic and body voices when seeking to present her research participants thoughts and ideas. King asserts that by the use of poetics to convey 'original' meaning, the reader becomes an active participant in the "phenomenological process of meaning making" (p.228). 
Giving voice to school nursing demands a distilling of the needs, purposes, activities, and meanings associated with school nursing care. Tierney $(1997, p .23)$ in writing concerning representations of reality in text writes, "In an age many describe as postmodern we develop experimental voices that expand the range of narrative strategies". By using poetic voice I have sought to give voice to the health care needs of the adolescent student population in an urban New Zealand secondary school, the 'scope' of school nursing interventions, and to illuminate the 'essences' of nursing care enacted within a school-based nursing practice.

\section{Poetic Voice}

This reflective topical autobiographical research project uses poetic vignettes from school nursing practice as raw data. The use of poetry in nursing research is an unconventional means to access practice knowledge and understanding. As I have experimented with poetic language to describe this practice domain, and as I have dwelt with the poetry that has been given I have felt the need to understand why poets write. I have spent time reading poetry and reading poetic analysis and craft (Baxter, 1979; Blake, 1957; Elliott, 1969; Frame, 1967; McKay, 1990)). I have chosen to include this section on 'poetic voice' in order to explain my need to write poetry about school nursing, and my choice to advance meaning in this way.

Throughout history poetry has been influenced by culture and socio-political context. Poetry has been used as a means of "arousing patriotism" and support for authority, and a means to celebrate and remember history (Thompson, 1978, p.112). Thompson suggests "oral poetry was one means whereby the culture of a people was transmitted from one generation to another, in general acting as a break upon sudden change" (p.89). Vendler (1988, p.X) reminds the reader that poets have an important position in society to offer "public exhortation" and to question accepted practices and beliefs. Vendler also contends that while offering pertinent insight into the human condition the poet frequently "seeks to answer all of life in a moment" $(p . X)$. Poetry is understood as a means to offer social commentary and it is in this sense that a connection can be made between poetry and voice (Hollander, 1995). Thompson $(1978, p .202)$ suggests "the poet has often been the spokesman of his society, saying what it wanted said but could not voice for itself'. 
Socrates expressed the opinion that poets were 'filled with divine inspiration', 'having god in them', while Aristotle speaks of the poetic task as logical, creative, philosophical, and one which pays attention to structure and form (cited in Else, 1986, p.5). Romantic thought expresses "the notion of the poet as prophet", and poet as priest (Jasper, 1985, p.12). Divine inspiration was considered to inhabit the poet, and the poet was understood to reveal the secrets of the divine. The poet Coleridge understood the poetic task as a religious endeavour, and for him poetry, theology and philosophy were intertwined.

The poetic craft has been defined by symbolism, structure, and rhythm, and the earliest recorded poems were associated with dance, drama, chant, and musical accompaniment. Early biblical writing from the Jewish and Christian traditions was written in poetic form, including the stress of words and repetitive thought forms. Early Greek thought included nine sister goddesses, or 'Muses', "to whom inspiration in music, poetry, and comedy was attributed" (The Pocket Oxford Dictionary, Fowler \& Fowler, 1969, p.527). These nine 'Muses' were named;

Calliope, Clio, Erato, Euterpe, Melpomene, Polyhymnia, Terpsichore, Thalia, Urania, muse of epic poetry, history, lyric poetry, music, tragedy, sacred song, dancing, comedy, astronomy (p.527)

The word muse is more commonly used to mean "ponder, meditate (on, upon)", and the muse is understood to be the "poet's inspiration or genius" (Fowler \& Fowler, p.527). When a person muses, they have time to reflect, to think, to hold up for inspection, to wonder about, and to imagine. The poetic art can be viewed as spending time with the Muse.

Understanding with regard to poetic activity recognises the 'triadic relationship' that exists between the poet, the poem and the audience (Rukeyser, 1982). Rukeyser (1982, p.169) affirms that a poem is an "imaginary work, living in time, indicated in language. It is and it 
expresses, it allows us to express". Rukeyser illuminates the poet's need to express the breadth of human consciousness, and recognises that the poet "responds to purity and corruption" (p.52). Poetic writing frequently explores the profoundly beautiful, perfect and holy but is equally called to announce the domain of evil, corruption and need.

There is a sense of urgency in the poet that calls for an essence to be given voice (Vendler, 1988). Vendler asserts that poetic writing frequently has an intellectual and a moral imperative, and that language and 'aesthetic form' combine to present a new way of seeing and hearing the world. Hagedorn (1995, p.1) offers the opinion that "the poet is enriched by a political perspective, so is the primary care nurse", this understanding affirms the moral and ethical imperative experienced by poets and nurses to 'give voice' to community need, and to address change through health policy initiatives and political endeavour.

Borges $(2000, p .5)$ makes it apparent that writing poetry is not only a means of communicating ideas, culture and understanding, but it can "also be a passion and a joy". The desire of the poet is to communicate, to articulate, and to give voice. The Russian poet Tsvetaeva (1992, p.138) describes the gifting of poetic voice when she says,

'The lyric tide most often lays fragments at our feet, albeit the most precious ones'.

Tsvetaeva perceives that the poetic task is to sort these lyric offerings and give them shape, to make known the unknown, to move with an idea, to explore its 'essence'. She recognises however the 'discomfort' of disclosing essence and meaning and the vulnerability of expressing the soul. She contends that the poet's voice is 'involuntary' and not 'deliberate' and there is a sense in which the poet can do no other. Tsvetaeva describes this announcement of voice as "deciding to part with oneself" (p.138). The poet Fleur Adcock in an interview by Ricketts (1986, p.131) suggests there is a sense in which the poet writes "out of a different strata of their being or their nature". Poetic writing is an expression of self in the 
world, self in relation to the world, self outside the world, self gifting meaning to the world. Fenton (2001, p.43) suggests, "If we can predict it, it is not poetry. We have to surprise ourselves". The creative art of poetry leads the writer to unexpected places, unexpected understanding, and unexpected results.

I am conscious that poetic writing is an advancement of self-knowing mediated by selfreflexivity. The kind of self-reflexivity that welcomes the poetic entrance of language, that gives voice to meaning and understanding. Thompson (1978, p.217) suggests "One who improves his own linguistic power, especially through wrestling with poetry, is not acquiring knowledge or technique, but (one hopes) increasing his understanding and ability to help others". Poetic writing is gifted to make possible understanding concerning lived-enactment and the world from which these enactment's arises. My experience of poetic writing has been that words have been given in order to mediate understanding. Not to propose knowing, but to open that which is already known, to give voice to the hidden. Like the poet Tsvetaeva I have been moved by the lyric tide and can do no other. I have found the image of the tides offering to be profound and moving. On the following page I have included a photograph taken at Foxton beach in January 2002, entitled 'the tides offering basked in setting rays'. A pictorial reminder of a place which has afforded restoration and times of personal reflection over many years. I am drawn to the picture language of the 'lyric tides offering' and the picture of the tides offering upon the sand. I stand before the power and the beauty of the lyric tide and await her gifts.

As I have waited for lines of poetry to arrive, lines have been given. Waiting has allowed time for a language sufficient to give meaning to the essence of school nursing. Holding the lives of students beyond time and place, beyond culture and background in order to announce vulnerability and care. I am conscious of the profound and the profane, mindful of victims and victories. I am content to share my time in the garden with the Muse. 
The lyric tide most often lays fragments at our feet, albeit the most precious ones.

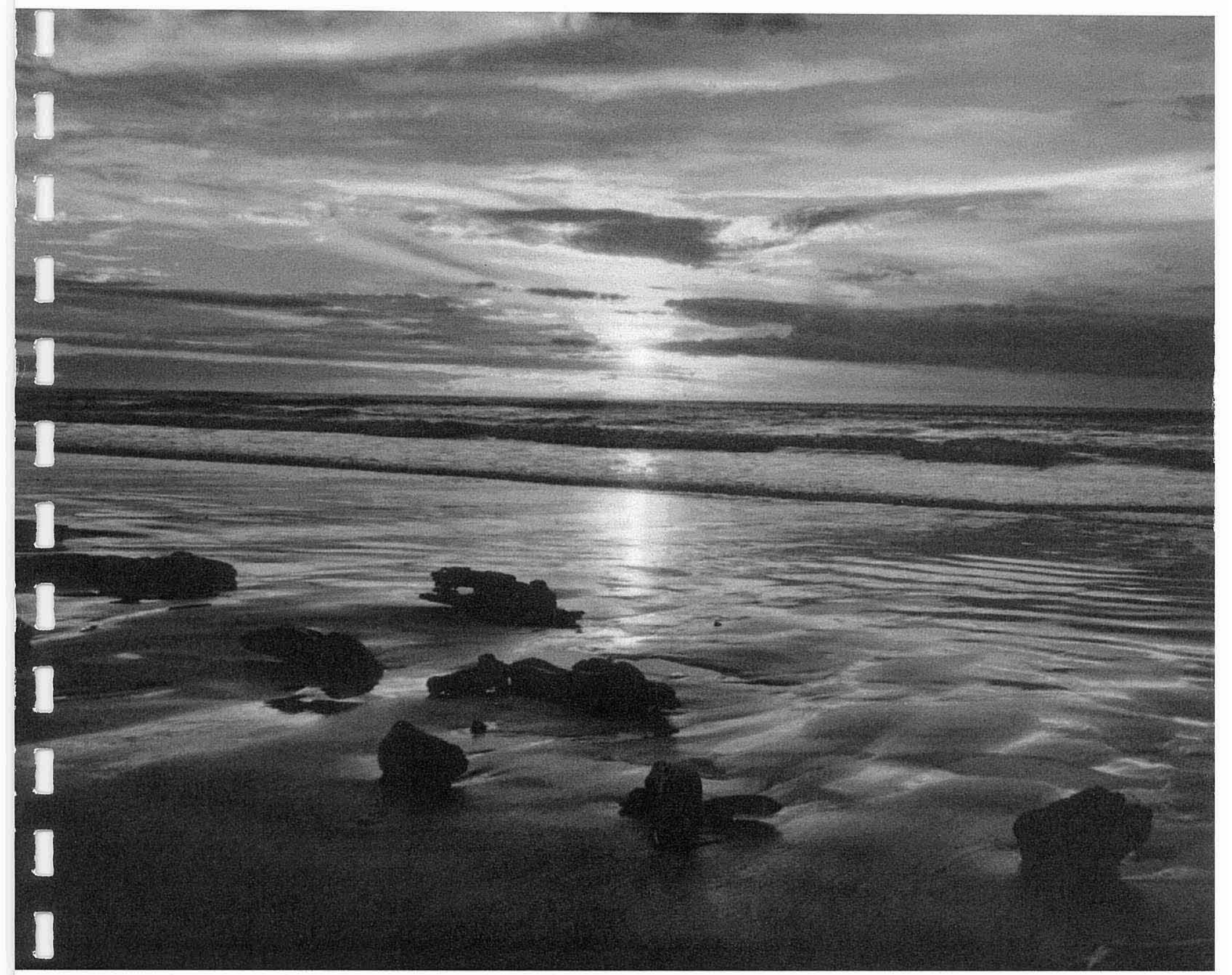

The tides offering basked in setting rays - Foxton Beach, North Island, New Zealand. 


\section{Conclusion}

The writing of poetry concerning self-lived-enactment places myself as the writer at the centre of the autobiographical discourse. The purpose of this form of inquiry is to articulate meanings from experience - in this instance my experience as a school nurse over a nineyear period. Meanings which have their base in personal experience, intuition, hopes and dreams concerning enriched school nursing care. Moustakas (1990, pp.23-24) writes, "Intuition facilitates the research process of asking questions about phenomena that hold promise for enriching life".

Autobiographical poetry from nursing practice has been explored to understand student health needs, the 'scope' of school nursing interventions, the 'essences' of practice, and the 'ideological values' that lie within the text (Vendler, 1988). This type of philosophical discourse has the potential to advance meaning and extend understanding concerning the discipline of nursing (Smythe, 1987). Autobiographical poetry and reflective discussion concerning school nursing has the potential to enrich the nursing domain and can be interpreted as a "critical moment for nursing scholars" as poetic vignettes are gathered and interpreted (Sandelowski, 1991, p.161). The presentation of autobiographical voice in nursing can be viewed as a vehicle for self-enrichment and the enrichment of the domain of nursing. Autobiographical research looks beyond self-stories and seeks to distil significance, meaning and purpose from lived-enactment. Similarities of knowing in nursing are held as common ground, and as such they advances "shareable understanding of common human experience" (Johnstone, 1999, p.25).

Autobiographical narrative has the potential to give direction and guidance to others. Within nursing research and education, research methods need to be explored that afford knowledge sharing and interpersonal knowing. Autobiographical memory is a 'resource', which is largely untapped in nursing; it is this resource that I have explored. 
Nurses contain within their person a rich pageant of memories. Memories of unfathomable depth, snatches of lives, moments in time, held out, perfect, imperfect, whole and broken. Stories of beginnings and endings, pasts little remembered, disturbed and disturbing. Erratic entrances of memories, futures to be imagined, dreams of possibilities, and unintended wonderings. Fleeting glances of families, relationships, tangible reminders of our humanity. The purpose of caring, honouring, serving, ministering, holding wisely, is revealed as nurses hold with care their stories and reveal their lived-enactment to one another.

I have found reflective topical autobiographical research to be a vehicle for the exploration of nursing practice and personal beliefs. From my reading of poetic discourse I am conscious that I present myself as a social commentator, and spokesperson concerning the human condition. I am also aware that I have wrestled with myself over saying things that need to be said concerning child and adolescent health in New Zealand. I have recognised the intellectual and moral imperative of giving voice. I understand more clearly my desire to address child and adolescent health care needs through health policy initiatives and political endeavour. I have been surprised by my poetry, and I have been mindful of what it has allowed me to express. I have found that like Coleridge, my poetic world is deeply connected to my personal philosophy and Christian faith. Reflective topical autobiographical poetry has been an opportunity to engage at a profound level with my own story, it expresses and it has allowed me to express the practice specialty of school nursing.

In PART FOUR I offer my reflective topical autobiographical poetry from school nursing practice, my personal reflection on each poem, and my interpretation of the 'essences' of school nursing practice. By placing reflective topical autobiographical poetry concerning school nursing within this thesis I am presenting an opportunity for others to enact with my story, and an opportunity for the sharing of knowledge. 


\section{PART FOUR}

\section{POETIC VOICE: AUTOBIOGRAPHICAL POETRY FROM SCHOOL NURSING PRACTICE AND REFLECTIVE INQUIRY}

For poetry doesn't fragment either within the poet in all its manifestations it is one entire thing, all of it is in each, just as, in essence, there are not poets, there is the poet - one and the same from the beginning of the world to its end a power which puts on the colours of particular times, tribes, countries, dialects, persons, passing like a river through those who carry it, between these or other banks, under these or other skies, over this or other ground. 


\section{POETIC VOICE: AUTOBIOGRAPHICAL}

\section{POETRY FROM SCHOOL NURSING PRACTICE AND REFLECTIVE INQUIRY}

\section{Introduction}

As I outlined in PART THREE the reflective topical autobiographical poetic method is a means to give voice to the school nursing practice specialty and to advance understanding about the role of the school nurse. By means of poetry nursing knowledge can be shared, in order to promote the development of school nursing and to advance the discipline of nursing. Smythe $(1987$, p.3) has considered the importance of poetry as a means to access knowing and experience,

To read a poem, to absorb a poem, is to capture a glimpse of the feelings of another. It is through such glimpses that the nurse may better come to understand.

Within this section I present my autobiographical poetry from school nursing practice. I have chosen to present the poems on separate pages to allow the reader to advance their own meaning prior to reading my interpretation of the poetic text. Poetry is usually presented in books of selected poems, or complete works. The poet may introduce a book of poems, or an editor may offer an introduction. Preserving the integrity of the poem is advanced by allowing the poem to announce its own meaning. Readers of poetry bring prior knowledge and understanding to poetry, and poetic announcement is received as poetry is read, reread, spoken, and heard. 
Following each poem I have included a Reflection on the poem, including what the text invokes or calls on, and what the text evokes or calls up. I have included what the poetry means for me personally, and what the poetry presents about the school nursing practice specialty. The first dimension to be examined is the student health needs represented in the poetry and the 'scope' of nursing interventions undertaken within the school domain. The health needs represented in this poetry call out the best in policy makers and planners to advance positive nursing initiatives and positive health outcomes for the student client group. Below is a list of autobiographical poems from school nursing practice to be presented within this section

\author{
Offered are Such \\ Music Bringer \\ Iniquity \\ Dare to Dream \\ I'll Remember \\ Relief of Grief \\ Fragments Most Holy \\ Broken \\ Quietly Stilled \\ Stay with Me \\ Different Playing Fields
}

I then move to illuminate the essences of school nursing practice, distilled from within the poetry. These essences are described as; entrusting, gitt giving, wise holding, safe space, health care mediation and building success. This form of reflective and reflexive inquiry enables self-growth and offers the potential for increased practice understanding. As a result of this poetry it is proposed that the reader may come to redefine the nature of school nursing practice, the nursing needs of the adolescent population, and the essences of school nursing care. This poetry is an opportunity to offer a 'window' on my lived-enactment as a school nurse. 
Following this form of postmodern, interpretive inquiry, another set of poems emerged as a means to integrate the research experience and to afford a personal resolution. The poems that surfaced no longer contained images of explicit adolescent health need, but had moved into the world of philosophy and metaphor. Ideas contained in this concluding set of poems move the reader to consider; thought, the human condition, justice and hope. These poems have been included as a means to bring resolution and completion for the reader and myself as researcher. The poems included in the Resolution are entitled;

\section{On Thought}

\section{A New Will to Rise}

Forest Secret

The Autobiographical poetry from school nursing practice and Reflections found on the following pages are presented in order to give voice to school nursing as a primary health care specialty. 


\section{Offered are Such}

Simple knock at, clinic door stricken visage, tightened jaw closed shut hand, knuckles strained moist eyes tangi, pain contained

Infected tissue, reddened hue diet lacking, such is the clue erupted lesions, of the skin need to contact, whãnau, kin

Breakfast lacking, every day lunch omitted, so you say after school, paid work till late headaches frequent, are your fate

Talk of subjects, what's your flare sport, music, workshop, you declare books a trial, the text is hard reading truncated, has left you scarred

Offered are such, wounds of yours where in lies, a certain cause financial pressure, employment's curse crowded housing, makes thing worse

Erosion of the welfare state reading recovery, years to late request for comfort, relief of pain assist a healing, self reclaimed 


\section{Offered are Such: Reflection}

The poem Offered are Such is written in response to the adolescent health needs relating to infected skin tissue, headaches, fatigue, anemia, and depression due to school failure. The student client in this poem presents to the health clinic, crying (Māori-tangi), in pain, and vulnerable. School nursing practice is familiar with addressing the vulnerability, shame, and fear of personal health challenges. School nursing frequently requires the assessment of infected eczema, boils, and infected skin wounds. Nursing care that gives attention to wound dressing, promotes healing and addresses the need for antibiotic treatment when it is required. Nursing care which involves health teaching and instruction concerning personal hygiene and self-care. This poem uses the Maori word whānau meaning extended family, in relation to informing family/caregivers of the health needs of student clients.

The poem then moves to include the socio-economic dimension of child and adolescent health need including; poverty, inadequate diet and the pressure on some students to contribute financially to families by undertaking paid employment after school and on the weekend. It is my experience that many students work up to 20 hours per week in paid employment. This places students under pressure to combine paid employment with academic commitments, home responsibilities, religious, sporting, and cultural activities.

The fourth verse relates to the mental health of students for whom literacy and numeracy are problems, and the resultant school failure, which reduces self-esteem and self worth. The last verses evoke images of socio-economic stress, including crowded housing and unemployment, which are a constant reality for a significant number of student clients. School nursing practice includes home visits to the families of students represented in this poem. Frequently such families do not have telephones, and a personal visit is required to discuss student health, the need for medical assessment, antibiotics, and blood testing to check for anemia. 
The student client brings the whole context of their lives when they access nursing care in the school setting. They usually present with one primary health concern but under this lies, the depth and breadth of additional need. The gift they bring is themselves, their experience, their journey and their health need. 


\section{Music Bringer}

Marvelous tonight were your refrains hidden gems worth great sums joyous your musicianship on drums beating the rhythm of your veins capture the ecstatic moment of cultural frenzy majestic haka responds to incandescent call

Creative passion resplendent beneath the sky blended tones resonate towards crescendo subtle movements of sensual innuendo snatches of dramatic enterprise arresting rap songs hidden craft displayed remind me of this tomorrow least I forget

The muse within escapes to Hermes abode speak to me of such splendid jewels when you bring me gifts

Perchance you fall and strain or pain or loose your brain remember the music and passion when you can't move or groove to the beat that's sweet

All the while smile praising the amazing music bringer and singer 


\section{Music Bringer: Reflection}

The poem Music Bringer reflects the positive dimensions of adolescent health. This poem was written following attending a musical and cultural evening at school where I was able to see students offer their items with confidence, purpose and joy. The first and second verses capture all that is positive concerning youth vibrancy, energy, enthusiasm and selfexpression. The talents that a wide range of students offered during this musical and cultural evening included; piano playing, band (guitar, drums, voice), break dancing, rap, haka (Māori war like chant with actions), Japanese dance, Samoan cultural singing and dance, choir singing, and jazz band. I am reminded by this poem to remember these students, their talents and gifts, when they presented themselves for nursing care.

The third stanza of this poem takes the reader to a different place, a place of reflection and musing. The term muse is a reference to the gift of inspiration offered by the Muses. The reference to Hermes abode relates to the son of Zeus, a messenger of the gods. In this section I locate myself within the poem, and ask the Muse to bring me a message of reminder, to affirm and remember the whole person that comes to access nursing care within the school context. I am reminded that tomorrow they may bring me gifts of a different kind, in the line speak to me when you bring me such splendid jewels. The splendid jewels are the gifts of health need that students bring.

This poem calls the school nurse to see beyond the injury, anxiety, pain and or illness that students bring and to value them as a whole person connected to friends, family and culture. The line all the while smile, speaks of the pleasure that is engendered by involvement in this nursing specialty. The privilege of school nursing care, and the task of accompany students in their personal growth and development within the school domain. 


\section{Iniquity}

Through the door

muffled words

'Why are you here to see the nurse?'

It is a mystery entrusted to her alone

I look strong but my weakness is hidden

I bare my back and buttocks

connected wood to skin

I stand because ...

I stand tall ...

I can't sit easily today...

Forgotten tasks, undone duties

a mothers anger for poverty and loss

born on my flesh

A sign of my iniquity ...

or her iniquity...

or our iniquity ... 


\section{Iniquity: Reflection}

The poem Iniquity reflects the child and adolescent health concern of physical abuse. School nursing interventions relating to physical, emotion and sexual abuse feature as significant enactments within the school domain. New Zealand has a high level of reported child abuse relative to international data. School nursing involvement attends to student clients for whom family and personal violence is a common occurrence.

This poem opens with a question, Why are you here to see the nurse? A staff member outside the health clinic door is asking this question. To this staff member it is probable that the student appears well, and therefore not in need of nursing care. The poem then moves announce the purpose of the self-referral, a mystery entrusted to her alone. This line alludes to the privacy and confidentiality of school nursing engagements and the sad privilege of caring for an individual physically and emotionally scarred by physical abuse. Iniquity, alludes to the violence enacted by parents, caregivers, whānau, towards young people, which is precipitated by family stress, cultural values, and unmet adult expectations. Physical abuse disclosed within school nursing spans the scope from a rare occurrence of hitting to regular and violent personal assault causing bruising, fractures and abrasions. School nursing care frequently requires such injuries to be documented, should the student choose to involve the Child, Youth and Family Service (CYFS) at a later stage. On occasions the young person is supported to initiate CYFS and police involvement due to the severity of the injury or the fear of further harm.

The poem Iniquity alludes to the inability of the student to sit or engage in the learning task, and the nursing enactment of physical and emotional care. I have seen numerous examples of extensive bruising and abrasions caused by vacuum cleaner hoses, wood, and electric cords. The resulting injuries from this type of assault, prevent a young person from moving freely, participating in class activities, or sitting down in a classroom. It is these images that hide behind this poem. Outward physical injury is however, only a visible reminder of the emotional damage that such abuse causes. These are the students that frequently access 
school nursing services for nurture, care, understanding, advice and encouragement. They are also students that can perpetuate violence and bullying behaviour, or internalize this violence inward, to become alone, apathetic, unmotivated, or self-harming. This poem reminds the reader that child and adolescent health concerns reflect community need. That poverty, unemployment and family dysfunction have a direct influence upon child and adolescent health and educational outcomes. The poem Iniquity affirms the need to establish and maintain school nursing services within schools, where nurses can offer accessible, free and approachable health care, and early identification and intervention. The final line, or our iniquity, reminds the reader that child and adolescent health is the responsibility of communities to fashion a society, which affirms dignity, purpose and hope. 


\section{Dare to Dream}

How can life corrupt life?

reach into yourself with questions

grave and defining

What is it to bear a child

and regard it with vengeance

revenge for poverty and dissatisfaction

responsibility for parenthood rests lightly

dimmed by alcohols lubricant embrace

Family tree reflects gaol subscribers

care of off spring spurned

eight children in twelve years

march to the beat of a different drum

Beat strongly

beat, beat, beat

'my body broken for you'

Class work a mystery

attendance belies the ability to attend

numbers and maps fade before

images of a mother with no teeth

novels and poems contain no connection

with this troubled mind

how can such a one imagine

what there is to know

Listen to my crying eyes

see my wounds and wipe my tears

hold my story gently

tell me another story of what might be

release me from my captivity

allow my flight towards wholeness

Dare to dream with me

pour refreshing rain upon my dry ground that I might dance for joy

in a new and fragrant land 


\section{Dare to Dream: Reflection}

The poem Dare to Dream continues the theme of child physical abuse. This poem adds voice to the poem Iniquity, and looks further behind the action to determine the cause. The poem calls the reader to define this public health issue; reach into yourself with questions grave and defining. New Zealand society has had to face the harsh reality of prolonged and violent acts of harm, perpetuated by the adult family members and caregivers of young children. The type of violence that permeates some family groups has an intergenerational pattern, and has the potential to result in permanent emotional harm, disability and death. Acts of emotional and physical harm by which powerless individuals attain power over the vulnerable, in order to experience power.

As members of the public we are familiar with the personal face of domestic violence and child abuse, through the media. We are shocked by the photographs and the reports, and question the relationships between poverty, unemployment and alcohol abuse. The lines revenge for poverty and dissatisfaction, and dimmed by alcohols lubricant embrace speak to these issues.

The image marching to a different drum heralds the violent act; beat strongly, beat..., beat..., beat.... The line 'my body broken for you' is a Christian image of Christ accepting the sin of the world by his death on the cross. The subsequent verse concerning a young persons inability to function in the educational arena due to emotional damage, is heard in the lines attendance belies the ability to attend and novels and poems contain no connection with this troubled mind. The reported statistics concerning child abuse suggest that a further layer of unreported incidents remain hidden within families, and within the community.

School nursing practice attends to the child and adolescent victims of family and personal violence. Young people that have low self-esteem, depressive symptoms, and who engage in early sexual activity, drug and alcohol misuse and other risk-taking behaviour. Young people that are disengaged from learning, have difficulty setting goals and forming positive 
relationships. These are the students that self-refer to a school nursing clinic for a wide variety of nursing interventions, including; counselling, drug and alcohol interventions, contraceptive advice, sexual health education, headache assessment, mental health assessment, and mentoring.

This poem concludes by the young person invoking care; listen to my crying eyes, see my wounds and wipe my tears. A request for someone to listen, to hold with care, and tell him/ or her another story of what might be. This dimension of school nursing care seeks to mediate self-worth, and a belief in possibilities for a positive future. A significant adult role model that cares, affirms, and values the young person and assists them towards wholeness; that (they) might dance for joy in a new and fragrant land. 


\section{I'll Remember}

How can I explain

your home among many

glass door opens to post boxes

filled with forgotten mail

Foyer sparse and cold hangs closely

urine lingers from late night

entrances and exits

janola attempts to sterilize poverty

Numbered doors to numbered lives

community service card holders' welcome

child of ours

no phone

no ones home

You wish even to be at school when sick

a safe space to be

to dream and speak of dreams

Forgotten homework

forgotten gear

"believe in me when I forget" 


\section{I'll Remember: Reflection}

The poem I'll Remember highlights understanding concerning intergenerational poverty, and the implication for student health and school nursing practice. The reality of financial pressure, poor accommodation, crowded housing, and the inability of school personnel to contact family, caregivers, whānau (Māori word for family), during the school day, when student illness or injury occurs; child of ours, no phone, no ones home. Particular images that remain in my mind include the entrances to housing flats that serve numerous families. The smell of urine lingers from late night entrances and exits camouflaged by disinfectant chemicals - (janola). Post boxes filled with forgotten mail are the 'welcome home' experienced by many of the student clients for whom I care.

I'll Remember considers the implication of providing a 'safe space' for students, when life appears unsafe, or where health care needs appear diminished in the face of unemployment, personal grief, family violence and family dislocation.

The poem I'll Remember moves to consider the student that chooses to remain at school when unwell; believing that the care they will receive would not be given at home. This is because they understand family to be under stress, out, working, or likely to minimize their health need. The poem moves to describe the student that attends school knowing they are unwell but chooses school as the better option over staying home; you wish even to be at school when sick, a safe place to be. The student that is unable to participate in classroom activities such as PE because they have forgotten their gear, because they are not well enough to participate. The student that has an untreated chest infection, has finished their asthma medication and has breathing difficulties, or has an injury that has been left unattended.

The concept of forgetting, announced the lines forgotten homework, forgotten gear speaks to personal dysfunction, and the absence of an ability to plan, experienced by some students. I am mindful of the family dysfunction that attends the lives of some student clients, including 
the constant challenge of staying at different homes during the week due to parental separation, or adult shift-work commitments. The difficulty that accompanies students that live in crowded housing, and who share personal clothing and personal effects. Students that have little personal space at home to study, or adult caregivers that support homework activities. Students that have no access to a clothes dryer, to dry the only school uniform they own. The student represented in this poem calls upon school personnel and school nurses to 'believe in me when I forget'. This poem concludes by affirming the need to honour a young person's journey, to understand their experience, to value their personhood, and believe in a positive future for their lives; to dream and speak of dreams. 


\section{Relief of Grief}

Disclosure, a frighteningly lucid narrative why does it happen, a breach of trust a child's body taken in lust powers realm gathers memories offensive an embryo of self, dust to dust pulled to the underworld, Hades crib

Clamours for relief of grief

Silver and gold tinkling jingles softly tended body adornment, cryptic messages bright as due tongue rolls hiding bolt and screw majestic pain defiantly extended metallic glory, medals with strength imbue loss resonates pain, self-inflicted

Take it on the chin with pin

Remember latent glimpses of adults tender quest for loves touching embrace consumes sensual moments exchanged in smoke filled rooms vineyards yield anaesthetises unplanned surrender menses late by days signals life in womb wondrous creation, conceals hidden gender

What to do with you?

Chanceful risk understands not how generations slumber romantic fiction counterpoints with shame to have and hold or vanquish bairn sleep not nor visit images of cherubim without number eyes weep tears of grief and pain eloquent answers deny, infinite grace to stumble

Wisely hold this story told 


\section{Relief of Grief: Reflection}

The poem Relief of Grief articulates nursing interventions relating to sexual abuse, self-harm, unplanned pregnancy and abortion. The first verse evokes the pain and loss experienced by victims of sexual abuse. The word Hades is taken from the Greek and describes the Lower world, the abode of the departed (Fowler \& Fowler, 1969, p.368). The notion of Hades crib is intended to evoke the child's sleeping place of death and loss. The cry of the young person is heard, clamouring for relief of grief. This poem honours the young person in extremity bringing their gift of, vulnerability, loss and fear. The second verse seeks to describe the extensive body piercing, which can accompany troubled and at-risk youth. While announcing this image in poetic form, I recognise the normal range of body adornment, which is a part of self-expression and affirmation of personal choice.

The poem addresses the relationship between alcohol misuse and unprotected sexual behaviour. The search for love, when family dislocation makes love seem far away, and the difficult personal challenge of unplanned pregnancy. The rhetorical question is asked by the young person; What to do with you? The line chanceful risk understands not how generations slumber is a reminder of fertility and unprotected sexual activity. Romanticized ideals of parenthood are set against the shame and grief of informing family of a confirmed pregnancy. The image of cherubim without number is used to describe the unborn, beautiful child or angelic being. The grief of choosing to have a child or seek an abortion is articulated in the line to have and hold or vanquish bairn (to have; or to conquer, overcome, or destroy this child).

The final lines recognise the caring act of supporting a young person for whom unplanned pregnancy is a reality; eloquent answers deny, infinite grace to stumble. School nursing involves the enactment of care while undertaking a pregnancy test, honouring a most difficult journey, and standing beside a young person who is called to make a decision at extremity concerning completing the pregnancy or accessing abortion services. Frequently this nursing engagement involves working with the close friends of a young person, as frequently 
students accompany one another for care. This engagement may also involve supporting a young person to inform family, caregivers, whānau. When a pregnancy is not confirmed, the nursing enactment continues; affirming student choice to defer sexual activity, ensuring contraceptive education is given and contraceptives are obtained when required, and that sexual health concerns are addressed. School nursing care that affirms personal choice, personal safety and dignity, and wisely hold(s) this story told.

The New Zealand rates for physical abuse, sexual abuse, teenage pregnancy, sexual infection and youth abortion, require the reader to evaluate these statistics in the light of school nursing practice. This poem is a poetic narrative or story, but equally the verses stand alone as narrative vignettes. Sexual and physical abuse, are frequently occurring precipitating factors, which increase youth risk-taking behaviour. Personal loss and grief with regard to sexual violation underlies issues of poor self-esteem, lack of motivation and school failure.

New Zealand society has been forced to address the reality of child sexual violation and physical assault resulting in childhood mortality and permanent disability. Over nine years in school nursing practice I am aware of nursing interventions which relate to adolescent victims of similar personal trauma. The mental and emotional scarring sustained through childhood neglect and abuse results in adolescent students that have poor self-esteem, attachment difficulties, and exhibit the depressive symptoms of at-risk behaviour including; early sexual experimentation, drug and alcohol misuse, self-harming, violence and truancy. Adolescent mental health nursing and sexual and reproductive health nursing, are areas of school nursing practice, which demand expert school nurse practitioners. School nursing is a vehicle for offering primary health care to the child and adolescent population, and a means to make early health intervention possible, and protective health care a reality. 


\section{Fragments Most Holy}

Restless motion consumes visual connections perverted countenance plastered across classroom walls ungenerous thieves voices rage then whisper secretive calls images wonder loosely amidst minds entrancing reflections

Fashionable are the vagaries of individual difference knuckles misplaced against concrete wall defining spirit tortured, restless behind bravado and wild posturing unenviable the reminders of subjugating intolerance

Suggestions of feminine flavor, muted intentions search for wholeness beneath hair dyes subtle mask countenance entreats answers yet to ask 'to be or not to be, that is the question'

Difficulty remembering humble tasks casual moment music flares muffling hurtful vocal exchanges shine of knife and simple slit reveals inner dangers bowed head gifts life blood as simple covenant

Platted lines across youthful skin fade but slowly artistry such as this requires corporal medium for design reveal fine etching the story which is thine hold with wisdom the fragments offered most holy 


\section{Fragments Most Holy: Reflection}

The poem Fragments Most Holy alludes to the significant challenges of mental illness, sexual identity formation, poor self-esteem, and self-harming. The first verse in this poem offers a picture of mental distress, including visual hallucinations; perverted countenance plastered across classroom walls/ images wander loosely amidst minds entrancing reflections and auditory hallucinations; ungenerous thieves voices rage then whisper secretive calls. This verse evokes for me the confusion and distress of an acute mental illness. I recognize the extreme nature of this image, but equally recall the deep distress and vulnerability experienced by student clients for whom early psychosis and mental illness is a reality.

Within a school community school nurses undertake nursing interventions that result from the challenge of sexual identity formation and the developing awareness of sexual orientation. The line, suggestions of feminine flavor, muted intentions, alludes to this experience. The school environment can appear an unsafe environment for addressing theses issues, and school nurses are able to mediate a school environment where harassment; hurfful vocal exchanges is minimized and self-worth is supported. School nursing care involves accepting individual difference and supporting students to affirm personal choice and self-identity. The provision of a safe and confidential place to discuss personal concerns and challenges is a part of school nursing care.

Self-harming behaviour including; self-cutting, self-cigarette burning, and drug overdose are represented in verse three. The line; shine of knife and simple slit reveals inner dangers, highlights the possible risk of suicide, when a student exhibits self-harming actions. The words, bowed head gifts life blood as simple covenant seeks to conjure a picture of a contract between life and death. The desire to remove oneself from the circumstances of life, or to request 'concerned interest' in one's life is represented in this form of contract. The picture of a young person with ten, or twenty or thirty, self inflicted cuts to the forearm by an 
implement such as a craft knife is represented by the line; plaited lines across youthful skin fade but slowly. This corporal (of the human body) medium of design is a sad, but common reality of school nursing practice.

The numbing effect of emotional trauma can cause students to self-harm, in an effort to feel something, anything, even pain. Self-harming in these instances are indicative of a young person who is powerless seeking a measure of power over their own body. Students that exhibit theses behaviours are frequently trapped in an emotional limbo, and require ongoing support and care in a mentoring capacity in my role as a school nurse. They may also require specialist mental health referral and ongoing counseling interventions. School nursing mediates early intervention opportunities and ongoing mental health assessment and care. My role in school nursing involves supporting student clients to be towards emotional well-being or enrichment, through supportive and caring involvement in their lives. 


\section{Broken}

Self in weakness, broken and torn ball in hand

Young man falls towards another fingers still, thumb moves reluctantly

Weak arm held in gentle self-embrace self-made splint by self-protective design

Pained movement, irregular shape pale visage, pretends no more

Simple splint and triangular cloth

binds and stills the pain 


\section{Broken: Reflection}

The poem Broken represents accidental injury and resultant first-aid care, which is a frequent reason for students accessing nursing interventions in the school domain. First-aid interventions that seek to minimize further harm, promote healing, and reduce the need for prolonged secondary health service involvement. Early assessment and diagnosis opportunities, which serve to access medical intervention, $x$-ray services, and physiotherapy, care when they are required.

This poem is evokes memories of students that have fractured their limbs or sustained significant soft tissue injuries while participating in normal physical activity. The words, self in weakness, broken and torn, ball in hand, remind the reader of the common occurrence of sporting injury. The lines, fingers still, thumb moves reluctantly, and pained movement, irregular shape evoke for me, numerous memories of nursing assessments and first-aid care. The student that is referred or self-refers, holding their arm in a gentle self-embrace, with a dislocated finger, a sprained thumb, broken arm, or sprained wrist. The last lines, simple splint and triangular cloth binds, and stills the pain, represents the nursing assessment, intervention, and referral, which are involved in this caring act.

School students are a client group for whom sporting and social activities incur a high level of personal risk. Schools are learning environments that present opportunities for injury, including gymnasium, playing fields, technology classrooms, and science laboratories. The Department of Labour requires compulsory occupational heath nursing services, when an industry or organisation which employs a high number of employees. A provision, which is not translated to include children or adolescents enrolled in the school setting. This is an area of legislation that discriminates against child and youth health consumers, and requires legislation to establish a safe school nurse to student ratio in the school domain. 
School nursing involvement requires liaison with family, caregivers, whānau with respect to injuries sustained at school. The school nurse frequently liaises with family, caregivers, whānau in order to discuss treatment options, arrange for transport home, or to inform of the need for medical assessment or accident and emergency transfer. Accidental injuries sustained outside the school environment are also reviewed in the school health clinic. Examples of this are where a student sustains a burn or laceration at home and seeks a nursing assessment, where a concerned staff member refers a student who is unable to walk freely, or a family member phones requesting the assessment of a student who has extensive abrasions after falling from a bike the previous day. Family members of student's also phone or come in to school to discuss student health needs or to request a nursing assessment with regard to infected wounds, injuries, vision assessment, ear, throat or skin infections. The school nursing role includes assessment, nursing care intervention and referral for follow-up medical or other allied health services. School nurses working within the education setting are able to provide a direct link to outside health providers and 'mediate health services' for students and student families. 


\title{
Quietly Stilled
}

\author{
Moist air hangs coldly, chills the bones \\ touching skin with ice cold moans \\ breath is tight and drawn from walking \\ effort great from merely talking \\ Inhaler's finished, blue and brown \\ cash from family can't be found \\ desire there is to breath with ease \\ air passages thin can not appease \\ Well understood your need for air \\ tired eyes reflect a quiet despair \\ salbutamol pump and spray so pure \\ for you dear child there lies a cure \\ Rasping breathing quietens down \\ anxious visage looses frown \\ breath is calm and lungs are filled \\ restless motion quietly stilled
}




\section{Quietly Stilled: Reflection}

The poetic vignette Quietly Stilled captures the essence of 'health care mediation'. The dimensions of individual student health care, family involvement, and accessing appropriate outside health services are addressed. This poem commences with the picture of a student experiencing difficulty breathing due to asthma. The lines, breath is tight and drawn from walking and effort great from merely walking set the scene. This poetic vignette moves to describe the young person that has inadequate asthma medication available at home due to the cost of medical expenses and prescriptions. The line, cash from family can't be found, highlights the pressure of low socio-economic status on health service access it is my observation that many families are under financial pressure to meet the cost of housing, electricity and food, and the additional pressure to meet medical expenses results in health needs not being met. In my experience school nursing interventions can involve accessing medical care on behalf of students and their families, and supporting families to meet the cost of prescriptions through a student welfare fund, operated by the school.

The third verse of this poetic vignette moves the health condition towards a positive resolution. The line, for you dear child there lies a cure, reminds the reader that untreated health concerns such as asthma are not acceptable. Child and adolescent health consumers have no control over how families choose to spend, or are forced to spend their income. Children and adolescents are vulnerable recipients of an adult health care and social system. School-based nursing services are a mechanism which ensures the health needs of children and adolescents are addressed in a cost effective and accessible manner. The ability of student clients to self-refer to school nursing services has the potential to improve child and adolescent health outcomes. A student client that has moved from quiet despair to quietly stilled is a picture that is familiar within school nursing practice. The poem Quietly Stilled presents 'health care mediation' as an essence of school nursing practice, when financial pressure on families prevents health needs being met. It is important that the health and education sector actively support school based nursing services in schools, in order promote positive student health in New Zealand. 
Stay with me, Remain here with me

What is it to be sixteen

head covering shrouding plaited glory

glimpsed in a moment

head resting on protective cover

white knuckles of black hand

held tightly as injection flares

'stay with me

remain here with me

watch and pray

watch and pray'

Dentist, your den t'is frightening

enamel invaded by whirling pin

silver insert a reminder of hidden pain

four fillings, two extractions, one root treatment

'stay with me

remain here with me

watch and pray

watch and pray'

Dental care is free to those under eighteen

freedom to remember refugee camp's personal violation

freedom to revisit tragic memories

entrusted to mediate the unknown

privileged to accompany you in your healing

'stay with me

remain here with me

watch and pray

watch and pray' 


\section{Stay with me, Remain here with me: Reflection}

The poem Stay with me, Remain here with me alludes to the need for school nurses to accompany students as they access outside health providers. The barriers of outside health care provision experienced by many students are explored in this poem. A fear of the unknown health provider, physically invasive treatment, the fear of pain, and geographical distance are offered as barriers to care. From my experience many students require accompanying to appointments, so that as the 'known' nurse I can mediate the 'unknown'. The first verse seeks to describe the experience of supporting a refugee student to obtain dental care; head covering shrouding plaited glory. The image of white knuckles of black hand; is a memory of an African nation student holding my hand so tightly, at the dentist that my rings dug into my hand.

The refrain 'stay with me, remain here with me, watch and pray' is taken from the Christian Easter Service where Christ requests his Disciples to remain with him at his hour of need. Students frequently require my presence, or the presence of a school nurse to mediate the transition to outside health services. I am conscious that students from a wide range of ethnic backgrounds are also represented in this poem, as I frequently accompany Pacific Island, and Māori students in order for dental care to be achieved. Similar accompanying is required in accessing sexual and reproductive health services for student clients. The third verse includes a play on the word dentist; your den t'is frightening (your den is frightening). The reality of dental provision to refugee students is that some have excellent teeth which require preventative treatment only, while others arrive as new students in the school community with no experience of dental care and extensive dental decay; four fillings, two extractions, one root treatment.

Stay with me, Remain here with me is a poem that seeks to describe the paradox within the concept of free dental care. Free dental care can equal freedom to revisit past trauma. The emotional trauma experienced by refugee students requires nursing care that honours their experience and understands tragic loss and grief. My observation of some refugee students 
is that the basic needs for trust have not been established or are destroyed, and nursing care towards rebuilding of trust is necessary. Any nursing intervention, which follows from physical injury or which require physical intervention, such as skin lacerations or sprains, cause a high level of apprehension and fear. These students are vulnerable in the extreme and I am aware my nursing care interventions involve acute assessment and protection skills. The line entrusted to mediate the unknown contains two essence of school nursing practice; 'entrusting as an essence of school nursing practice' and 'health care mediation as an essence of school nursing practice'. The final phrase prior to the refrain, privileged to accompany you in your healing affirms my experience of personal enrichment as a result of my involvement in this specialty practice. 


\title{
Different Playing Fields
}

\author{
Creative energy dissipated by failure \\ examination papers resemble noughts and crosses \\ no longer a game to fill the time \\ measured and found lacking in one's prime \\ Intergenerational poverty hangs loosely \\ falling heavily upon unwilling shoulders \\ estranged from educations protective shroud \\ desperate self yearns to cry out loud
}

Sporting companions respect inherent skill and craft scoring where ethnic boundaries blend with sweat rewarding the points and grades achieved content within despite injuries perceived

Hurting self presented for ministration personal failure traumatises every creed educational playing field how uneven is your land distil gently a path for all to stand 


\section{Different Playing Fields: Reflection}

The poem Different Playing Fields illuminates the grief experienced by students that have little academic success at school. The line examination papers resemble noughts and crosses evokes memories of student with test results that have many zeros and crosses, because the answers have been less than adequate, absent, or wrong. Noughts and crosses, a game to pass the time has become a symbol of failure; measured and found lacking in one's prime. The student represented in this poem can appear unaffected by an examination mark, and to friends and teaching staff presents a jovial or blank mask. This pattern repeated across subjects and across time, assists in producing a young person for whom school is synonymous with personal failure, and learning becomes an experience to be endured. The following verse makes a link between poverty and educational failure. The line intergenerational poverty hangs loosely, reminds the reader that connectedness to school and educational success are protective factors against at-risk behaviours. The students represented in this poem can have a mask securely in place but under this mask lays a vulnerable and needy young person; desperate self yearns to cry out loud. The third verse reminds the reader that many students find self-esteem and self-worth through sporting endeavour. They are recognised by their peers and valued for what they can offer; Sporting companions respect inherent skill and craft. The scores achieved in the sporting arena are acceptable and worthy. The injuries on the sporting field that cause students to self-refer for nursing care pale into insignificance when compared to the damage caused by a hostile learning environment; content within despite injuries perceived.

The last verse reminds the reader that school students attend a school-based nursing service with their whole self. It recognises that trauma is not only physical but also extends to include personal identity damage, emotional distress and educational failure; educational playing field how uneven is your land. The last lines alert the reader to the role of the school nurse in the area of advocacy, mentoring and 'health care mediation'. The school nurse's role working alongside teachers to develop educational programmes that meet the needs of young people and 'build success'. Within school nursing practice it is possible to build 
relationships with students over time, as a primary health care provider and a health mentor. A school nurse is a significant adult that takes an active interest in all areas of a student's life including physical, emotional, social, mental and spiritual dimensions. The essence of 'building success' has a close relationship to the concept of enrichment. Enrichment in this sense is confidence, expectation, belief and hope. The enabling role of school nursing can be to assist a young person to overcome personal difficulties and health challenges, to find success; a path for all to stand.

In the next section I will explore the essences of school nursing practice that have emerged from reflection on the autobiographical poetry from school nursing practice.

\section{The essences of school nursing}

It is important when considering a specialty area of nursing practice to understand the qualities that define the specialty. The 'essences' that establish a distinctive area of practice, and facilitate practice understanding and development. The Pocket Oxford Dictionary, (Fowler \& Fowler, 1969. p.279) describes an essence as,

An (immaterial) existence or entity; absolute being; reality underlying phenomena; all that makes a thing what it is; indispensable quality or element; extract got by distillation.

As I have reflected upon the poetry, I have sought to understand the 'essences' of school nursing practice evident within the text. I have distilled six 'essences' of school nursing practice; entrusting, gift giving, wise holding, safe space, health care mediation and building success. These essences have a close connection to my philosophy of nursing which was introduces within PART ONE of this thesis. The essence of health care mediation is the basis of the conceptual framework to be presented in PART FIVE of this thesis. I will explore these essences in greater depth in the following section giving reference to the poetry. 


\section{Entrusting as an essence of school nursing practice}

The act of reflective poetic writing has distilled 'entrusting' as an essence of school nursing practice, a concept that has also been examined in conjunction within the personal philosophy section of this project. The line it is a mystery entrusted to her alone, in the poem Iniquity, and entrusted to mediate the unknown in the poem Stay with me, Remain here with me clearly articulate this essence of school nursing care.

Entrusting brings with it images of carrying, holding and containing another's pain, anxiety or health concern. Entrusting in the nurse-patient relationship recognises and upholds 'vulnerability' and need, and sets this against the need for 'nurture' and care (Johns, 1996; Boykin \& Schoenhofer, 1993). Entrusting brings with it images of carrying, protecting, nurturing, surrounding, treasuring and valuing.

The concept of trust has been explored in nursing literature and has been viewed as a cornerstone of the nurse-patient relationship (Meize-Grochowski, 1984). Trust can be viewed as having its emergence within a caring framework (Boykin \& Schoenhofer, 1993). Trust expresses the notion of confident reliance or expectation, integrity, honesty, justice of another and faith in another. Trust is also described in terms of custody, care and keeping. The verb form of trust alludes to having trust in someone or something, relying upon another, committing into the care of another. The concept of trust also brings with it ideas of expecting with confidence or hope, having belief in, confidence in, or the ability to confide in. Trust can be viewed as being 'reciprocal' in nature, fragile, changing, developing, based on past experience, bound in time and involving risk (Thorne \& Robinson, 1988).

Entrust has a more specific meaning than the concept of trust described in nursing literature. You entrust someone with something or entrust something to someone. The word entrust is closely aligned with a notion of care, nurture, safekeeping, shelter, protection and giving over. It is these images, which give credence to the concept that entrusting is a central essence of school nursing and the wider domain of nursing. These ideas of entrusting enable the nurse who is entrusted with much, to affirm a sense of mission, ministry and 
purpose in the caring act. The nurse is able to value self and carry with respect, dignity, wisdom and knowledge that which is entrusted for a time. The idea of carrying wisely, and holding a treasured gift with care, are expressions of the art and essence of nursing.

\section{Gift giving as an essence of school nursing practice}

Poetic vignettes from school nursing practice describe the gifts which students bring for care. The concept of gift giving honours the giver and esteems the gift. Within school nursing practice I am challenged to recognise the 'gifts' which students make in giving their health concern to me for safe keeping and care at a time of vulnerability and need (Morse, 1989; Marck, 1990). The poem Offered Are Such recognises the entrusting of health need for care and the vulnerability expressed in giving. I understand all concerns that students bring to be gifts. Given with an expectation of acceptance, with an expectation of nursing knowledge, and with an expectation of a healing entrance into their lives.

The poem Music Bringer includes the phrase; when you bring me such splendid jewels, these splendid jewels are interpreted as health needs, and also as gifts; when you bring me gifts. School nursing care attends to physical, mental, and emotional health concerns, recognising that the whole person is met within this specialty domain. 'Gift giving' as an essence of school nursing practice affirms the gifting of health need, and the answering of need with care. Through the poetry I came to see the links between personal voice, philosophical voice, and the essences of school nursing care. Gift-giving as an essence of practice was present in all the poems, giving and receiving. The offering of need and the answering care, the placing of pain and the healing act, the gifting of concern and the wise holding. The full 'scope' of health needs brought for care are recognised as 'gifts', given with the expectation of wise holding and care.

\section{Wise holding as an essence of school nursing practice}

Wise holding is an essence of school nursing practice is distilled from the poem Relief of Grief, where the concluding line of the poem is wisely hold this story told. The theme of wise 
holding is also contained in the poem Fragments Most Holy. In this poem the school nurse is reminded to; hold with wisdom the fragments offered most holy. This essence of school nursing practice is embedded in the text of many other poems, where health need is requested with the expectation of counsel, nursing knowledge and practice expertise. Holding deems a capacity to embrace with care and a desire to offer security amidst challenge and change. Caring for student clients while they gain strength to continue, make decisions, and address personal health challenges. The school nurse is a significant adult that affords constancy and security when circumstances and events of life bring personal concern. Wisdom is a gift of knowing which allows the benefactor to assist self-growth and change in another. Wisdom affords protection and allows the student client to claim dignity, autonomy, and self-worth even in challenging situations.

Wise holding as an essence of school nursing practice, recognises the capacity of the school nurse to provide an approachable and accessible primary health care service. The concept of wise holding affirms nursing knowledge, nursing experience and nursing care. The essence of wise holding honours the individual student's health need and reflects the enabling capacity of nursing to 'mediate health care'. The ideas of carrying wisely, holding a treasured gift with care, are for me expressions of the art of nursing. Wisdom in nursing ensures that a safe space is provided to address health need.

\section{Safe space as an essence of school nursing practice}

A school health clinic provides a safe space for adolescent student clients to access primary health care. The provision of a safe space to be, in the poem I'll Remember, is understood as an essence of school nursing practice. Quin (1992, p.27) asks the question, "How can I become a safe space, a sacred healing vessel for this client in this moment?" When entrusted by a student I become a vessel and am able to contain the student's need in a safe space. Safety brings connotations of freedom from danger or risks. A safe space to discuss personal health issues, expose personal concerns and evaluate personal circumstances. 
A school nursing clinic is an environment where students can access confidential health care and receive pertinent personal health information. The school nurse works in a close relationship with teaching staff, and privacy and confidentiality are maintained with respect to personal health. Permission is sought from student clients when the need arises to discuss personal health issues in relation to educational progress and involvement in programmed activities. School nursing actively seeks to provide an environment where acceptance, respect and trust are esteemed and personal autonomy and choice are affirmed. A safe space where the school nurse can advance protection, nurture and care. A safe space to impart health knowledge, hear the life story of another, visit the past and plan towards the future, and to feel heard and understood.

\section{Health care mediation as an essence of school nursing practice}

The definition of the word mediate in the New Zealand Pocket Oxford Dictionary (1984, p.472) is to make a connection "not directly but through some other person". It is this understanding of the word mediation that is applied in reference to 'health care mediation' within the school context. The enacting of nursing care within a school-based nursing practice seeks to mediate the capacity of students to overcome obstacles to health or positively address health challenges. Individual health care mediation or the provision of primary health care is the first level of nursing intervention undertaken within the school domain. The poem Broken alludes to the activity of individual health care mediation with respect to physical injury; Simple splint and triangular cloth, binds and stills the pain. The lines, Listen to my crying eyes, see my wounds and wipe my tears, in the poem Dare to dream explore the dimension of individual mental health care mediation.

Liaison with family, caregivers, whānau with respect to student health need, is a significant health care mediation role undertaken by school nurses. The poem Offered are Such reflects the health care mediation enactment where family, caregivers, whānau are notified of student health concerns; need to contact, whānau, kin. I frequently contact family to discuss the health of a student, to notify them in the case of a physical injury while at school, to advise them of the need to obtain medical assessment, antibiotic treatment, optician 
assessment, or physiotherapy intervention. The Medicines Amendment Act 1999, which enables an extension of prescribing rights to nurses working in the area of child and family health, will advance the health protection opportunities available to school nurses. Following the successful completion of the required nurse prescribing programme, school nurses such as myself will be in a position to augment the nursing care they currently provide, to include the prescription for antibiotics and contraceptives.

School nurses enact 'health care mediation' within a school community by supporting teachers to develop appropriate educational programmes for students which address individual health needs. Individualised educational programmes are developed for students with physical, emotional, social or mental health concerns. The goal of this health mediation process is to reduce barriers to learning, to promote positive health outcomes and to advance emotional, social and academic success. The poem Different Playing Fields affirms the role of the school nurse in mediating the health and educational needs of student clients; educational playing field how uneven is your land, distil gently a path for all to stand.

Health care mediation is enacted with form teachers, subject teachers, deans and senior management staff and involves the support of family, caregivers, whānau. I have valued being a member of a 'Full Service Education' model of student care, which operates within the school. The 'Full Service Education' model includes a guidance counsellor, school support worker, school social worker, truancy officer, mentor co-ordinator and resource teachers of learning and behaviour. In my role, I work with the Full Service Education team to 'mediate' student health and build student success. Within the school environment, health care mediation also includes health education on a one-to-one basis and in the classroom setting. It is important that school nurses are equipped and professionally qualified to teach health within the Health and Physical Education Curriculum. I have found that having a Diploma of Teaching (Secondary) specialising in Health and Science has more firmly provided a mandate for my nursing role to address health promotion within the school setting. As a nurse holding a professional nursing and teaching qualification I am able to mediate the two worlds of health and education. 
Health care mediation involves providing a link between students, and students and their families, caregivers, whānau in relation to community health services. The poem Stay with me, Remain here with me, describes the role of the school nurse with respect to community health care mediation; entrusted to mediate the unknown, ....privileged to accompany you in your healing. School health nurses maintain close links with outside health care providers such as medical practitioners, family planning, sexual health services, optician, physiotherapist, child and adolescent counselling service, drug and alcohol service, rape crisis, and dentists. The links established with allied health services ensures that student clients are referred and supported to access additional care when it is required. Advocacy and accompanying student clients to access care is understood to be an important role of the school nurse. Advocacy is understood as assisting students to "discern and clarify their values in the situation, and on the basis of self examination, to reach decisions" that are congruent with their values and understanding (Gadow, 1980, p.85)

The enacting of nursing care, which occurs within school nursing practice seeks to mediate the capacity of students to overcome obstacles to health, to address positively health challenges and to build success in the social, emotional, and academic domains.

\section{Building success as an essence of school nursing practice}

The poem Behind the Veil concerns youth depression, learning difficulties and intergenerational poverty. Depressive illness in the adolescent population is frequently masked by at-risk behaviour. In many instances academic failure with regard to literacy and numeracy results in truancy, alcohol and drug use, early sexual experimentation and antisocial behaviour. The role of the school nurse at the interface of the health and education sectors allows a health perspective to be voiced with regard to student concerns. Spending time with students in a confidential environment, allows the school nurse to hear the stories which students offer. School nursing enactment provides opportunities to engage at a deep level, and explore motivation, interests, and difficulties. It provides opportunities to discuss past experience and plan towards future possibilities. 
I am conscious that building success in the lives of students is a critical factor in achieving positive adolescent mental health outcomes. Freedman et al $(1999$, p.227) contends that "many students have been deeply scarred by school experiences, in particular when their talents and knowledge have not been recognized" The lines, distil gently a path for all to stand in the poem Different Playing Fields alerts the reader to the possibility of change and hope. In my role as a school nurse I am aware of affirming student's with respect to their individual abilities and talents and working with teaching staff to develop educational programmes that can 'build success' in their lives, and move students 'Towards total wellbeing: Whaia te hauora'

\section{Resolution}

The in-depth introspection involved in the writing of reflective topical autobiographical poetry from practice, and subsequent reflective analysis, has demanded the sifting of memories and the interpretation of experience. I have been surprised and moved by these memories and the language that has emerged. Reflective topical autobiographical inquiry addresses personal questions and public concerns. The use of poetry within this method allows access to professional practice experience, memories, and intuition. Poetry sits outside the self and illuminates the self. I am aware that it is my school nursing practice I have presented, and myself that I have presented. I have allowed the reader access to my experience, beliefs, motivation, philosophy, concerns, hopes and dreams. I have made public the domain of school nursing, believing that child and adolescent health in New Zealand will be well served by developing this primary health care specialty.

Poetry is able to speak for its self, and I have been able to speak to the poetry. The poetry has formed a platform, from which I have been able to offer further reflection and discussion. Without the poetry as a platform, the discussion and explanation may not have emerged. The 'lyric tide' has allowed access to the deep places in myself. Reflection has allowed another layer of understanding to be exposed. The exploration of youth health needs and school nursing interventions is clearly positioned within the poetry. 
The poetry that emerged concerning school nursing practice has emphasised the high level of youth health need and the professional demands of nursing within this practice specialty. It has also served to highlight the 'scope' of nursing interventions undertaken in the school domain. The relationship between intergenerational poverty and adverse student health has been examined. New Zealand has poor child and adolescent health determinants when compared to our international counterparts, and this reality is evident in the reflective topical autobiographical poetry from school nursing practice. Adolescent health concerns examined within the poetry include; physical abuse, sexual abuse, teenage pregnancy, youth abortion, self-harming behaviour, depression, mental illness, drug and alcohol misuse, infected skin lesions, asthma, dental care uptake, refugee trauma, accidental injury, and school failure.

This research method has been a means to give voice to student health needs and the role of school nursing to mediate health provision in the school domain. School nursing provides an opportunity to address child and adolescent health care promotion and health care prevention in a way that is approachable, accessible, and free to the consumer. School based nursing services allow student clients to self-refer for care which advances early assessment and early intervention across a range of health care needs. Postgraduate school nursing education opportunities need to be developed and supported, to ensure that nurses working in this practice area and those entering school nursing practice, are well equipped to address the health needs of child and adolescent clients.

The interpretation of the 'essences' of school nursing practice emerged as I spent time with the poetry, and time with myself. Some essences, such as 'entrusting', 'safe space', and 'wise holding' can also be recognised in the wider nursing domain. The essences of 'health care mediation' and 'building success' have direct links to primary health care and school nursing. Understanding more clearly the essences of practice, allows the practice domain of school nursing to affirm its role in relation to the wider system of health care delivery. The essence of 'health care mediation' will be addressed in PART FIVE of this project, where I have developed this concept, and offer Health Care Mediation in School Nursing as a nursing practice framework. 
The reflective topical autobiographical method is understood as a postmodern research method which has close links with naturalistic inquiry. Naturalistic inquiry accepts intuitive knowing, and the emerging dimension of the research design. A further link is established between naturalistic inquiry and reflective topical autobiography where it is possible for theory to emerge from the inquiry. The development of a framework of school nursing practice that emerged from an 'essence' of school nursing practice, is understood as an emerging theory. The reflective topical autobiographical research method has also presented an alternative means to afford a resolution to this research.

\section{Reflexive poetry as a response to autobiographical voice and as a resolution}

In the final stages of this project, I have needed to again express my thoughts in poetic form. The introspective nature of reflective topical autobiography has been an emotionally demanding exercise and the return to poetry has met a need to integrate my experience. The philosophical language which surfaced, has replaced poetry representing individual narrative and explicit pictures of youth health need. The poetry that has emerged relates to thought, the human condition, justice and hope. This set of poems has been a way to position myself beyond the research process, and has offered resolution and completion. I have found this stage of poetic writing to be healing and restorative.

I have included these poems within this research, as they have been an important conclusion to the reflective and reflexive process for myself, and I offer them also as a means of resolution for the reader. This set of poems position this school nursing research within the world of ideas and philosophical thought, in the belief that it is important to "locate philosophical inquiry within a framework of relevance to the practice of nursing and its role in society' (Fry, 1992, p.94). 


\section{On Thought}

Deep thought envelops, surrounding like a cloud mastery and experience fade behind fine droplets shield familiar and apparent hide from view consuming commitments lie abandoned

Watching and waiting for pristine clarity expectant of nothing but solitude content to remain beyond the habitual and expected time slows and rests, comforted by distant gaze

Philosophy and passion play together dancing without inhibition or expectation memories recline amidst future dreams the divine accompanies and inspires

The Muse enters and softly gifts her gift of gold, frankincense, and myrrh surprising announcements and interpretations woven in the texture of fragile due 


\section{On Thought: Reflection}

This poem arrived in almost its complete form, unbidden and unexpected. In retrospect it was written as an offering on the process of thinking, indwelling, and introspection, which have been a part of this reflective topical autobiographical research process. I was conscious while immersing myself in the poetry that my musing on the poetic text came in times of solitude, but also in the midst of activity; consuming commitments lie abandoned. I was conscious that reflective practice requires being open to the unexpected entrance of ideas; content to remain beyond the habitual and expected. I have also been challenged by the time it has taken to reflect upon experience and consider memories from practice; time slows and rests, comforted by distant gaze.

Verse three offers the connection between philosophy and personal interest, and suggests the two are closely interconnected; philosophy and passion play together, dancing without inhibition or expectation. Philosophy informs practice activity and practice activity informs personal philosophy. The ideas contained in the poem afford the connection between memories and dreams and considers that dreams are informed by the memory of experience; memories recline amidst future dreams.

This poem relates my experience of a personal faith in God, who is close in my thinking; the divine accompanies and inspires. The final verse moves to address my ease with the Greek idea of the Muse who offers gifts of inspiration; the Muse enters and softly gifts her gift. I then develop the theme of gifts, the gifts of gold, frankincense, and myrrh given to the Christ child by the Magi. The line surprising announcements and interpretations reflect the possible entrance of unexpected revelation and understanding, when one spends time in thought.

The final line, woven in the texture of fragile due reminds of the reader of the ethereal quality of thought. Thought can return to where it began, thought 'abandons' itself to it own opening, and thought can take a person to a place of new disclosure and announcement (Nancy, 1992). 


\begin{abstract}
A New Will to Rise
The character gestures and positions painted detail displays human enterprise relationships portrayed in simplified parody announce and respond to unprepared lines

Painful expression answers sharp interjection energy and joy dissipated in a moment outward structure collapses like a puppet without a hand within to guide

Marionette string snaps unexpectedly awkward transition to immobility unfolds limbs appear in improbable positions humour and spontaneity prostrate upon the dais

Pained this visage upon crumpled torso create in this collection of parts a new will to rise with gentle hands and caring intent pull the strings to charm the void

Subtle and responsive the gloved hand aseptic technique and artistic technique binding the broken and advancing restoration lifted above the boards to dance
\end{abstract}




\section{A New Will to Rise: Reflection}

The poem A New Will to Rise is a reflection on the human condition, the vulnerability of mortal flesh, and the affliction of emotional, mental and physical harm. The poem also considers the importance of justice and care. The first line of the poem introduces the marionette puppet, a representation of human kind; painted detail displays human enterprise. This puppet, like humanity, gestures, positions, relates to others, and cannot predict the future; announce and respond to unprepared lines.

The second verse responds to the entrance of adverse events; emotional damage, and personal grief; painful expression answers sharp interjection. The poem moves to illuminate the effect of negative circumstances on an individual that cause the individual to falter and loose strength; energy and joy dissipated in a moment, outward structure collapses like a puppet. The final line of this verse alludes to the loss of autonomy and choice, and the absence of support; without a hand within to guide. The line pained this visage upon crumpled torso, evokes a picture of personal pain and defeat.

The third verse moves to describe the entrance of an envoy of hope. Impossibility translated to possibility, injury towards healing and suffering towards well-being; create in this collection of parts a new will to rise. The image of gentle hands and caring intent is a picture of the healing entrance of care. The words pulling strings to charm the void, is a return to the puppet metaphor used at the beginning of the poem, and claims the need for people to address the needs of others. The final verse includes a language familiar to nursing, and is used to interpret the enactment of care and healing; aseptic technique and artistic technique. The image of a gloved hand is a returning of the metaphor of puppet, although this hand brings a notion of gentleness, purpose, and skill; subtle and responsive the gloved hand. The final lines of the poem highlight the act of care and the movement towards wholeness; binding the broken, and advancing restoration. The final words evoke the transition to wellbeing and hope; lifted above the boards to dance. 
This poem is a portrayal of nursing endevour and nursing craft. It is also a poem that reflects negative dimensions of the human condition; intolerance, injustice and neglect, and the corresponding grief and pain. The poem at its end however reflects the power of good; the need for a just society that affirms individuals, protects the vulnerable, supports them when in difficulty and offers hope for the future. 


\section{Forest Secret}

Forest mantle wisely guards secret knowing cloaked in verdant raiment epaulettes of golden rays descend confirming a different clarity and presence

Tender shoots seek shafts of light reliant on the shelter of those that came before dappled leaves filter warm spring rain reducing the power of orb's bright light

Voices in the river stones laugh and question ridges commend a view beyond the apparent valley captures warm zephyrs and bird song privilege and position lie at rest across a stream

Nectar of the gods supplied in abundance fruit, seeds, and cones gladly introduce spring various in announcement, presume rich planting minute seedlings share common sustenance

Fern and rimu content to abide in this domain emerging difference gladly accepted beauteous frond unfurls fragile tendrils trunk's girth accepting of years answering rings

Protecting all life and honouring that which emerges difference and identity understood in simplicity texture and form, colour and strength refreshed and restored walk I this forest path 


\section{Forest Secret: Reflection}

The poem Forest Secret is a metaphorical poem that finds connection with interpersonal relationships and justice. This poem was written following a day walking in the bush with my family, where an enjoyable recreational activity gave the opportunity to disengage from the concerns of nursing practice and academic writing. An opportunity to distance myself from my working world became an opportunity to think and connect with the world of ideas, philosophy and meaning.

The first lines of the poem illuminate the forest setting, and advise the reader of the healing dimension presented by nature; confirming a different clarity and presence. The forest is understood as offering its own sense of order and knowing; forest mantle wisely guards secret knowing. The mantel is understood as a protective source of wisdom that reaches close to the light, and sees above that which rests below. Tender shoots can be regarded as a metaphor for children and youth seeking purpose and hope, reliant upon wise counsel, love and care; Tender shoots seek shafts of light, reliant on the shelter of those that came before. The words dappled leaves filter warm spring rain, reducing the power of orb's bright light is a metaphor for young being reliant on adults to protect from the risk of harm.

The third verse moves to describe the sounds and movement of the bush, and the line privilege and position lie at rest across a stream connects ideas self-importance and age being vulnerable to changed circumstances. The following verse reminds of the diversity of creation, and the need to affirm individuality; various in announcement, presume rich planting. The line minute seedlings share common sustenance is a reminder that all of humanity experiences similar needs for safety, warmth, nutrition, love and care. The poem then moves to address the human need for contentment and acceptance; Fern and rimu content to abide in this domain, emerging difference gladly accepted. Variety and individuality, and the acceptance of aging are affirmed in the lines beauteous frond unfurls fragile tendrils, trunk's girth accepting of years answering rings. The final verse commends the honoring of individuality, appearance, culture, belief, status and ability; difference and 
identity understood in simplicity. The last line of the poem is offered as a resolution and evokes the peace and contentment found when all experiences a just and fair society; refreshed and restored walk I this forest path. This line also alludes to the refreshment afforded by nature, and time to be.

Philosophy and metaphor have been presented as a means to integrate the process of reflective topical autobiographical research. They have also provided the means to experience resolution and completion to this section of autobiographical writing. In PART FIVE of this project I move to examine the essence of school nursing practice described as health care mediation, and from it I have developed a conceptual framework for school nursing practice delivery in New Zealand. This framework is designed to graphically display school nursing as a primary health care specialty. 


\section{PART FIVE}

\section{FUTURE VOICE: THE DEVELOPMENT OF A FRAMEWORK FOR SCHOOL NURSING PRACTICE}

Magician, priest, historian, provider of entertainment at noble courts or religious festivals - these were some of the functions of the primitive poet. In addition he was seer and prophet, maintaining the stability, celebrating the values and speaking out in the best interests of the society he served. These functions have been diluted, and the poet has gained freedom while loosing power; but there has remained a constant element: his duty to speak out. 


\section{FUTURE VOICE: THE DEVELOPMENT OF A FRAMEWORK FOR SCHOOL NURSING PRACTICE}

\section{Introduction}

School nursing offers a complementary contribution to Total Well-being: Hauora within the school setting. The school nurse as a primary health care professional and a health teacher within the Health and Physical Education curriculum makes possible health promotion and health protection to the student population. School nursing involvement has the potential to address a wide range of child and adolescent health issues, including those issues that I have highlighted as key areas for community health gains. These issues include; depression, suicide, self-harming, drug and alcohol misuse, teenage pregnancy and abortion, sexually transmitted infections, physical and sexual abuse, violence, infected skin lesions, asthma, and dental care. The welcome consequences of school health initiatives are the health enrichment of the individual student, staff member, the school and the wider community.

Within the naturalist paradigm it is acceptable for the research design to emerge or flow, and for theory to emerge from the inquiry (Lincoln \& Guba, 1991). As the result of this reflective topical autobiographical inquiry a conceptual framework of school nursing practice has emerged, based on the essence of 'health care mediation'. The concept of mediation used within this section was introduced on p. 133, where mediation was defined as making a connection, not directly but through some other person. Within this proposed framework of school nursing practice the nurse and student are centrally positioned. The school nurse makes a health connection with students, family, caregivers, whānau, staff, and community health service providers, that advances personal health, health education and a healthy school community. 


\section{School nursing practice framework: Health mediation in school nursing (He pou tarāwaho tiakitanga mō ngā Nēhi Kura: Te Takawaenga Hauora i roto ingā Kura)}

The 'Health Care Mediation in School Nursing: Te Takawaenga Hauora i roto i ngā Kura' conceptual framework demonstrated on the following pages, is a graphic representation of health mediation enactment undertaken by the school nurse. The first layer to be examined within this framework places school nursing within the Health Promoting Schools, the Healthy Schools, and the Full Service Education models (Fig.1). The Healthy Schools model and the Health Promoting Schools model, promote student well-being by advancing individual health, health education, health policy development, and community liaison opportunities. These models support health promotion and health protection, and I regard these concepts as being central to advancing child and adolescent well-being. The Full Service Education model of student care positions allied health services within the school setting, including the school nurse, guidance counselor, school support worker, school social worker, mentor coordinator, and truancy officer. These services are positioned on-site within schools to promote accessibility, and to advance student well-being and academic success.

The second level of 'health care mediation' places the reciprocal school nurse-student client relationship at the centre of school nursing activity (Fig.2). School nursing seeks to promote student well-being by enabling students to overcome obstacles to health and positively address health challenges. The self-referral of student clients increases the opportunity for early assessment and early intervention with regard to physical and mental health concerns. Health promotion and health protection are central to the school nurse-student client relationship.

School nursing also actively 'mediates' student health with family, caregivers, whānau (Fig.3). Liaison with family is enacted where health outcomes can be advanced and due respect is given to the confidentiality of student health needs. Liaison with family seeks to promote student health and well-being by early identification and early intervention, health 
needs notification, health promotion and education, and advice concerning the need to access medical or other services.

The fourth layer demonstrated within this conceptual framework is mediating student health care needs within the school domain. This level of nursing intervention affirms the role of the school nurse working with teaching staff, resource teachers of learning and behaviour, deans, and senior staff in the development of individualised health/educational programmes, which promote personal enrichment and success (Fig. 4). The school nurse as a health education specialist and primary health care provider advances health promotion and health protection within the school community.

The fifth area of 'health care mediation' within school nursing is referral, accompanying, and advocacy for student clients with respect to specialist health care services within the community (Fig. 5). School nursing care ensures that appropriate community health services are accessed on behalf of student clients, and when necessary students are supported to attend community health services. The wide range of health services accessed on behalf of student clients includes; medical practitioner, dentist, community mental health/child and adolescent service, drug and alcohol service, family planning, sexual health service, accident and emergency service, physiotherapist, and eating disorders service.

School nurses trained as health educators are in a position to 'mediate' health education on a one-to-one basis, and also in the classroom setting. Health curriculum development and health teaching are an important part of school nursing practice. The school nurse also has an important role in the area of health and safety policy development and implementation within schools. Health teaching, health curriculum development, and health and safety policy development and implementation are presented as the sixth level of health mediation within the school nursing framework (Fig.6).

The complete Health Mediation in School Nursing framework is presented in the final figure within this writing (Fig.7). This figure addresses the full 'scope' of school nursing interventions undertaken within the schools. The framework positions school nursing as a 
significant primary health care specialty that can positively address the health needs of student clients. Table 5 presented below is an outline of the School nursing practice framework: Health mediation in school nursing (He pou tarāwaho tiakitanga mō ngā Nēhi Kura: Te Takawaenga Hauora i roto i ngā Kura) to be demonstrated in the figures on subsequent pages.

\section{Table 5. School nursing practice framework: Health mediation in school nursing (He pou tarāwaho tiakitanga mō ngā Nēhi Kura: Te Takawaenga Hauora i roto ingā Kura)}

1. Health Mediation in School Nursing within the 'Healthy Schools' model, the 'Health Promoting Schools' model, and the 'Full Service Education' model of student care

2. Mediating Health Care Needs with Individual Students

3. Mediating Student Health Care Needs with Family, Caregivers, Whānau

4. Mediating Student Health Care Needs within the School Domain (the development of individualised health/educational programmes)

5. Mediating Student Health Care with respect to Community Health Service

6. Mediating Health Curriculum Development, Health Education in the Classroom Setting, Health and Safety Policy Development and Implementation

7. School Nursing Practice Framework: Health Mediation in School Nursing (He pou tarāwaho tiakitanga mō ngā Nēhi Kura: Te Takawaenga Hauora i roto ingā Kura) 


\section{Fig 1: A Practice Model: Health Care Mediation in School Nursing}

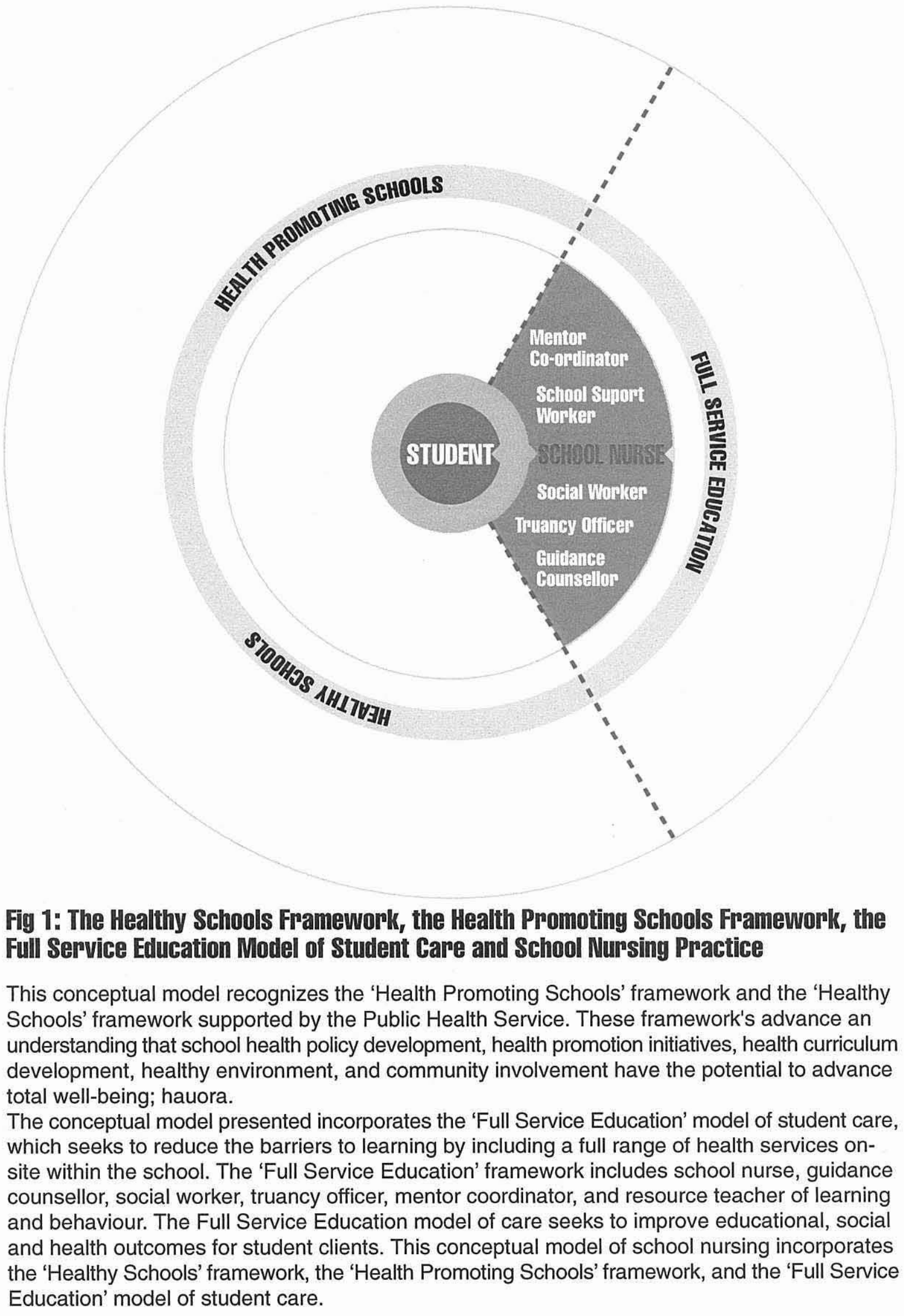




\section{Fig 2: Mediating Student Health Care Needs with Individual Students}

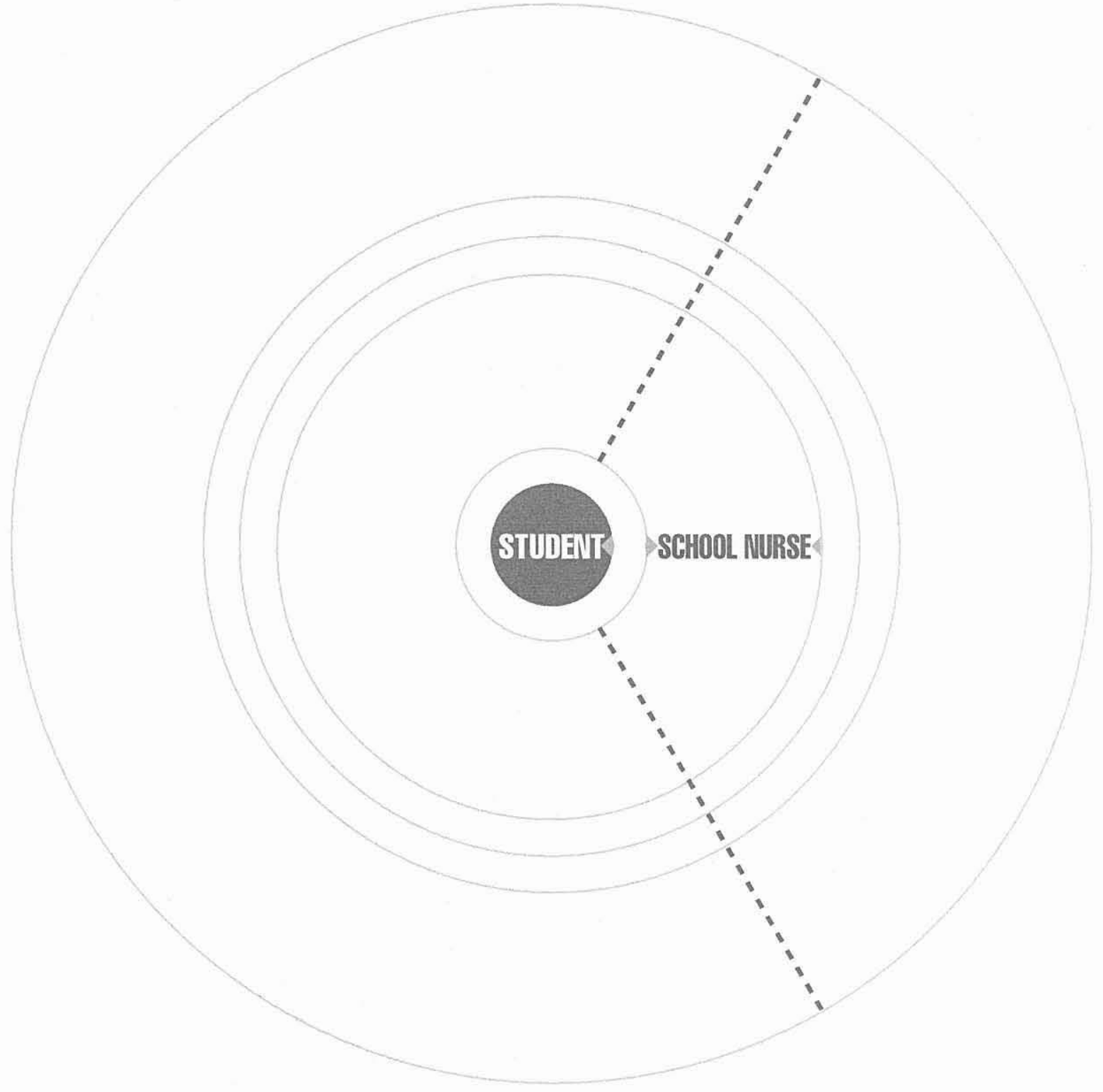

Fig 2: Mediating Student Health Care Needs with Individual Students

Central to this conceptual model of school nursing is the student client. School nursing seeks to promote student well-being by enabling students to overcome obstacles to health and address positively health challenges. The reciprocal relationship between the student client and the school nurse is central to school nursing practice. The self-referral of student clients increases the opportunity for early assessment and early intervention with regard to physical and mental health concerns. The provision of free, approachable and accessible primary health care within schools advances child and adolescent health promotion and health protection opportunities. 


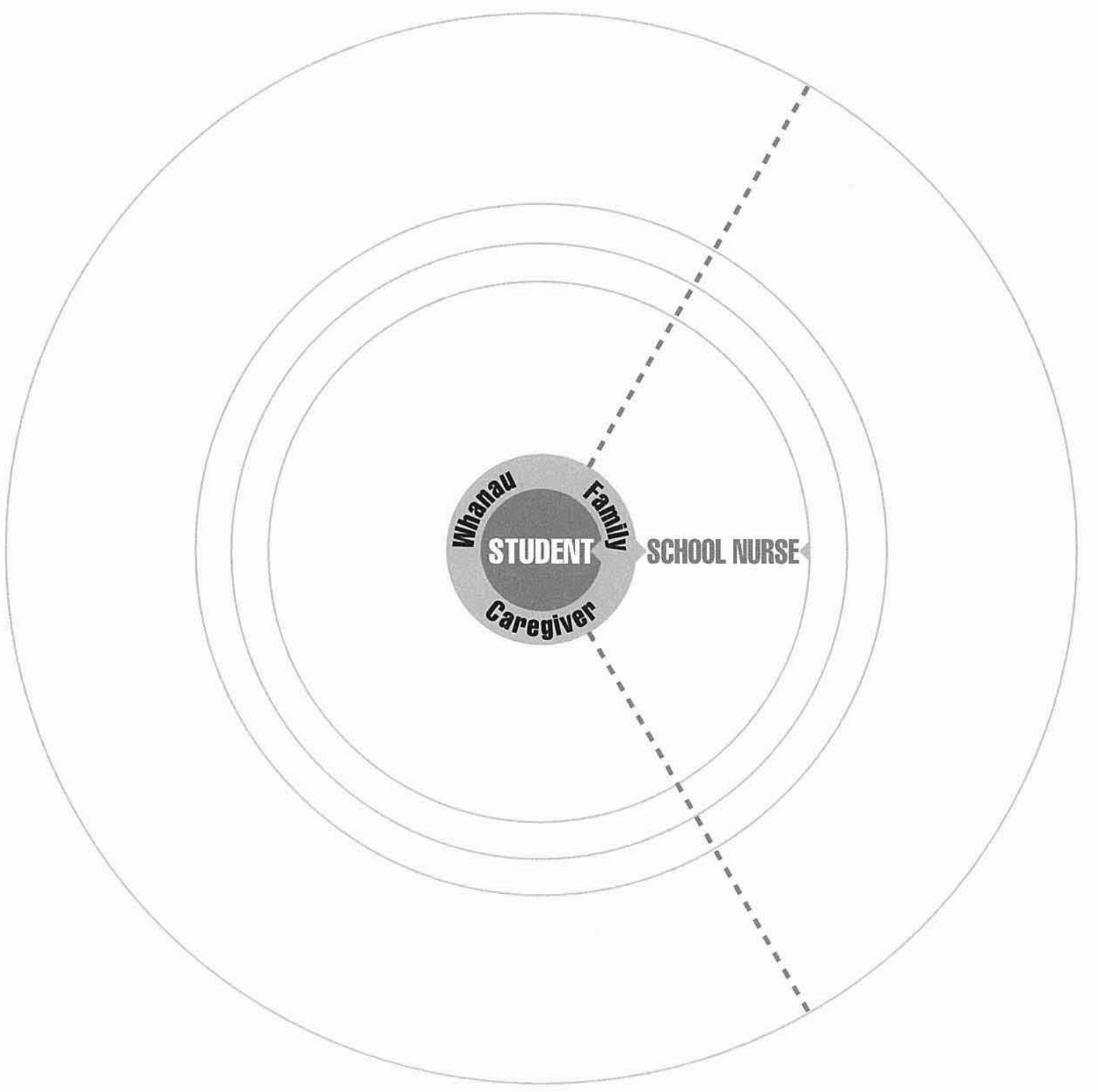

Figure 3: Mediating Student Health Care Needs with Family; Caregivers; Whānau

The subsequent level of 'health care mediation' advanced within this conceptual framework of school nursing involves liaison with family; caregivers; whānau with respect to health needs or concerns. Liaison with family is enacted where health outcomes can be advanced and due respect is given to the confidentiality of student health needs. The need to involve family; caregivers; whānau is always discussed with adolescent students and informed consent is obtained to involve such persons, unless the personal safety of the individual student or others is at risk. Liaison with family; caregivers; whānau seeks to promote student health and well-being by, early identification and early intervention, health needs notification, health promotion and education, and advice concerning the need to access medical or other services. 


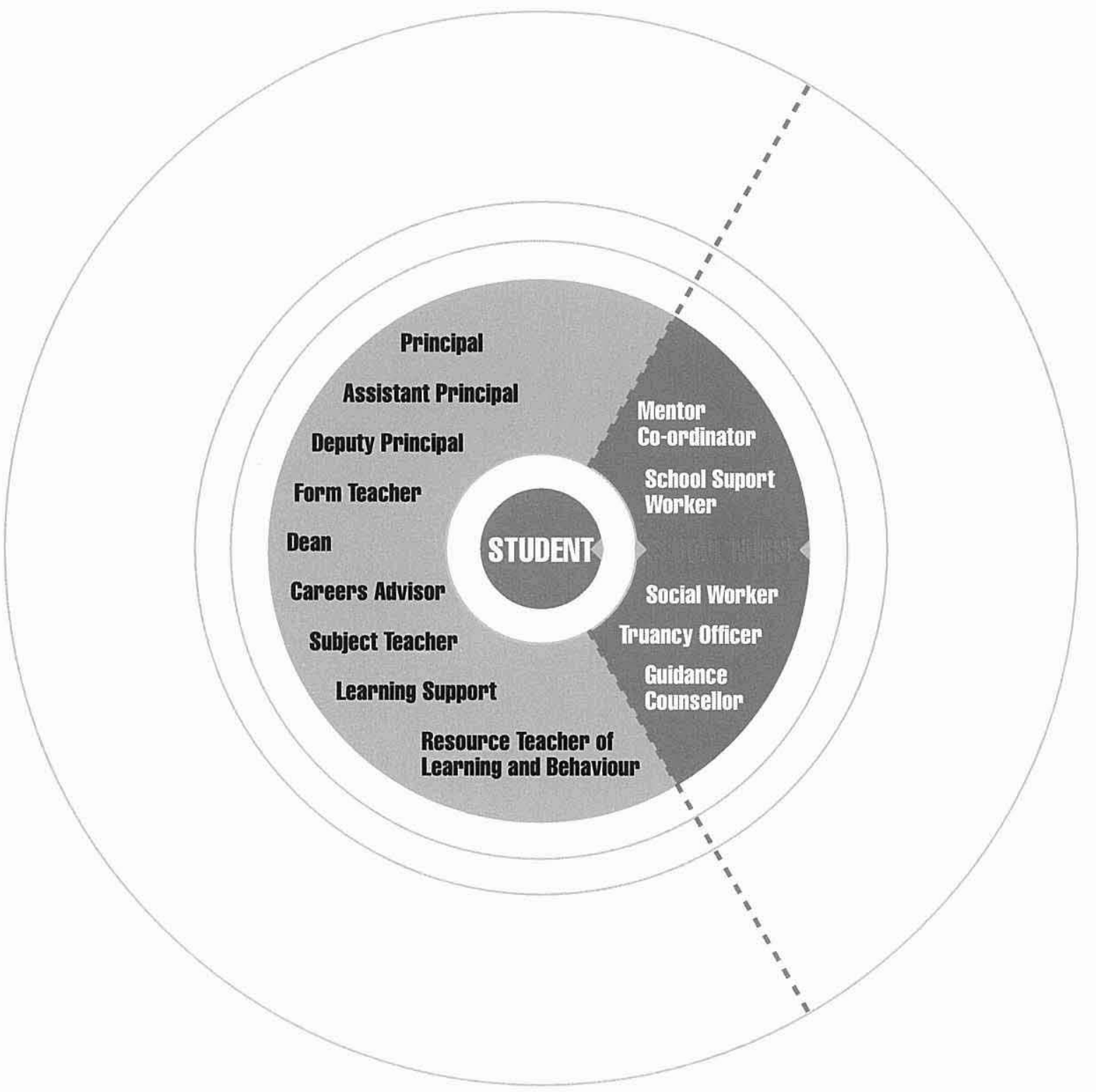

\section{Figure 4: Mediating Student Health Care within the School Domain}

The development of individualised health/educational programmes

School nursing involvement supports the development of individualised education programmes, which address the health, social, emotional, and education needs of students. The school nurse is actively involved with the 'Full Service Education' team, teaching staff, deans, and senior management, and resource teachers of learning and behaviour in mediating the health of students. The school nurse's role provides an agency for adapting programmes to suit the needs of students. This may involve adjusting a subject because a student is experiencing low self-esteem due to poor achievement and building student success by modifying subjects and class programmes. This health care mediation role may involve reducing timetabled classes for medically compromised students such as those with cancer, or students challenged by physical injury or mental illness. Ensuring that educational programmes meet both educational and health goals are a significant task undertaken by school nurses within the school domain. 


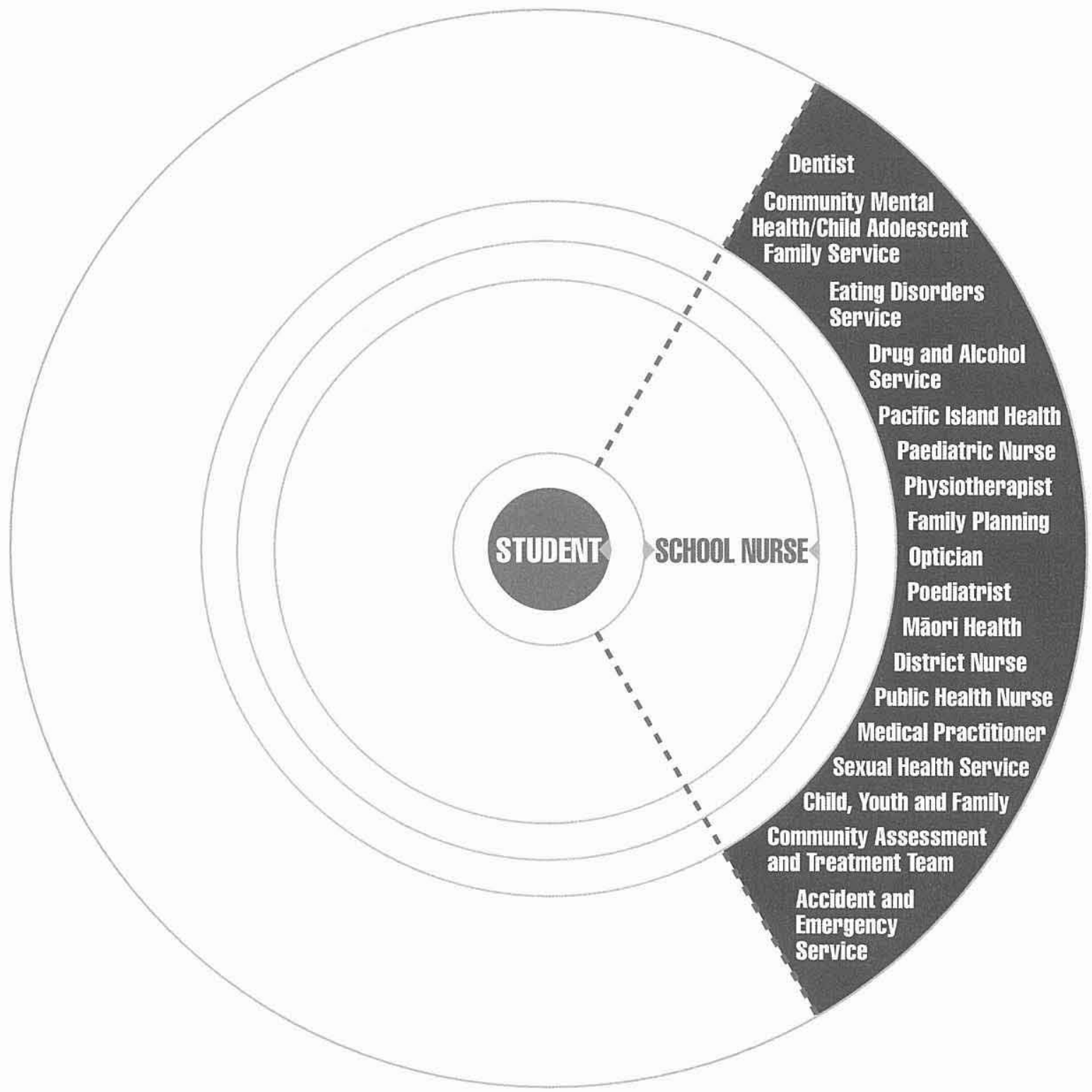

Figure 5: Mediating Student Health Care Needs with Respect to Community Healith Services

'Health care mediation' as an essence of practice, involves accessing community health services as required by students. Primary health care seeks to provide a first port of contact for individual health concerns but also has a role in accessing additional health services as required. This involves liaison with outside health providers, and when necessary, establishing these links with, for and on behalf of students and student families. Advocacy for students with regard to outside health provision and mentoring or accompanying students to access services is a significant part of the school nurses role. Students for whom links with outside services are supported, are more likely to continue these community links when they are required in the future. 
Fig 6: Mediating Health Curriculum Development and Health Education in the Classproom Setting / Mediating Health Policy Development and Health and Safety Planning and Implementation

\section{Fig 6: Mediating Health Curpiculum Development and Health Education in the Classroom Setting}

School nursing interventions are supported by active involvement in classroom health education. The school nurse is seen as a person with specialized health knowledge and has a valuable role in the school community as a mediator of health knowledge. The New Zealand Health Curriculum is a core curriculum area, and as such an essential learning area. School nurses that have professional qualifications in Health teaching are well positioned to develop teaching material, and undertake classroom teaching. Health teaching in the classroom setting enables the school nurse to become actively involved in health promotion. School nursing involvement in classroom health teaching makes possible self referral for primary health care and health teaching when a confidential environment when this is required.

\section{Fig 6: Mediliting Health Policy Development and Health and Safety Planning and Implementation}

School nursing involvement ensures professional collaboration opportunities with regard to health policy development and health and safety initiatives. The school nurse has an active interest I supporting school personnel enact health policy initiatives including; nutrition/ canteen, drug and alcohol, smoking, infectious diseased, sun safety, and anti-harassment. The school nurse facilitates positive student health by supporting cultural awareness, and the acceptance of difference. School nursing involvement within school communities advances positive student relationships and a healthy school environment. 


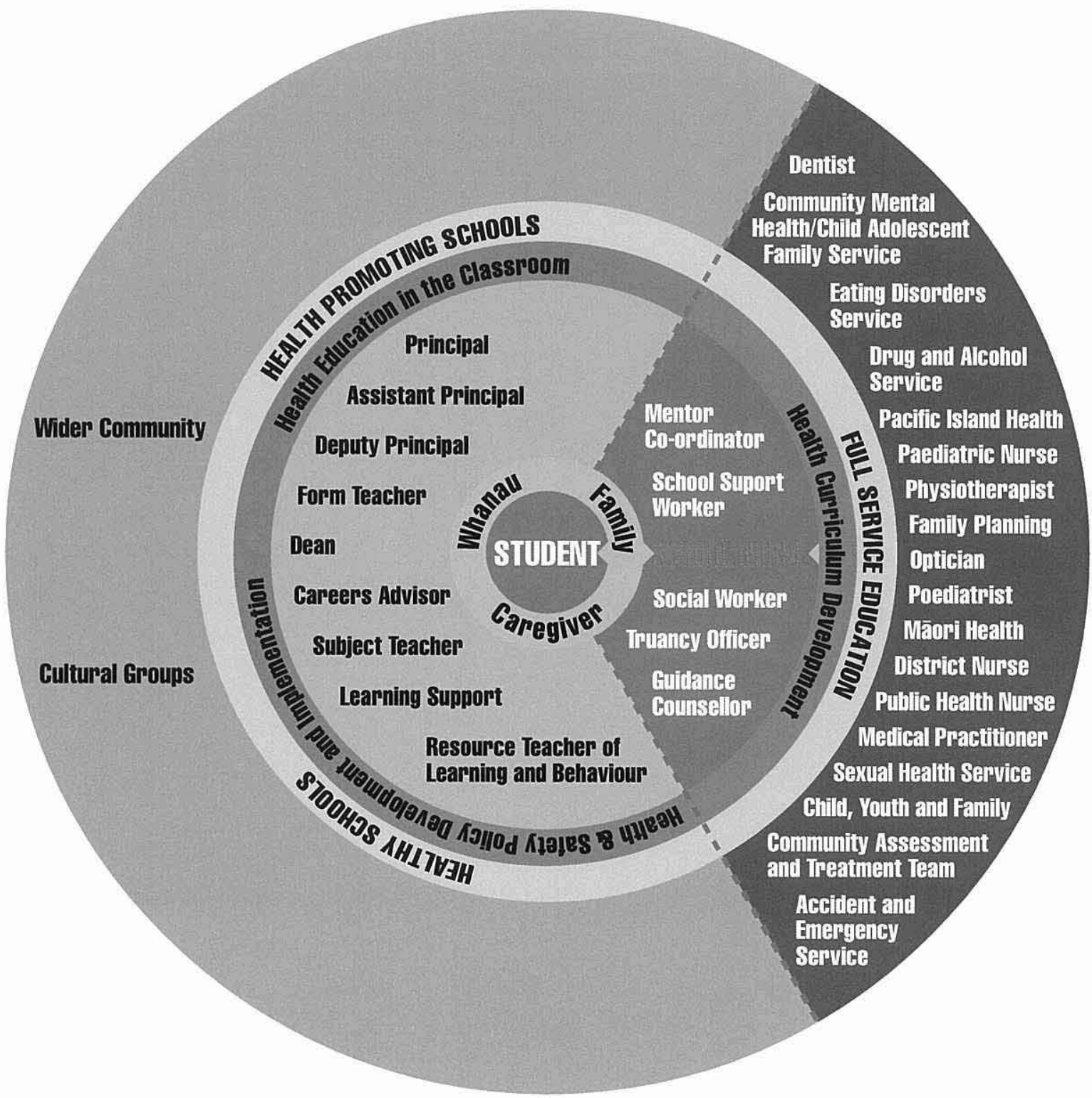

\section{Figure 7: School Nursing Practice Framework: Health Mediation in School Nursing}

\section{(He pou tarāwaho tiakitanga mō ngā Nēhi Kura: Te Takawaenga Hauora i roto i ngā Kurra)}

The School Nursing Practice Framework: He pou tarāwaho tiakitanga mō ngā Nēhi Kura described as Health Mediation in School Nursing: Te Takawaenga Hauora i roto i ngā Kura seeks to address individual student health needs and the health needs of the wider school community. School-based nursing services seek to advance health promotion and health protection opportunities and to promote total well-being: hauora. This conceptual framework of school nursing, advances an understanding, that the health needs of student's are central to the specialty of school nursing. The school nurse also engages family; caregivers; whānau, school personnel, and community health services, in order to address individual health concerns. School nursing is represented as having a significant role in health teaching, health curriculum development, health and safety planning, and health policy development and implementation within the school. The conceptual framework presented above describes in a visual way the 'scope' of school nursing enactment within this specialty practice of nursing. 


\section{Summation}

This thesis has brought together multiple voices from within the domain of school nursing. Reflective inquiry concerning school nursing has supported the examination of school nursing publications, policy documents written from within the New Zealand health and education sectors, and articles offered by school nurse writers. Literature from New Zealand, Australia, the United States, and the United Kingdom, has been used to determine current 'best practice' opportunities in school nursing, and to plan for future practice development in New Zealand.

School nursing in New Zealand has remained an invisible nursing specialty, and only recently has any nursing research been directed to analyse community health need with respect to school-based primary nursing care delivery (Clendon \& White, 2001). Nursing involvement within schools, reduces health related barriers to learning, and promotes child and adolescent health and well-being. School nursing is an important child and adolescent primary health care initiative, that requires thorough exploration, collaborative research endeavour, and planned funding from within the health and education sectors, to advance best practice opportunities in the school nursing domain. Funding for school nursing services needs to be established at a level that recognises the scope of school nursing practice and professional competencies of school nurses. Funding for school nursing positions needs to reflect an emerging career pathway for school nurses as nurse practitioners and health teachers within the New Zealand health and physical education curriculum.

Literature from within school nursing practice highlights the potential for collaborative policy and practice development initiatives. The future direction of school nursing in New Zealand requires a range of national policy initiatives to be implemented. These proposed future policy initiatives include; a legislative requirement for registered school nurses in schools, a safe student to school nurse practice ratio, appropriate practice funding, a salary and career pathway that reflects professional practice, experience, and qualifications, and government funded postgraduate education and training. 
The future development of school nursing as a primary health care specialty also requires attention to professional practice development needs. A review and critique of school nursing literature points towards practice development initiatives which include; a New Zealand National Association of School Nurses, supported professional liaison opportunities, professional practice standards, school nursing competencies, postgraduate education in child and adolescent primary health care and health teaching, and school nursing research.

There is a need to progress school nursing research in order to develop this specialty practice. Research information concerning the geographical distribution of school nurses in New Zealand, level of qualifications, health education commitments, practice development needs, and the scope of school nursing interventions are a potential aid to practice development. The use of case study research, key informant interviews, and focus group interviews are possible research approaches that need to be explored in order to advance practice knowledge.

Within this thesis autobiographical poetry from school nursing practice and reflective inquiry have been used as a means to identify the nature of student health needs, and the scope of nursing interventions undertaken in school nursing practice. School nurses undertake a wide range of nursing interventions, and are able to address the need for early identification and intervention across a broad range of physical and mental health needs. The child and adolescent statistics in New Zealand reflect poor health status within this client group when compared to international data. Social concerns with regard to teenage pregnancy, youth abortion, sexually transmitted infections, self-harming, suicide, depression, physical and sexual abuse, dental care uptake, and youth violence, can be positively influenced by developing school nursing services in New Zealand schools.

Reflective topical autobiographical poetry from school nursing practice and reflective inquiry has also been used to complement epidemiological data concerning child and adolescent health, and literature from within this practice domain. A wide range of student health needs have been explored within the poetry, and have been offered as a window to school nursing 
practice. This form of postmodern, interpretive research has challenged research norms in nursing, but in so doing, has allowed a new method of nursing practice inquiry to be presented.

The reflective topical autobiographical method has enabled six essences of school nursing practice to be distilled. Central to this practice specialty is, entrusting of care, gift giving of health need, and wise holding of student health concerns. School nursing practice provides a safe space for student clients to confidentially share health concerns, receive health information, and positively address personal health issues. The essence of building success in the social, emotional, and academic domains has been found to be an important essence of school nursing care. Autobiographical poetry from school nursing practice and reflective inquiry has found health care mediation to be a central essence of school nursing practice, and this has been developed into a conceptual framework for school nursing in New Zealand.

A conceptual framework to describe this practice domain is an important moment for school nursing in New Zealand. It removes the invisibility of this practice setting, and presents school nursing as an important child and adolescent primary health care initiative. School nursing provides child and adolescent health consumers with free, accessible and approachable health care provision. The conceptual framework presented in this thesis presents a platform from which future policy and professional practice can be discussed. It also allows school personnel, community members, health service providers, and policy makers to recognise school nursing as a primary health care specialty.

The New Zealand Health curriculum which supports total well-being: hauora, can be complemented by supporting the education and training of school nurses as health educators, and establishing and supporting school nursing primary health care provision within New Zealand schools. School-based primary nursing services have the potential to positively influence child and adolescent health outcomes. 
This thesis about school nursing practice has allowed a new view of the practice specialty of nursing to be presented. The use of personal practice experience, nursing philosophy, the review and critique of school nursing literature, reflective topical autobiographical poetry as reflective inquiry, and the development of a framework for school nursing practice has allowed this practice domain to be made visible.

This research has also allowed me to access many layers of practice understanding, and this knowledge is now placed within the wider nursing domain, and the public domain. I have experienced personal enrichment as the result of this writing and reflection, and I commend the professional nursing care undertaken by school nurses in New Zealand, as they work on behalf of student clients. I continue to believe that developing school nursing as a primary health care specialty can positively address child and adolescent health outcomes in New Zealand, and present students that are towards enrichment: whaia te ara tika in their lives. 


\section{Glossary of Māori words}

Ara - way, path

Haka - warlike chant with actions

Hauora - spirit of life, health, vigour, healthy, fresh, well

Hinengaro - seat of the thoughts and emotions, mind

Kura - school (whare kura-building devoted to instruction of knowledge)

Nēhi - nurse

Pou tarāwaho - boundary marks

Takawaenga - go-inbetween, mediator

Tangi - cry, weep, song of mourning, lamentation

Tika - straight, direct

Tinana - body

Wairua - spirit, soul

Whānau - family group, family in a broad sense 


\section{Appendix 1}

\section{School health clinic sample week}

\section{MONDAY}

\section{Teaching Hours:}

Teaching: Period 1, Year 11- Health: Social Education

Teaching: Period 5, Year 9 - Health

\section{Nursing Interventions:}

Year 11 - Male: ingrown toenail, dressing, antibiotic therapy required, mother phoned, liaison with teaching staff re: physical education

Year 10 - Female: throat infection, ulcerated and swollen, caregiver notified, medical appointment arranged.

Year 10 - Female: leg-knee abrasion, dressing, large wound, family notified concerning mobility, transport home at the end of the day.

Year 11 - Female: Sexual abuse counselling, liaison with guidance counsellor, liaison with CYPFS social worker.

Year 11 - Female: menstrual problem, nursing assessment, health information exchange, liaison with caregiver re: medication, exercise, diet.

Year 12 - Female: Physical abuse leading to depressive illness, accompanied to medical appointment.

Year 10 - Male: headache, nursing assessment, liaison with caregiver, re: diet, sleep patterns, vision screening, stress, medication.

Year 11 - Male: mental illness, counselling, liaison with Early Intervention Team, liaison with parents, re: modified educational programme. 
Year 12 - Female: Depressive illness due to abusive family history, counselling, mentoring, liaison with dean, guidance counsellor.

Year 11 - Male: Neck injury during physical education class, assessment, first aid, liaison with teaching staff, liaison with caregiver re: ACC assessment

Year 13 - Female: Counselling and support concerning alcohol use - misuse, counselling, health information exchange concerning safe sexual practice, contraceptive use, pregnancy test.

Year 12 - Female: Urinary incontinence, under Specialist care, counselling concerning family and peer issues.

Year 10 - Male: Ankle injury during P.E. class, first aid treatment, liaison with family, health information exchange concerning care of injury, medical assessment, physiotherapy

Year 9 - Male: craft knife injury to index right, wound assessment, steri strip, dressing, and liaison with family.

Year 11 - Female: headache, rest in health clinic, psychosocial assessment, concerns disclosed, lack of success in two subject areas, liaison with form teacher, dean.

Year 10 - Female: infected eye, conjunctivitis, area cleaned with normal saline, family notified with regard to antibiotic treatment.

Year 10 - Female: head lice, referred by teaching staff, liaison with family.

Year 13 - Male: back pain resulting from rugby injury on weekend, assessment, range of movement, health information exchange, physiotherapy/ ACC referral, liaison with family

Year 10 - Male: Right ankle sprain, first aid, family notification, transfer home by family.

Year 12 Female: Sexual health counseling, referral to sexual health service for medical appointment, appointment arranged for following day.

\section{Meeting:}

Full Staff, $3.30-4.30$ : 


\section{TUESDAY}

\section{Teaching Hours:}

Teaching: Period 1, Year 9 - Health

\section{Nursing Interventions:}

Year 11 - Male: Abdominal pain, assessment, nausea, vomiting, and liaison with family.

Year 9 - Male: laceration to knee following fall on concrete, dressing required.

Year 11 - Male: Asthma, assessment, peak flow measured, medication given, peak flow assessed after 10 minutes, action plan, family notified, transferred to medical practitioner for acute care management.

Year 12 - Male: Injured middle finger, basketball, assessment, first aid, finger strapped for support, liaison with family, health care information exchange.

Year 12 - Female: counselling concerning unprotected sexual activity, discussion concerning use of emergency contraceptive, contraceptive and sexual health education, liaison with sexual health provider, accompanied to appointment.

Year 13 - Male: Abrasion to elbow, P.E., wound dressing.

Year 12 - Female: counselling and assessment, elevated neck glands, tiredness, discussion concerning possibility of glandular fever, liaison with family, referral to doctor for assessment and medical certificate.

Year 11 - Female: counselling, physical abuse, verbal abuse at home, ongoing support, permission to undertake liaison with dean and teaching staff concerning educational programme.

Year 10 - Female: Student with mental health concerns, counselling, liaison with teaching staff, liaison with resource teacher learning and behaviour, discussion concerning modified programme.

Year 11 - Male: headache, health assessment, rest in health clinic, follow-up vision screening date arranged when student feels well 
Year 11 - Female: menstruation, sanitary requirements, and health information

Year 10 - Female: Boils lower leg area, wound dressing, liaison with family concerning antibiotic treatment, blood test for anemia, health information exchange, diet, exercise, rest, stress, hygiene, wound care.

Year 9 - Male: craft knife injury, re-dressed, clean, healing.

Year 13 - Male: abrasion to elbow, re-dressed, healing, wound care management education.

Year 11 - Female: vomiting, assessment, care, and liaison with family.

Year 10 - Male: Possible fracture to nose, bleeding nose, first aid, assessment, liaison with family re: $\mathrm{X}$-ray and medical assessment. Transfer to $A \& E$ Department.

Year 10 - Female: dental assessment, on examination abscess present on gum, no current dentist, family notified, appointment with dentist arranged.

Year 11 - Male: Flu symptoms, elevated temperature, and headache, family notified.

Year 9 - Male: Boil, buttock area, wound dressed, liaison with family, medical assessment and antibiotics required, health information exchange.

Year 10 - Female: infected abdominal piercing, wound dressing, psychosocial assessment, grief and separation issues, counselling support.

Teaching Staff Member: Blood pressure assessment, elevated, record for medical practitioner maintained, $2 X$ weekly record, health information exchange concerning elevated blood pressure, diet, exercise, time management, stress.

Teaching Staff Member: Assessment of knee strain, health information exchange, exercise discussion, strapping, physiotherapy referral.

Home visit:

Year 10 - Female: Infected scabies, no phone, medical appointment arranged, treatment for siblings also required, liaison with teaching staff due to absence from school, work to be supplied to student at home.

\section{Meeting:}

Public Health Nurse/School Nurse - professional supervision and practice development. 


\section{WEDNESDAY}

\section{Teaching Hours:}

Teaching: Period 4, Year 9 - Health

\section{Nursing Interventions:}

Year 9 - Male: Referral from teaching staff for vision assessment, referral to optometrist required, and liaison with family, referral letter home.

Year 9 - Male: Throat infection, liaison with family, medical referral, re: antibiotic treatment.

Year 10 - Male: Attention Deficit Disorder, liaison with family, discussion concerning slow relase form of medication, letter written for medical specialist, liaison with teaching staff with regard to classroom behaviour, programme development.

Year 12 - Female: Flu symptoms, elevated temperature, headache, family liaison.

Year 9 - Female: Ankle injury, assessment, first aid, family liaison, X-rays required.

Year 10 - Female: Depression, counselling, liaison with guidance staff

Year 10 - Female: splinter in foot, removal of splinter, dressing.

Year 10 - Male: Fall from skateboard previous afternoon, wrist injury nil family intervention, X-rays required, possible fracture, liaison with caregiver.

Year 10 - Female: Burn to hand at home requiring dressing, no dressing in situ., wound requires daily dressing, liaison with family,

Year 9 - Male: Boil, buttock area, wound re- dressed, antibiotics continue, selfcare information exchange.

Year 11 - Female: Knee injury during P.E., assessment, first aid, liaison with family, medical assessment arranged.

Year 11 - Female: counselling, re: family relationships, depressive symptoms, selfharming, self-cutting, permission to liaise with guidance staff. 
Year 13 - Female: Sexual health, infection present, appointment with sexual health service arranged, and student requested advocacy at this appointment, accompanied to appointment.

Year 11 - Female: head lice, liaison with family, medication purchased through student welfare fund due to family financial problems.

Year 10 - Female: contraceptive education, liaison with sexual health provider, support to access medical care.

Year 13 - Male: abrasion to elbow, re-dressed, healing,

Year 10 - Male: Drug and alcohol, liaison with Assistant Principal with regard to drug and alcohol counselling, liaison with family and teaching staff re: educational programme.

Year 12 - Female: ear infection, assessment, antibiotics required, on independent youth benefit, supported to access medical care, counselling support.

Year 9 - Female: Abdominal pain, menstrual education and support, rest in health clinic.

Year 10 - Female: Throat infection, elevated glands in neck, caregiver notified, antibiotic treatment required.

Year 10 - Male: referral from class teacher for hearing assessment, assessment, liaison with family, referral to audio-tester.

Year 12 - Male: Infected finger, dressing required, antibiotic therapy, discussion with father, medical assessment arranged.

Year 11 - Female: Infected eczema, wound dressing, antibiotic treatment required, family liaison, health information exchange re: topical treatment, antibiotic, dressing.

Year 9 - Male: Abrasion right elbow, dressing applied.

Meeting:

Period 1, Full Service Education team meeting 


\section{THURSDAY}

\section{Teaching Hours:}

Teaching: Provide basic life support/ First aid teaching

Teaching: Alternative programme - Provide resuscitation/ CPR

\section{Nursing interventions:}

Year 10 - Female: Burn to hand, re-dressing, wound clean.

Year 11 - Female: Self-harming behaviour, cutting to wrist, had taken drug overdose and required accident and emergency intervention previous week, counselling, liaison with - family, guidance staff, hospital crisis action team, social worker, teaching staff.

Year 9 - Male: Assault at school, bleeding nose, bruising to rib area, assessment, treatment, liaison with teaching staff/ family.

Year 11 - Female: Pregnancy test, negative result, contraceptive advice, liaison and referral to medical service.

Year 10 - Male: Back injury during P.E., assessment and first-aid, liaison with family, referral to doctor.

Year 13 - Male: Sprained ankle during lunch break, first aid, liaison with family, referral for $\mathrm{X}$-ray at accident and emergency service.

Year 9 - Female: Sexual abuse counselling, liaison with guidance staff.

Year 13 - Male: Assessment of skin lesion, infected area, dressing applied.

Year 10 - Male: laceration to finger during technology class, steri-strip and dressing applied.

Year 10 - Female: Asthma, peek flow assessment, medication administered, liaison with family, nil medication at home, medical appointment arranged.

Year 12 - Female: Dental pain, assessment, referral to dentist, appointment arranged. 
Year 9 - Male: Abrasion to leg, dressing.

Year 11 - Female: breast lump concern, assessment, family liaison, medical referral.

Year 12 - Female: Infected scabies lesions, assessment, family liaison, treatment options discussed.

Year 10 - Male: Eczema, extensive skin involvement, assessment, liaison with family concerning treatment.

Year 11 - Female: Fractured forearm during P.E. activity, first aid, splint for support, liaison with family, accompanied to accident and emergency service.

Year 10 - Female: contraceptive education.

Year 9 - Male: Hearing referral from teaching staff, assessment, liaison with family, hearing testing arranged.

Year 10 - Female: Irregular and painful menstrual cycle, health information exchange, exercise, diet, medication options.

Year 11 - Male: Large infected abrasion on elbow, area dressed, antibiotic treatment required, referral to health center.

Year 10 - Female: Personal weight counselling, nutrition, exercise, self-esteem.

Year 13 - Female: Ingrown toenail, dressing applied, antibiotics required, medical referral.

Year 10 - Female: Peer relationship difficulty, counseling support.

\section{Meeting:}

Health and Safety Meeting 3.30pm 


\section{FRIDAY}

Teaching:

Period 2, Year 11 - Health.

Period 5, Year 9 - Health

\section{Nursing Interventions:}

Year 11 - Female: Depression and suicidal thoughts, counseling, liaison with guidance staff, liaison with social worker Child and Family service.

Year 9 - Male: Head injury, assessment, liaison with family.

Year 12 - Female: Symptoms of possible sexual infection liaison with sexual health service.

Year 9 - Male: Infected eye, conjunctivitis, area cleaned, antibiotic treatment required, liaison with family.

Year 10 - Female: Depressive illness, family relationship difficulties, counselling, C.Y.P.F.A. Social worker liaison.

Year 12 - Female: Abdominal pain, assessment, liaison with family.

Year 11 - Female: Pregnancy test, counseling, contraceptive advice, liaison and transport to Youth Health Service for medical assessment.

Year 10 - Male: Knee injury, specialist care, liaison with family.

Year 12 - Female: Special needs student, menstrual problem, excessive bleeding, specialist assessment, support to attend specialist appointment with family.

Year 10 - Female: Alcohol and drug misuse, support, liaison with drug and alcohol service, assessment and counselling at school arranged.

Year 11 - Male: Knee abrasion, wound dressing completed.

Year 9 - Male: Infected right elbow, wound dressing, follow-up dressings required, family notified of treatment. 
Year 13 - Female: Abdominal pain, assessment, rest in health clinic, counseling concerning relationship difficulties resulting in reduced academic achievement.

Year 10 - Female: Home visit, discussion with family regarding non-attendance at school, poor body image, interpersonal relationship difficulties, liaison with RTLB staff, dean, modified academic programme, alternative school based programme.

Year 10 - Male: Infected left great toe, ingrown toe-nail, liaison with family, financial difficulty, medical appointment arranged, school welfare fund support for medical expenses and prescription charges.

Year 9 - Female: Menstrual support, abdominal pain, rest in health clinic during last period

Year 12 - Female: Ear infection, raised glands neck, antibiotic treatment required, caregiver notified.

Year 9 - Female: Vision testing, referral from teaching staff, liaison with family concerning vision difficulty in class, vision test undertaken, referral to optician required. 


\section{Apendix 2}

\section{School nursing interventions used from every day to once a month}

\author{
Documentation \\ First Aid \\ Medication Management \\ Medication Administration: Oral \\ Medication Administration \\ Infection Control \\ Health Screening \\ Health Education \\ Telephone Consultation \\ Heat/ Cold Application \\ Presence \\ Emotional Support \\ Infection Protection \\ Health Care Information Exchange \\ Pain Management \\ Learning Facilitation \\ Teaching Prescribed Medication \\ Allergy Management \\ Analgesic Administration \\ Self Esteem Enhancement \\ Vital Signs: Monitoring \\ Medication Administration: Topical \\ Counseling \\ Humor \\ Wound Care \\ Touch \\ Teaching: Disease Process \\ Health Policy Monitoring \\ Bleeding Reduction; Nasal \\ Learning Readiness Enhancement
}

Behavior Management: Overactivity

Fever Treatment

Limit Setting

Self Responsibility Facilitation

Teaching: Individual

Referral

Eye Care

Behavior Modification; Social Skills

Behavior Management

Behavior Modification

Calming Technique

Oral Health Promotion

Decision Making Support

Seizure Precautions

Bleeding Reduction: Wound

Ear Care

Coping Enhancement

Distraction

Exercise Promotion

Multidisciplinary Care Conference

Body-Image Enhancement

Self-Awareness Enhancement

Values Clarification

Environmental Management: Safety

Delegation

Anxiety Reduction

Socialization Enhancement

Family Support

Incident Reporting

Hair Care

(Cavendish, R., Lunney, M., Kraynyak, B., \& Richardson, K. (1999). National Survey to Identify the Nursing Interventions Used in School Settings, Journal of School Nursing, 15 (2): p.17. (Adapted)) 


\section{Appendix 3}

\section{Interventions identified by participants as used in school settings but not}

as part of the nursing intervention classification

1. Alternative Health Information

2. Coordination of Health Services at Home(children in home schooling programs)

3. Community Outreach

4. Curriculum Development

5. Fund Raising (egg. catastrophic illness of a child)

6. Grant Writing

7. Health Records Maintenance

8. Health Plan of Care Development

9. In-service Education: Staff and Teachers

10. Policy and Procedure Manuals: Development and Maintenance

11. Research

12. Routine Screening: Vision, Hearing, Hepatitis B, Dental, scoliosis, Substance Abuse, Pediculosis, Immunizations, Tinea Capitus, Attention Deficit Disorder.

13. Student Advocate

(Cavendish, R., Lunney, M., Kraynyak, B., \& Richardson, K. (1999). National Survey to Identify the Nursing Interventions Used in School Settings, Journal of School Nursing, 15 (2): p.17. (Adapted)) 


\section{Appendix 4}

\section{Additional interventions used more frequently with specific grades}

\author{
Grade levels \\ Elementary \\ Elementary and Intermediate \\ Intermediate \\ Intermediate and High School
}

High School

\author{
Interventions \\ Bowel Incontinence \\ Development Enhancement \\ Urinary Incontinence Care: Enuresis \\ Self care Assistance \\ Anger Control Assistance \\ Reality Orientation \\ Behavior Management: Sexual \\ Cognitive Restructuring \\ Contact Lens Care \\ Controlled Substance Check In \\ Eating Disorder management \\ Exercise Promotion: Stretching \\ Family Planning: Contraception \\ Nutritional Counseling \\ Parent Education: Adolescent \\ Sexual Counseling \\ Smoking Cessation Assistance \\ Splinting \\ Substance Use Treatment \\ Substance Use Prevention \\ Teaching: Safe Sex \\ Teaching: Sexuality \\ Weight Reduction Assistance \\ Child Birth Preparation \\ High Risk pregnancy Care \\ Pregnancy \\ Risk Identification: Childbearing Family
}

(Cavendish, R., Lunney, M., Kraynyak, B., \& Richardson, K. (1999). National Survey to Identify the nursing Interventions Used in School Settings, Journal of School Nursing, 15(2), p.18. Adapted) 


\section{Appendix 5}

\section{Standards of school nursing care}

\section{Standard I}

The school nurse utilizes a distinct knowledge base for decision making in nursing practice.

\section{Standard II}

The school nurse uses a systematic approach to problem solving in nursing practice.

\section{Standard III}

The school nurse contributes to the education of the client with special health needs by assessing the client, planning and providing appropriate nursing care, and evaluating the identified outcomes.

\section{Standard IV}

The school nurse uses effective written, verbal, and non-verbal communication skills.

\section{Standard V}

The school nurse establishes and maintains a comprehensive school health program.

\section{Standard VI}

The school nurse collaborates with other school professionals, parents, and caregivers to meet the health, development, and educational needs of clients.

\section{Standard VII}

The school nurse collaborates with members of the community in the delivery of health and social services and utilizes knowledge of community health systems and resources to function as a school-community liaison.

\section{Standard VIII}

The school nurse assists students, families, and the school community to achieve optimal levels of wellness through appropriately designed and delivered health education.

\section{Standard IX}

The school nurse contributes to nursing and school health through innovations in practice and participation in research or research related activities.

\section{Standard X}

The school nurse identifies, delineates, and clarifies the nursing role, promotes quality of care, pursues continued professional enhancement, and demonstrates professional conduct.

(School Nursing Practice-Roles and Standards: Proctor, S., Lordi, S. \& Zaiger, D. (1993) Scarborough, Maine: National Association of School Nurses). 


\section{References}

Abortion Supervisory Committee. (1997). Report of the Abortion Supervisory Committee for 1997. Wellington: Abortion Supervisory Committee.

Aranda, S., \& Street, A. (2001). From individual to group: Use of narratives in a participatory research process. Journal of Advanced Nursing, 33(6), 791-797.

Barwick, J. (1992). The impact of economic and social factors on health. Wellington: Public Health Association of New Zealand.

Baum, F. (1995). Researching public health: Behind the qualitative - quantitative methodological debate. Social Science Medical, 40 (4), 459-468.

Baxter, J. K. (1979). Collected poems: James K. Baxter. Oxford: Oxford University Press.

Beautralis, A., Coggan, C., Fergusson, D., \& Rivers, L. (1997). The prevention, recognition and management of young people at risk of suicide: A guide for schools. Wellington: The Ministry of Education and the National Advisory Committee on Health and Disability (National Health Committee).

Bednarz, P. (1998). The Omaha system: A model for describing school nurse case management. Journal of School Nursing, 14(3), 24-30.

Benner, M. (1991). The role of experience, narrative, and community in skilled ethical comportment. Advances in Nursing Science, 14(2), 1-21.

Berg, B. (1995). Qualitative research methods for the social sciences (2nd Ed.). Boston: Allyn \& Bacon. 
Blaber, C., Jordans, R., \& Weyl, E. (1997). Comparing the effectiveness of two methods of delivering continuing education to school nurses. The Journal of Continuing Education, 28(6), 263-268.

Blake, W. (1957). Selected poems of William Blake. London: Oxford University Press.

Borgatti, J. (1999). School nursing today. Nursing Spectrum, Metro Ed, 11A (9), 23 M.

Borges, J. (2000). This craft of verse. Cambridge: Harvard University Press.

Bowden, P. (1997). Gender sensitive ethics. London: Routledge.

Boykin, A., \& Schoenhofer, S. (1993). A model for transforming practice. New York: National League for Nursing Press.

Bradley, B. (1997). The school nurse as health educator. Journal of School Health, 67(1): 3-8.

Bradley, B. (1998). Establishing a research agenda for school nursing. Journal of School Health, 68(2), 53-61.

Brener, N. D., Vernon, M. E., Bradley, B. J., Santelli, J. S., DuShaw, M. L., Lewis, P J., \& Brainerd, E. F. (1999). Assessment of school health nursing services in the United States. Journal of Health Education, 30(5), 50-57.

Brindis, C., Sanghvi, P., Melinkovich, P., Kaplan, D. W., Ahlstrand, K. R., \& Phibbs, S. L. (1998). Redesigning a school health workforce for a new health care environment: Training school nurses as nurse practitioners. Journal of School Health, 68(5), 179-183.

Carroll, P. (1993). Adolescents' health care under attack. New Zealand Herald, 3 March, pp. 2-3. 
Cash, P., Brooker, J., Penney, W., Reinbold. J., \& Strangio, L. (1997). Reflective inquiry in nursing practice or 'revealing images'. Nursing Inquiry, 4, 246-256.

Cato, P. (1997). Making a difference in schools. Kai Tiaki: Nursing New Zealand. May, 14-15.

Cavendish, R., Lunney, M., Kraynyak, B., \& Richardson, K. (1999). National survey to identify the nursing interventions used in school settings. Journal of School Nursing, 15(2), 14-21.

Central Health Funding Authority. (1997). Child Health Strategy. Wellington: Ministry of Health.

Central Regional Health Authority, (1995). Young and Healthy: Whiti Te Ra. Wellington: Ministry of Health.

Charleston, S., \& Denman, S. (1997). The school nurse's contribution to health promotion. Health Visitor, 70(8), 302-304.

Cheesbrough, S., Ingham, R., \& Massey, D. (1999). Reducing the rate of teenage conceptions: A review of the international evidence on preventing and reducing teenage conceptions: The United States, Canada, Australia and New Zealand. London: Health Education Authority.

Clandinin D. J., \& Connelly, F. M. (2000). Narrative inquiry: Experience and story in qualitative research. San Francisco: Jossey-Bass Publishers.

Clendon, J., \& White, G. (2001). The feasibility of a nurse practitioner-led primary health care clinic in a school setting: A community needs analysis. Journal of Advanced Nursing, 34(2), 171-178. 
Coggan, C.A., Fanslow, J.L., \& Norton, R.N. (1995). Intentional injury in New Zealand. Wellington: Public Health Commission and the Injury Prevention Research Centre.

Collard, E. (1994). Territory school nurses. Australian Nursing Journal, 1(8), 20-22.

Conway, M. (1990). Autobiographical memory: An introduction. Philadelphia: Open University Press.

Cotton, L., Brazier, J., Hall, D., Lindsay, G., Marsh, P., Polnay, L., \& Williams, T. (2000). School nursing: Costs and potential benefits. Journal of Advanced Nursing, 31(5), 10631071.

Crosby, R.A., \& St. Lawrence, J. (2000). Adolescents use of school-based health clinics for reproductive health services: Data from the national longitudinal study of adolescent health. Journal of School Health, 70(1), 22-27.

Diekelmann, N. (1990). Nursing education: Caring, dialogue, and practice. Journal of Nursing Education, 29, 300-305.

Diekelmann, N. (1991). The emancipatory power of the narrative. In R. H. Schapero (Ed.), Curriculum revolution: Community building and activism (pp.41-62). New York: The National League for Nursing Press.

Dennehy, J. (2000). Measuring the outcomes of school nursing practice. Journal of School Nursing, 16(1), 2-4.

Dennehy, J., \& Poulton, S. (1999). The use of standardized language in individualized healthcare plans. Journal of School Nursing, 15(1), 38-45.

Denzin, N. (1978). The research act. New York: Mc Graw- Hill. 
Denzin, N. (1989). Interpretive biography. Newbury Park, CA: Sage.

Denzin, N. (1992). The many faces of emotionality. In C. Ellis \& M. Flaherty (Eds.), Investigating subjectivity: Research on lived experience, (pp.17-30). London: Sage.

Department of Health. (1992). Adolescent Health: Potential for action. Wellington.

Department of Health. (1986). Public health nursing: Report of the review committee to the Director-General of Health. Wellington.

Dickson, N., Sporle, A., Rimene, C., Tahu, N., \& Paul, C. (2000). Pregnancy among New Zealand teenagers: Trends, current status and international comparisons. New Zealand Medical Journal, 113 (1112), 241-245.

Dow, D.A. (1995). Safeguarding the public health: A history of the New Zealand Department of Health. Wellington: Victoria University Press.

Draucker, C. (1999). The critique of Heideggerian hermeneutical nursing research. Journal of Advanced Nursing, 30(2), 360-373.

Dryfoos, J. G. (1994). Full-service schools. San Francisco, CA: Jossey-Bass.

Dychkowski, L. (1998). Helping nurses identify, assess, and refer students at risk. School Nurse News, 15(4), 1-25.

Elbaz, R. (1987). The changing nature of the self: A critical study of the autobiographical discourse. lowa City: University of lowa Press.

Ellis, C., \& Bochner, A. (1992). Telling and performing personal stories. In C. Ellis \& M. Flaherty (Eds.), Investigating Subjectivity (pp.79-101). Newbury Park, CA: Sage. 
Eliot, T.S. (1969). The complete poems and plays of T.S. Eliot. London: Faber \& Faber.

Else, G. F. (1986). Plato and Aristotle on poetry. Chapel Hill: The University of North Carolina Press.

Felton, J. S., \& Keil, C. P. (1998). School nursing: a study of perceptions and visions. Journal of School Nursing, 14(3), 5-13.

Fenton, J. (2001). The strength of poetry. Cornwall: Oxford University Press.

Fenwicke, R., \& Purdie, G. (2000). The sexual activity of 654 fourth form Hawkes Bay students. New Zealand Medical Journal, 113(1121), 460-464.

Fergusson, D. (1998). The Christchurch health and development study: An overview and some key findings. Social Policy Journal of New Zealand, June, 10.

Fergusson, D., \& Harwood, L. (2000). Cannabis use and dependence in a New Zealand birth cohort. New Zealand Medical Journal, 113(1109), 156-158.

Field, A., \& Casswell, S. (1999). Drug use in New Zealand. Comparison Surveys, 1990 and 1998. Auckland: Alcohol and Public Health Research Unit.

Fielden, J. (2001). Creating a child abuse policy that reflects an ethic of care. Nursing Praxis in New Zealand, 16(3), 26-37.

Fitzgerald, M. (1995). The practical implications of a critique of traditional science. International Journal of Nursing Practice, 1, 2-11.

Frame, J. (1967). The pocket mirror. Auckland: Vintage. 
Freedman, F., Simons, E., Kalnin, J., \& Casareno, A. (1999). Inside city schools: Investigating literacy in multicultural classrooms. New York: Teachers College Press.

Friedrich, P. (1998). Multiplicity and pluralism in anthropological construction/ synthesis. Anthropological Quarterly, 61(3),103-112.

Fry, S. (1992). Neglect of philosophical inquiry in nursing: Cause and effect. In J. F. Kikuchi \& H. Simmons (Eds.). Philosophic inquiry in nursing, (pp.85-96). Newbury Park: Sage.

Gadamer, H. (1976). Philosophical hermeneutics. D.E. Linge, (Ed. \& Trans.). Berkeley: University of California Press.

Gadow, S. (1980). Existential advocacy: Philosophical foundation of nursing. In S. Spicker \& S. Gadow (Eds). Nursing images and ideals, (pp. 79-101). New York: Springer.

Gauld, R. (2001). Revolving doors: New Zealand's health reforms. Wellington: Victoria University Wellington.

Gooch, P. W. (1996). Reflections on Jesus and Socrates: Word and silence. New Haven: Yale University Press.

Hacker, K., \& Wessel, G. (1998). School-based health centres and school nurses: Cementing the collaboration. Journal of School Health, 68(10), 409-414.

Hagedorn, S. (1995). The politics of caring: The role of activism in primary care. Advances in Nursing Science, 17(4),1-11.

Hamill, P. (1997). Checking students' health. Kai Tiaki: Nursing New Zealand. May, 1516. 
Harper, A. (1987). Nurses' school days. New Zealand Nursing Journal, July, 17-18.

Harper, A. (1989). Doing well at school. New Zealand Nursing Journal. May, p.17.

Heidegger, M. (1962). Being and time. J. Macquarrie \& E. Robinson, (Trans.). New York: Crossroads.

Heidegger, M. (1968). What is called thinking? F.D. Wieck \& J. Glenn Garry (Trans.). New York: Harper \& Row Publishers.

Hollander, J. (1995). Vision and resonance: Two senses of poetic form. New York: Oxford University Press.

Hutt Valley Health. (2000). Cannabis and Youth: A report on cannabis and youth in Kapiti and the Wairarapa from Regional Public Health. Lower Hutt.

Igoe, J. (1990). School nursing and school health. In J. Natapoff, \& R. Wieczarek (Eds.). Maternal - Child health policy: A nursing perspective, (pp.153 -188). New York: Springer.

Igoe, J. (1994). A closer look: a preliminary report of findings from the national survey of school nurses and school nurses supervisors. Denver, Colorado: University of Colorado Health and Science Center.

Jones, R. A. (1997). The presence of self in the person: Reflexive positioning and personal constructs psychology. Journal for the Theory of Social Behaviour, 27 (4), 452-471.

Jasper, D. (1985). Coleridge as poet and religious thinker. London: MacMillan Press.

Jennings, J., Pearson, G., \& Harris, M. (2000). Implementing and maintaining schoolbased mental health services in a large, urban school district, Journal of School Health, 70(5), 201-205. 
Johnstone, M-J. (1999). Reflective topical autobiography: An under utilised interpretive research method in nursing. Collegian, 6 (1), 24-29.

Johns, J. (1996). A concept analysis of trust. Journal of Advanced Nursing, 24, 76-83.

Jones, R. (1997). The presence of self in the person: Reflexive positioning and personal constructs psychology. Journal for the Theory of Social Behaviour, 27 (4), 453-471.

King, A. (1995). Giving permission to embodied knowing to inform nursing research methodology: The poetics of voice (s). Nursing Inquiry, 2, 227 - 234.

King, P. (1994). Health promotion: The emerging frontier in nursing. Journal of Advanced Nursing, 20, 209-218.

Kisker, E., \& Brown, R. (1996). Do school-based health centres improve adolescents' access to health care, health status, and risk-taking behaviour? Journal of Adolescent Health, 18(5), 335-343.

Lambie, M. (1927). Duties of a school nurse. Kai Tiaki: Journal of the Nurses of New Zealand, XVI(3), 116.

Langley, J., Nada-Raja, S., \& Aslop, J. (2000). Changes in methods of male youth suicide. New Zealand Medical Journal, 113(1113), 264-265.

Larter, N., Chernick, L., Maire, J., \& DuBois, E. (1999). The health consultation program: A model school nurse education program. Journal of School Nursing, 15(3), 20-24.

Li-Biondo-Wood G., \& Haber, J. (1994). Nursing research methods, critical appraisal and utilization (3rd ed). St Louis: Mosby. 
Lincoln, Y., \& Guba, E. (1991). Naturalistic Inquiry. Newbury Park: Sage.

Lyotard, J-F. (1992). The postmodern explained. Minneapolis: University of Minnesota Press.

McClure, L. (1995). Defining the future for school nursing. Nursing Standard, 10(7), 2730.

McDonald, A-L., Langford, I., \& Boldero, N. (1997). The future of community nursing in the United Kingdom: District nursing, health visiting and school nursing. Journal of Advanced Nursing, 26, 257-265.

McKay, F. (1990). The life of James K. Baxter. Auckland: Oxford University Press.

McNicholas, A., Bennett, S., Turley, M., \& Garrett, N. (2001). Surveillance of sexually transmitted infections in New Zealand, 1998. New Zealand Medical Journal, 114(1134), 279283.

Maling, N. (2001). When school staff care, children change. Sunday Star Times, 30 December, p.A5.

Marck, P. (1990). Gift giving. Advances in Nursing Science, 13(1), 49-59.

Mayeroff, M. (1971). On caring. New York: Harper \& Row.

Mayerhoff, B., \& Metzger, D. (1980). The journal as activity and genre: On listening to the silent laughter of Mozart. Semiotica, 30, 1-2.

Meize-Grochowski, R. (1984). An analysis of the concept of trust. Journal of Advanced Nursing, 9, 563-572. 
Ministry of Education. (1999). Health and physical education in the New Zealand curriculum. Wellington: Learning Media.

Ministry of Health. (1994). Report and recommendations of the steering group on youth mental health and suicide prevention. Wellington.

Ministry of Health. (1995). Effective health services for young people; Te Toiora o Tōku Whanaketanga. Wellington.

Ministry of Health. (1996). 1995 Hospital and selected morbidity data. Wellington.

Ministry of Health. (1997a). 1996 Hospital and selected morbidity data. Wellington.

Ministry of Health. (1997b). Mental Health Services for Young People. Wellington.

Ministry of Health. (1998a). 1997 Hospital and selected morbidity data. Wellington.

Ministry of Health. (1998b). Family violence: Guidelines for health sector providers to develop protocols. Wellington.

Ministry of Health. (1999a). Better times: Contributing to the mental health of children and young people. Wellington.

Ministry of Health. (1999b). Strengthening families: Report on Cross-sectoral Outcome Measures and Targets. Wellington.

Ministry of Health. (2000a). Our Health, Our Future: Hauora Pakari, Koiora Roa. Wellington.

Ministry of Health. (2000b). The New Zealand Health Strategy. Wellington. 
Ministry of Health. (2001a). Core elements for health provider response to victims of family violence: The bare bones (draft). University of Auckland: Injury Prevention Research Centre.

Ministry of Health. (2001b). Health promoting schools in action in Aotearoa/New Zealand. Wellington: Brebner Print.

Ministry of Health. (2001c). The Primary Health Care Strategy. Wellington.

Ministry of Youth Affairs, (2001a). Supporting the Positive Development of Young People in New Zealand: A Discussion Document for Consultation on a Youth Development Strategy. Wellington.

Ministry of Youth Affairs. (2001b). New Zealand Youth Suicide Prevention Strategy: In Our Hands and Kia Piki Te Ora O Te Taitamariki. Wellington: Ministry of Youth Affairs, Ministry of Health, Te Puni Kokiri.

Ministry of Youth Affairs. (2002). Youth development strategy Aotearoa: Action for child and youth development. Wellington.

Marck, P. (1990). Therapeutic reciprocity: A caring phenomenon. Advances in Nursing Science, 13(1), 49-59.

Morse, J. (1989). Reciprocity for care: Gift giving and the nurse-patient relationship. Canadian Journal of Nursing Research, 21(1), 33-45.

Morse, J. (1991). Negotiating commitment and involvement in the nurse-patient relationship. Journal of Advanced Nursing, 16, 455-468.

Moustakas, C. (1990). Heuristic research: Design methodology and application. California: Sage. 
Nancy, J-L. (1990). Sharing voices. In G.L. Ormiston \& A.D. Schrift (Eds.). Transforming the hermeneutic context: From Nietzsche to Nancy. (pp. 211-259). Albany: State University of New York Press.

Nancy, J-L. (1993). The birth to presence. Stanford, CA: Stanford University Press.

National Health Committee and the Ministry of Education. (1997). A guide for schools: The prevention, recognition and management of young people at risk of suicide. Wellington: National Advisory Committee on Health and Disability.

Nehls, N. (1995). Narrative pedagogy: Rethinking nursing education. Journal of Nursing Education, 34(5), 204-210.

Newman, M. (1990). Newman's theory of health as praxis. Nursing Science Quarterly, $3(1), 37-41$.

Newman, M. (1994). Health as expanding consciousness. (2nd ed.). New York: National League for Nursing.

New South Wales (NSW) Department of Health, NSW Department of School Education, Catholic Education Commission, NSW, \& Association of Independent Schools, NSW, (1996). Towards a health promoting school. New South Wales: NSW Department of School Education Curriculum Directorate.

New Zealand Nurses Organization, (1995). Policy. Wellington.

Noddings, N. (1984). Caring: A feminine approach to ethics and moral development. Berkley: University of California Press.

Norris, C. (1993). The truth about postmodernism. Cambridge, Massachusetts: Blackwell. 
Norris, K. (1999). The cloister walk. Oxford: Lion.

Paladino, C. A. (2000). School nursing: Scope of practice (Part II): Dilemmas of school nursing practice. New Jersey Nurse, 30(10), 3-6.

Papa, P., Rector, C., \& Stone, C. (1998). Interdisciplinary collaborative training for schoolbased health professionals. Journal of School Health, 68(10), 415- 419.

Parse, R. (1992). Human becoming: Parse's theory of nursing. Nursing Science Quarterly, 5(1), 35-42.

Partington, M. (1989). Beyond bandages. New Zealand Nursing Journal, May, pp. 20, 28.

Passarelli, C. (1994). School nursing: Trends for the future, Journal of School Health, 64(4), 141-146.

Paterson, J. \& Zderad, L. (1976). Humanistic Nursing. New York: Wiley.

Peddie, B. (1982). Child health care in primary schools. The New Zealand Nursing Journal, Feb, 18-29.

Plato's Phaedo. (1955). Hackforth, R. (Trans.). Indianapolis: The Bobbs-Merrill Company.

Price, J., Telljohann, S., \& King, K. (1999). School nurses' perceptions of and experience with school health research. Journal of School Health, 69 (2), 58-62.

Poster, E., \& Marcontel, M. (1999). School nursing role and competence. Journal of School Nursing, April, 15(2): 34-42. 
Proctor, S., Lordi, S., \& Zaiger, D. (1993). School nursing practice: Roles and standards. Scarborough, Maine: National Association of School Nurses.

Public Health Commission, (1994). Healthy Schools: Kura Waiora: A Public Health Commission Discussion document: Wellington.

Pybus, M. (1983). The nurse in the community: community health nursing in New Zealand: McGraw-Hill Book Company.

Quinn, J.F. (1996). Holding sacred space: The nurse as healing environment. Holistic Nursing Practice, 6(4), 26-36.

Redes, S., \& Lunney, M. (1997). Validation by school nurses of the nursing intervention classification for computer software. Computers in Nursing, 15(6), 333-338.

Reed, A.W. (2001). Concise Māori Dictionary, Auckland: Reed Publishing.

Remen, R. (1997). Kitchen table wisdom. Sydney: MacMillan.

Resnick, M. (2000). Protective factors, resiliency, and healthy youth development. Adolescent Medicine: State of the Art Reviews, 11(1), 157-164.

Richardson, L. (1992). The consequences of poetic representation: Writing the other, rewriting the self. In C. Ellis \& M. Flaherty Investigating subjectivity: Research on lived experience, (pp. 125-137). Newbury Park, CA: Sage.

Ricketts, H. (1986). Talking about ourselves: Twelve New Zealand poets in conversation with Harry Ricketts. Wellington: Mallison Rendel Publishers.

Roberts, K., \& Taylor, B. (1998). Nursing research process: An Australian perspective. South Melbourne: Nelson. 
Roche, M. (1973). Phenomenology, language and the social sciences. London, Boston: Routledge \& Kegan Paul.

Rogers, M. (1961). Educational revolution in nursing. New York: McMillan.

Rogers, M. (1970). An introduction to the theoretical basis of nursing. San Francisco: Robert Briggs.

Rose, A. (1997). School nurses struggle for recognition. Kai Tiaki: Nursing New Zealand. March, 7.

Ross, S. (1999). The clinical nurse specialist's role in school health, Clinical Nurse Specialist, 13(1) 28-33.

Rukeyser, M. (1992). Out of silence: Selected poems. Evanston: TriQuarterly Books.

Rukeyser, M. (1996). The life of poetry. Ashfield: Paris Press.

Sandelowski, M., Davis, D., \& Harris, B. (1989). Artful design: Writing the proposal for research in the naturalist paradigm. Research in Nursing and Health, 12, 77-84.

Sandelowski, M. (1991). Telling stories: Narrative approaches in qualitative research. Image: Journal of Nursing, 23(3), 161-166.

Schneider, M., Friedman, S., \& Fisher, M. (1995). Stated and unstated reasons for visiting a high school nurse's office. Journal of Adolescent Health, 16(1), 35-40.

Scholes, P. (1970). The Oxford companion to music. J. O. Wood (Ed.). London, New York, Toronto: Oxford University Press. 
Smythe, E. (1987). The poet as our mentor. Nursing Praxis in New Zealand, 2(2), 3-7.

St. Leger, L., \& Nutbeam, D. (2000). A model for mapping linkages between health and education agencies to improve school health. Journal of School Health, 70(2), 45-50.

Stumph, S. (1966). Socrates to Sartre: A history of philosophy. New York: McGraw-Hill.

Tan, S-L., \& Moghaddam, F. (1995). Reflexive positioning and culture. Journal for the Theory of Social Behaviour, 25(4) 387-340.

The New Zealand Pocket Oxford Dictionary (1969). Fowler \& Fowler (Eds.), Auckland: Oxford University Press.

The New Zealand Pocket Oxford Dictionary (1984). R.E. Allen (Ed.), Auckland: Oxford University Press.

Thompson, D. (1978). The uses of poetry. London: Cambridge University Press.

Thorne, S., Canham, C., Dahinten, S., Hall, W., Henderson, A., \& Kirkham, S. (1998). Nursing's metaparadigm concepts: Disimpacting the debates. Journal of Advanced Nursing, $27,1257-1268$.

Thorne, S., \& Robinson, C. (1988). Reciprocal trust in health care relationships. Journal of Advanced Nursing, 13, 782-789.

Tierney, W. (1997). Lost in translation: Time and voice in Qualitative research. In W. G. Tierney \& Y. S. Lincoln (Eds.), Representation and the text: Re-framing the narrative voice, (pp.23-36). Albany: State University of New York Press.

Toohey, P. (1996). Epic lessons: an introduction to ancient didatic poetry. New York: Routledge. 
Tsvetaeva, M. (1992). Art in the light of conscience: Eight essays on poetry by Marina Tsvetaeva, A. Livingstone (Trans.). Cambridge, Massachusetts: Harvard University Press.

Ulmer, G. (1989). Teletheory. New York: Routledge.

Van der Zalm, J., \& Bergum, V. (2000). Hermeneutic - phenomenology: providing living knowledge for nursing practice. Journal of Advanced Nursing, 31(1), 211-218.

Van Manen, M. (1990). Researching lived experience: Human science for an action sensitive pedagogy. New York: State University of New York Press.

Van Manen, M. (1991). The tact of teaching. Albany, New York: State University of New York Press.

Vendler, H. (1980). Part of nature part of us: Modern American poets. Cambridge: Harvard University Press.

Vendler, H. (1987). Voices and visions: Poets in America. New York: Random House.

Vendler, H. (1988). The Music of what happens. Cambridge: Harvard University Press.

Verhey, M., \& Ferretti, C. (1996). Quality management in a school-based nursing centre: Program development and implementation. Journal of Nursing Care Quality, 10(3), 59-67.

Wainwright, P., Thomas, J., \& Jones, M. (2000). Health promotion and the role of the school nurse: A systematic review. Journal of Advanced Nursing, 32(5), 1083-1091.

Waldegrave, C., King, P., \& Stuart, S. (1999). The monetary constraints and consumer behaviour in New Zealand low income households. Wellington: The Family Centre Social Policy Research Unit. 
Watson, J. (1988). Nursing: Human Science and human care: A theory of Nursing. New York: National League for Nursing.

Watson, J. (1990). Caring knowledge and informed moral passion. Advances in Nursing Science, 13(1), 15-24.

Watson, J. (1995). Postmodernism and knowledge development in nursing. Nursing Science Quarterly, 8(2), 60-64.

Webb, V. (1995). Young people and alcohol in New Zealand: A literature review. Alcohol Advisory Council of New Zealand: Grey Matter Research Ltd.

While, A., \& Barriball, L. (1993). School nursing: history, present practice and possibilities reviewed. Journal of Advanced Nursing, 18, 1202-1211.

Whitmarsh, J. (1997). School nurses' skills in sexual health education. Nursing Standard, 11(27), 35-41.

Williams, H. W. (1992). Dictionary of the Maori language. Wellington: GP Publications

Wold, S. (1981). School nursing: A framework for practice. North Branch, Minnesota: Sunrise River Press. 